DYNAMIC SITTING TO PREVENT PRESSURE ULCERS

IN SPINAL CORD INJURED

JASPER REENALDA 
Address of correspondence:

Jasper Reenalda

Roessingh Research and Development

PO Box 310

7500 AH Enschede

The Netherlands

$+31-53-4875726$

j.reenalda@rrd.nl

The publication of this thesis was generously supported by:

Roessingh Research and Development

Het Roessingh Centre for Rehabilitation

PR Sella, Pressure Related Seating Products

Laboratory of Biomechanical Engineering, Faculty of Engineering Technology, University of Twente, Enschede, the Netherlands

Department Health Technology \& Services Research, University of Twente, Enschede, the Netherlands

This study was partly funded by the Dutch Ministry of Economic Affairs, SenterNovem (TSIT3043)

\section{SenterNovem}

Printed by: Gildeprint Drukkerijen, Enschede

ISBN: 978-90-365-2884-9

(C) Copyright Jasper Reenalda, Enschede, the Netherlands, 2009

All right reserved. No part of this publication may be reproduced, stored in a retrieval system, or transmitted, in any form or by any means, electronic or mechanical, photocopying, recording, or otherwise, without the prior written permission of the holder of the copyright. 


\title{
DYNAMIC SITTING TO PREVENT PRESSURE ULCERS IN SPINAL CORD INJURED
}

\section{PROEFSCHRIFT}

\author{
ter verkrijging van \\ de graad van doctor aan de Universiteit Twente, \\ op gezag van de rector magnificus, \\ prof. dr. H. Brinksma, \\ volgens besluit van het College voor Promoties \\ in het openbaar te verdedigen \\ op donderdag 8 oktober 2009 om 15:00 uur
}

door

Jasper Reenalda

geboren op 18 februari 1979

te Enschede 
Dit proefschrift is goedgekeurd door:

Prof. dr. J. S. Rietman (promotor)

Prof. dr. M. J. IJzerman (promotor)

Dr. M. J. A. Jannink (assistent-promotor) 
De promotiecommissie is als volgt samengesteld:

Voorzitter en secretaris:

Prof. dr. F. Eising

Universiteit Twente

Promotoren

Prof. dr. J. S. Rietman

Universiteit Twente

Prof. dr. M. J. IJzerman

Universiteit Twente

Assistent Promotor

Dr. M. J. A. Jannink

Oost NV

Leden

Prof. dr. ir. H. F. J. M Koopman

Universiteit Twente

Prof. dr. ir. D. J. Schipper

Universiteit Twente

Prof. dr. D. J. Bader

Queen Mary University of London, United Kingdom

Prof. dr. A. G. G. M. van Leeuwen

Universiteit van Amsterdam

Prof. dr. L. H. V. van der Woude

Rijksuniversiteit Groningen

Dr. G. J. Snoek

Revalidatiecentrum Het Roessingh

Paranimfen

Ir. J. G. Leusink

Dr. ir. W. Ruijter 



\section{Contents}

$\begin{array}{llr}\text { Chapter 1 } & \text { Introduction } & 9 \\ \text { Chapter 2 } & \text { The clinical use of interface pressure to predict pressure ulcer } & 27 \\ & \begin{array}{l}\text { development: A systematic review } \\ \text { Chapter 3 }\end{array} & \begin{array}{l}\text { Analysis of healthy sitting behavior: Interface pressure } \\ \text { distribution and subcutaneous tissue oxygenation }\end{array} \\ \text { Chapter 4 } & \text { Effects of actuated postural change on (sub-)cutaneous tissue } & 63 \\ & \text { oxygenation } & \\ \text { Chapter 5 } & \text { Effect of actuated tuberal support on tissue load and on tissue } & 75 \\ & \text { perfusion and oxygenation } & \\ \text { Chapter 6 } & \text { Effects of dynamic sitting interventions on tissue oxygenation in } & 91 \\ & \text { individuals with spinal cord disorders } & 105 \\ \text { Chapter 7 } & \text { Discussion and conclusions } & 117 \\ \text { Summary } & & 121 \\ \text { Samenvatting } & & 127 \\ \text { Curriculum Vitae } & & 129 \\ \text { Publications } & & 131 \\ \text { Dankwoord } & & 135 \\ \text { Progress range } & & \end{array}$



CHAPTER 1

INTRODUCTION 


\subsection{Pressure ulcers}

Pressure ulcers (PU) are defined as all degenerative changes in the skin and the subcutaneous tissue as a result of pressure, shear forces and friction or a combination of these [1]. The National Pressure Ulcer Advisory Panel (NPUAP) defines a pressure ulcer as localized injury to the skin and/or underlying tissue, usually over a bony prominence, as a result of pressure, or pressure in combination with shear and/or friction [2]. Pressure ulcers are a great problem and can be life threatening without treatment due to complications. Particularly individuals that use a wheelchair for their mobility, like individuals with a spinal cord injury, are at risk of developing pressure ulcers. Due to a static sitting posture they experience prolonged load of their tissue. Pressure ulcer incidence rates vary considerably by clinical setting, ranging from $0.4 \%$ to $38 \%$ in acute care, from $2.2 \%$ to $23.9 \%$ in long-term in-patient care, or $0 \%$ to $17 \%$ in home care [3]. The prevalence of pressure ulcers in the spinal cord injured (US veteran) population are reported as high as 39\% [4]. In The Netherlands, prevalence of pressure ulcers vary between 12 and 35\% in Dutch hospitals and nursery homes [1]. Depending on the severity of the pressure ulcer, the costs of treatment range from 2000 to 30.000 US\$ on average. However, they may be as high as 70.000 US\$ per pressure ulcer if reconstructive surgery is needed [5]. It has been estimated that annual societal costs of treating pressure ulcers in the United States of America are in the order of 11 billion dollars [6-8]. The prevention of pressure ulcers is therefore crucial.

\subsection{Prevention of pressure ulcers in patients at-risk}

An effective prevention of pressure ulcers starts with the identification of patients at-risk. A risk profile can be obtained by assessment of several components including the mobility status, sensory deficiency, presence of incontinence, and finally the nutritional status. At present, the Braden Scale is the most widely utilized assessment tool in the United States, but additional assessment include the Norton Scale, Gosnell Scale, Knoll Scale, and Waterlow Scale [9, 10]. Frequent visual skin inspection of at risk patients by the nursing staff and the patient itself is used to detect pressure ulcers in an early stage. These first indications of pressure ulcers will progress if not treated correctly. Additional loading, like for instance external pressure during sitting, will lead to aggravation of the pressure ulcers. To prevent this aggravation, complete unloading of the tissue by means of bed-rest is advised, which severely limits the mobility of the patient. In addition, a deep pressure ulcer that has reached the skin will usually not heal 
without surgical intervention. In summary, pressure ulcers, create a large physical, psychological and financial burden to patients, caregivers and society.

In addition to frequent inspection and unloading of the risk zones after early signs of pressure ulcers are detected, a lot of clinical effort has been put into minimizing the external load at the tissue during sitting in a wheelchair. Furthermore periodically relieving the load on the tissue by means of alternating load cushions has been advised. Minimizing the external load can be achieved by adjusting the geometry of the wheelchair [11], or by using different types of pressure distributing and custom contoured cushions [12, 23]. Besides modifying the wheelchair, modifying sitting behavior is important in the prevention of pressure ulcers. Wheelchair users are advised to reposition every 15 minutes in order to relieve the tissue. If they lack sufficient motor function to perform this repositioning, like for instance as a result of a spinal cord injury, they have to be repositioned by caregivers or nursing staff every hour [AHCPR, AHRQ guidelines 19940 [24]. This time interval is merely based on clinical observations than on a theoretical basis [25]. Repositioning can occur by lifting (generally known as push-ups), by leaning sideward or forward in the wheelchair or by rotating the pelvis. This variation in sitting behavior will help the restoration of blood flow and will recover the tissue from deformation. However, these actions require specific motor control that is likely to be absent in the at-risk population. For instance, even with sufficient motor control, lifting creates severe loads on the shoulders and upper arms, which can lead to other injuries. Furthermore, repositioning can create shear forces and friction. Often the skin of patients identified at-risk for pressure ulcers is easily torn during repositioning, which can result in trauma to the skin, eventually leading to superficial ulcers. In addition to repositioning, electrical stimulation of the gluteal muscles has been used as a clinical method to prevent pressure ulcers. Due to electrical stimulation muscle mass increases. The latter results in decreased interface pressures due to a larger pressure distribution surface [26, 27].

\subsection{Towards an explicative etiological model of Pressure ulcers}

\subsubsection{Description of an explicative etiological model to understand the etiology of} pressure ulcers.

Much is still unclear about the etiology of pressure ulcers. It appears that an unbalance between the loads exerted on the tissue and the ability of the tissue to withstand the load, causes ischemia and tissue deformation, eventually resulting in tissue necrosis. Recently, the distinction has been made between superficial pressure ulcers and deep pressure ulcers [28]. 
Superficial skin ulcers develop mainly due to shear forces, during sitting in a chair and lying in bed but can also develop as a consequence of trauma to the skin during transfers. Superficial skin ulcers develop at the skin and progress inwards. In contrast, deep pressure ulcers, defined by the NPUAP as pressure related injuries to subcutaneous tissue under intact skin [29] or deep tissue injury [4], are a result of prolonged external load on the tissues and develop subcutaneously before progressing outwards to the skin. It is understood that deep pressure ulcers result from prolonged pressure and develop usually near the bony prominences where internal pressures are high. Deep pressure ulcers are therefore merely a result of prolonged sitting in one static position.

In order to obtain more insight in the etiology of superficial and deep pressure ulcers, and as such to aid the prevention of these ulcers, the following etiological model can be proposed (fig 1). The different steps in the etiological model of superficial and deep pressure ulcers will be described below.

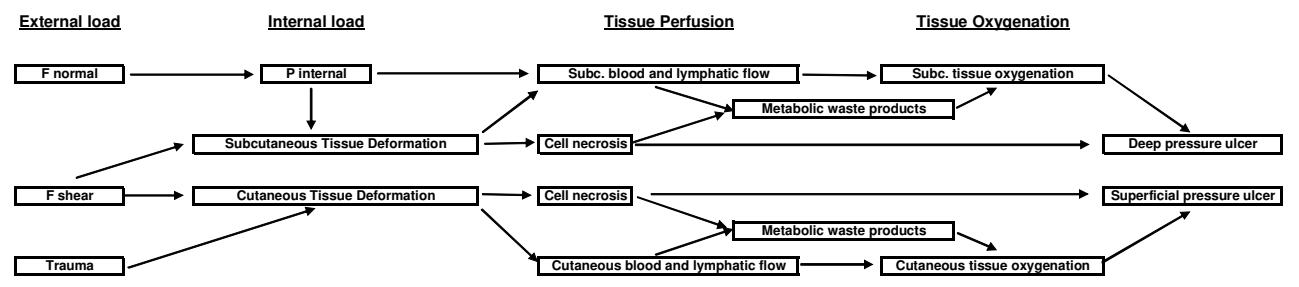

Figure 1: Etiological model for superficial and deep pressure ulcers.

Considering deep pressure ulcers, the external load results in a raise of internal load on the subcutaneous tissue, causing occlusion of blood vessels and lymphatic vessels [8-12]. The external load is a result of the sitting posture of the subject and the local support by the wheelchair. This external load causes deformation of the cutaneous and subcutaneous tissue. Deformation has a direct and indirect effect on the development of pressure ulcers. The direct effect causes necrosis of the cells by rupturing its walls. In addition it has an indirect effect by creating a pressure gradient over the blood and lymphatic vessels [36-39]. The pressure gradient over the blood and lymphatic vessels causes squeezing and deformation of the vessels and consequently limits blood and lymphatic flow. Lymphatic flow is partly responsible for the removal of metabolic waste products from the cell. Hence, obstruction to this lymphatic flow results in toxification of the cells. The perfusion of the tissue is a factor in the development of 
pressure ulcers because it is the blood that provides the tissue with the critical nutrients necessary for its survival [40]. Tissue oxygenation is a direct result of the blood flow to the tissues and describes the amount of oxygen bonded to hemoglobin. As such, tissue oxygenation reflects the metabolic state of the tissue. The duration of the occlusion determines whether this occlusion will result in a decreased oxygenation and ischemia and accumulation of metabolic waste products, eventually resulting in a pressure ulcer. Therefore, it can be assumed that the tissue oxygenation is a measure of the viability of the tissue, which determines if a tissue gets ulcerated or not given a certain load. It has been hypothesized that pressure ulcers in subcutaneous tissues can occur as early as during the first 4 to 6 hours of loading [41]. The development of superficial pressure ulcers follows a slightly different pathway. Shear forces, friction and tissue trauma play an important role while prolonged pressure is less important as an initiator. Due to shear forces the local blood vessels will be occluded and deformation of the cutaneous tissues and blood vessels occurs, resulting in cell necrosis and limitation of the cutaneous tissue perfusion. A consequence of the limited cutaneous blood flow is a reduction in tissue oxygenation. The cell necrosis and limitation in cutaneous blood flow causes superficial pressure ulcers. External pressure will aggravate the development of the pressure ulcers into deeper tissue layers.

\subsubsection{External load}

External load has usually been quantified in the interface pressure, which is the pressure between seat and body. The interface pressure on the buttocks is equal to the normal force. The measurement of interface pressure is used widely in the clinical setting because of its ease of use. At present, interface pressure is measured mainly by means of pressure mapping devices that consist of an array of pressure sensors. Several pressure magnitude/duration diagrams have been developed in which higher pressures are associated with a higher incidence of pressure ulcers, however no clear threshold value has been established yet [14, 32, 34, 42-

48]. Although the measurement of interface pressure is easy to use in the clinical setting, measurements are largely influenced by creep, drift and hysteresis of the pressure sensors [4950]. This limits the reliability and reproducibility of interface pressure measurements. In addition, finite element modeling (FEM), animal experiments and studies with test-buttocks have shown that the interface pressure is not equal to the internal pressure [23, 46, 51-60]. Therefore, interface pressure cannot quantify the internal load which is important in the development of pressure ulcers. 
It has long been assumed that the value for the capillary closure pressure, $30 \mathrm{mmHg}$ as determined in 1930 by Landis [61], was useful as a clinical interface pressure threshold for the development of pressure ulcers. It was assumed that interface pressures above $30 \mathrm{mmHg}$ should be avoided as they could result in capillary closing and ischemia. Unfortunately, this value was based on pressure experiments with a micropipette on the finger nail-bed of one single subject and is therefore of little value as a threshold for interface pressure in the clinical setting.

In addition to interface pressures (normal forces), shear forces are an important factor in the development of superficial pressure ulcers. Shear forces are mainly a result of a poor sitting posture and poor support in the wheelchair. Contrary to the measurement of interface pressure, the measurement of shear forces has received little attention [62, 63]. Although global shear force can be measured with multiple force sensors [64, 65], it remains difficult to measure shear forces locally. It has been shown however, that shear forces limit the cutaneous perfusion and oxygenation in human subjects and increase skin breakdown and ulceration in pigs $[35,43,44,62,63,66]$.

\subsubsection{Internal load}

Internal pressure is a result of the external forces compressing the tissue against the bony prominences of the pelvis. Because deep pressure ulcers originate subcutaneously, the assessment of the internal pressure is important in the development of these deep pressure ulcers. However, it has been very difficult to measure internal pressures in vivo, especially in a clinical setting. Attempts have been made to measure the pressure within the tissue by means of needle-electrodes. Aside from ethical reasons that limit the use of these internal pressure measurements, the measurement method is not very reliable in vivo [32, 36, 46, 67]. This means that at present, in vivo, it is not possible to actually measure the internal pressure reliable. With finite element modeling it is possible to calculate the internal pressure, stresses and strains without actually measuring them. In congruence with animal experiments [46, 68] and test buttock models [23, 69], FEM have shown that internal pressure exceeds the interface pressure and peaks under the bony prominences of the pelvis. However, the relation between external pressure and internal pressure is not linear [51-60, 70-72].

Besides ischemia, other factors, like the deformation of tissue, play a role in the development of pressure ulcers $[28,37,38,73]$. As calculated with FEM, the deformation of tissue is highest in the muscle layer under the bony prominences of the pelvis. [51, 53-56, 58-60, 72, 74-76].

This is in congruence with in-vivo (animal) experiments showing the highest sensitivity for 
pressure ulcers in the muscle layer under the bony prominences $[42,45,77]$. This is also the region where deep pressure ulcers originate, indicating that cell deformation plays an important role in the development of deep pressure ulcers. It has been hypothesized that prolonged deformation of the cells forms the initial trigger for pressure sore related damage, whereas changes in biochemical environment of the cell may cause additional damage $[74,78]$.

\subsubsection{Tissue perfusion}

Tissue perfusion is characterized by the amount of blood that flows through the blood vessels in the tissues. Xenon-clearance is reliable technique to measure the perfusion of the tissue and has therefore been regarded as a golden standard. Unfortunately, it is an invasive technique as it uses injected radio-active tracer material to measure tissue perfusion [79-81]. Therefore other techniques have been developed that measure tissue perfusion. Laser Doppler flowmetry has proven to be a good indicator of skin perfusion when tested against the technique of Xenon-clearance. It has been shown that cutaneous perfusion is restricted as a consequence of external load [77, 82-88]. However, no threshold values have been developed because the time limit for ischemia to result in reversible or irreversible damage is not known [87]. The current measurement depth of the laser Doppler device is limited to 1 or 2 millimeter. This penetration depth is insufficient to investigate the perfusion at depths associated with deep pressure ulcers. For this purpose a measurement depth of approximately 10 millimeter is required. Therefore, at present, laser Doppler flowmetry is not suitable to quantify the risk of developing deep pressure ulcers.

\subsubsection{Tissue Oxygenation}

Tissue oxygenation is a result of the tissue perfusion, the blood flow to the tissue. The oxygenation of the tissue reflects the amount of oxygen bonded to the hemoglobin and as such describes the metabolic state of the tissue. Therefore, tissue oxygenation is directly related to the viability of the tissue. Tissue viability is a measure of the state of the tissue and determines if a tissue will get ulcerated or not given an external load.

The oxygenation of the tissue has been measured by means of transcutaneous oxygen tension $(\mathrm{tcPO})$. It has been shown that oxygenation tension decreases with an increase in external pressure [55, 84, 89-96]. Unfortunately, the measurement of transcutaneous oxygen tension is limited technically by the fact that the skin needs to be heated up to 44 degrees Celsius to induce maximal vasodilatation. This heating may change the normal physiological response of the microcirculation of the skin. It is possible that this changes local mechanisms that mediate the blood flow to the tissues and eliminates the influence of the sympathetic nervous system 
[97]. An other technique to measure cutaneous tissue oxygenation is tissue reflectance spectrophotometry. Tissue reflectance spectrophotometry uses the different light absorption characteristics of the various constituents of the skin to measure variances in these constituents. The variance in concentration of oxygen-bound and non-oxygen-bound hemoglobin is a good indicator of the tissue oxygenation, and thus of its viability. The technique is non-invasive and can be implemented easily in the clinical practice. With tissue reflectance spectrophotometry is it possible to detect pressure ulcers in an early stage due to an increased flow of blood to the ulcerating site when no load is present [89, 99].

Unfortunately the measurement depth of $\mathrm{tcPO}_{2}$ and tissue reflectance spectrophotometry is limited to a few millimeters. Therefore it is not able to give information about the blood supply in the subcutaneous tissue near the bony prominences. As a consequence, it has not led to the establishment of useful threshold values or guidelines for the prevention of pressure ulcers. A larger penetration depth is needed to give information about the development of sitting acquired pressure ulcers because the measurement of the tissue oxygenation at the depth where deep pressure ulcers develop is essential. Due to the limited penetration depth of transcutaneous oxygen tension and tissue reflectance spectroscopy, it is at present not possible to measure the oxygenation subcutaneously. A greater penetration depth of approximately 10 millimeter is needed to study the development of deep pressure ulcers that occur mainly due to prolonged sitting.

\section{$1.4 \quad$ Objectives of the Thesis}

From the discussion of the etiological model it becomes clear that important steps in the development of pressure ulcers are missing. In order to aid pressure ulcers prevention, more research is required. Considering the external load, more insight is needed into the quantification of the external load and its relation with the development of pressure ulcers. Because interface pressure measurements have been performed frequently in the research setting, a systematic review of the literature on interface pressure measurements and pressure ulcers could help developing a relation between the interface pressure and the development of pressure ulcers. In addition, it can be concluded from the discussion of the etiological model, that especially the internal tissue load is important in the development of pressure ulcers. However, up till now, it has not been possible to quantify the representatives of the internal tissue load (the subcutaneous tissue perfusion and oxygenation) due to technical limitations. In order to quantify the internal load and to define its relation with the external load, new 
measurement techniques are required that are able to non-invasively measure the internal state of the tissue.

At present, the clinical interventions to prevent pressure ulcers are not fully successful in defining the risk of pressure ulcer development and as such in eventually preventing pressure ulcers. As a result, the prevalence and incidence values of pressure ulcers remain unacceptably high. The present thesis proposes an alternative approach at preventing pressure ulcers. It is common sense that healthy subjects do not develop pressure ulcers due to a dynamic variation in sitting posture. This dynamic sitting behavior can be identified and used as a reference value for the optimal sitting behavior and the repositioning frequency of wheelchair user at-risk of developing pressure ulcers. Because wheelchair users with a spinal cord injury often lack sufficient motor control to reposition, an experimental sitting device needs to be developed to impose this dynamic sitting behavior. The effects of the imposed dynamic sitting behavior on the tissue viability can be investigated by a measurement technique that is able to noninvasively measure the perfusion and oxygenation of the subcutaneous tissue.

The subsequent objectives of this thesis are hereby threefold:

1) To gain more insight into the relation between the interface pressure and the development of pressure ulcers and to introduce a new measurement technique to quantify the load on the internal tissues.

2) To investigate the dynamic sitting behavior of healthy subjects and to use this sitting behavior as a reference value for the sitting behavior of spinal cord injured subjects.

3) To develop and experimental sitting device (the Dynasit chair) in which the dynamic sitting behavior can be imposed on wheelchair users that lack sufficient motor control to reposition and to investigate the effects of these interventions on the tissue viability.

Based on the objectives, the main research question that will be answered in this thesis is: "Does imposing dynamic sitting behavior by means of the Dynasit chair result in elevated tissue viability in spinal cord injured individuals?” 


\subsection{Thesis outline}

Before answering the actual research question a couple of steps has to be taken. From the description of the etiological model, it became clear that more insight is needed into the relation between external pressure and internal pressure and their relation with the development of pressure ulcers. Therefore a systematic review of the literature on interface pressure measurements and the development of pressure ulcers has been performed in order to define clinically usable threshold values for interface pressure. The systematic review (chapter 2) describes the randomized clinical trials that used the measurement of interface pressure to quantify the risk of developing pressure ulcers.

Because no quantitative clinical relation could be found between interface pressure measurements and pressure ulcer development, an analysis of the dynamic sitting behavior of healthy subjects has been performed in chapter 3. The sitting behavior of healthy subjects can be used as a reference value for the sitting behavior of spinal cord injured individuals. This analysis of healthy sitting behavior included the measurement of interface pressure as well as the measurement of the (sub-) cutaneous tissue oxygenation. The measurement of (sub-) cutaneous tissue oxygenation should give more insight in the internal tissue load. The measurement of the (sub-)cutaneous tissue oxygenation, by means of the Oxygen to See (O2C, LEA Medizintechnik, Giessen Germany) is a new technique to quantify the internal load. From the description of the etiological model it was concluded that the internal load is important in the development of pressure ulcer but is difficult to quantify non-invasively due to technical limitations.

Recognizing the need for dynamic sitting behavior, the Dynasit chair has been developed because individuals with a spinal cord injury often do not posses the motor function to reposition themselves. The Dynasit chair is an experimental seating device that can impose dynamic different kinds of sitting behavior. The Dynasit chair contains a mechanical system for actuated postural and pelvic orientation variation and a mechanical system for actuated tuberal variation. Chapter 4 describes the validation of the system for actuated postural variation and pelvic orientation in healthy male subjects, by means of the measurement of the (sub-) cutaneous tissue oxygenation. The validation of the system for actuated tuberal support variation in healthy male subjects is described in chapter $\mathbf{5}$.

The main research question of this thesis will be answered in chapter $\mathbf{6}$. In this chapter a clinical validation study is described in which the Dynasit chair is used to impose dynamic sitting behavior on 9 male individuals with a spinal cord disorder. The effects of this dynamic 
sitting behavior, based on the sitting behavior of healthy individuals, is investigated on the cutaneous and subcutaneous tissue viability. General conclusions and a discussion of the present study and the current state of the art in pressure ulcer research can be found in chapter 7 . 


\subsection{References}

1) Health Council of the Netherlands: Pressure Ulcers. The Hague: Health Council of the Netherlands, 1999; publication no. 1999/23.

2) Black J, Baharestani M, Cuddigan J, Dorner B, Edsberg L, Langemo D, Posthauer ME, Ratliff C, Taler G; National Pressure Ulcer Advisory Panel. National Pressure Ulcer Advisory Panel's updated pressure ulcer staging system. Dermatology and Nursing, 2007, Aug; 19(4):343-9.

3) Lyder $\mathrm{CH}$. Pressure ulcer prevention and management. Journal of the American medical association, 2003, Jan 8;289(2):223-6.

4) Garber SL, Rintala DH. Pressure ulcers in veterans with spinal cord injury: a retrospective study. Journal of rehabilitation research and development, 2003, Sep-Oct; 40(5):433-41.

5) Amlung SA, Miller WL, and Bosley LM. The 1999 National Pressure Ulcer Prevalence Survey: A benchmarking approach. Advances in Skin \& Wound Care, November/December, 2001;14(6):297-301.

6) Reddy M, Gill SS, Rochon PA. Preventing pressure ulcers: A systematic review. Journal of the American Medical Association, 2006; 296:974-984

7) Redeling MD, Lee NE, Sorvillo F. Pressure ulcers: More lethal than we thought? Advances in skin \& wound care, 2005; 18(7):367-372.

8) Whittington K, Patrick M, and Roberts JL. A national study of pressure ulcer prevalence and incidence in acute care hospitals. Journal of Wound, Ostomy and Continence Nursing, July 2000;27(4):209-215.

9) Ayello EA, Braden B. How and why to do pressure ulcer risk assessment. Advances in skin \& wound care, 2002;15(3):125-131.

10) Baharestani MM, Ratliff $C$, and the National Pressure Ulcer Advisory Panel. Pressure ulcers in neonates \& children: An NPUAP White Paper. Adv Skin Wound Care, 2007; 20(4):208-220.

11) Maurer C L, Sprigle S. Effect of seat inclination on seated pressures of individuals with spinal cord injury. Physical Therapy, 2004 Mar;84(3):255-61.

12) Bar CA. The response of tissues to applied pressure. Dissertation, University of Wales, 1988.

13) Economides, N.G., Skoutakis, V.A., Carter, C.A., Smith, V.H. Evaluation of the effectiveness of two support surfaces following myocutaneous flap surgery. Advances in wound care, 1995, 8(1), 49-54.

14) Conine TA, Hershler C, Daechsel D, Peel C, Pearson A. Pressure ulcer prophylaxis in elderly patients using polyurethane foam or Jay ${ }^{\circledR}$ wheelchair cushions. International journal of rehabilitation research, 1994, Vol. 17:123-137.

15) Koo TK, Mak AF, Lee YL. Posture effect on seating interface biomechanics: comparison between two seating cushions. Archives of physical and medical rehabilitation, 1996, Jan; 77(1):40-7.

16) Hamanami $\mathrm{K}$, Tokuhiro A, Inoue H. Finding the optimal setting of inflated air pressure for a multi-cell air cushion for wheelchair patients with spinal cord injury. Acta Medica Okayama, 2004, Feb; 58(1):37-44.

17) Sprigle SH, Faisant TE, Chung KC. Clinical evaluation of custom-contoured cushions for the spinal cord injured. Archives of physical and medical rehabilitation, 1990, Aug; 71(9):655-8

18) Sprigle S, Chung KC, Brubaker CE. Reduction of sitting pressures with custom contoured cushions. Journal of rehabilitation research and development, 1990, Spring; 27(2):135-40.

19) Conine TA, Daechsel D, Hershler C. Pressure sore prophylaxis in elderly patients using slab foam or customized contoured foam wheelchair cushions. Occupational therapy journal research. 1993;13:101-116. 
20) Sprigle S, Schuch JZ. Using seat contour measurements during seating evaluations of individuals with SCI. Assistive technology, 1993; 5(1):24-35

21) Brienza DM, Karg PE. Seat cushion optimization: a comparison of interface pressure and tissue stiffness characteristics for spinal cord injured and elderly patients. Archives of physical and medical rehabilitation, 1998, Apr; 79(4):388-94.

22) Brienza DM, Lin CT, Karg PE. A method for custom-contoured cushion design using interface pressure measurements. IEEE Transactions on rehabilitation engineering, 1999, Mar; 7(1):99-108.

23) Staarink HAM. Sitting posture, comfort and pressure. 1995, Delft University Press, Delft, The Netherlands.

24) Agency for Health Care Policy and Research (AHCPR). Treatment of pressure ulcers, in: Clinical Practice guidelines no. 15 US Department of health and Human Services, Publication no. 95-0652, 1994.

25) Hagisawa S, Ferguson-Pell M. Evidence supporting the use of two-hourly turning for pressure ulcer prevention. Journal of Tissue Viability, 2008, Aug; 17 (3), 76-81.

26) Levine SP, Kett RL, Gross MD, Wilson BA, Cederna PS, Juni JE. Blood flow in the gluteus maximus of seated individuals during electrical muscle stimulation. Archives of Physical and Medical Rehabilitation. 1990 Aug; 71(9):682-6.

27) Van Londen A, Herwegh M, Van der Zee CH, Daffertshofer A, Smit CA, Niezen A, Janssen TW. The effect of surface electric stimulation of the gluteal muscles on the interface pressure in seated people with spinal cord injury. Archives of physical and medical rehabilitation, 2008, 89(9):1724-1732.

28) Bouten CVC, Bosboom EMH, Oomens CWJ. The aetiology of pressure sores: A tissue and cell mechanics approach. In: Biomedical aspects of manual wheelchair propulsion. L.H.V. Van der Woude et al. (Eds.) IOS Press (1999): 52-62.

29) Black JM, NPUAP. Moving toward consensus on deep tissue injury and pressure ulcer staging. Advances in skin \& wound care, 2005, Vol. 18(8):415-421.

30) Ankrom MA, Bennet RG, Sprigle S, Langemo D, Berlowitz DR, Lyder CH, NPUAP. Pressure-related deep tissue injury under intact skin and the current pressure ulcer staging system. Advances in skin \& wound care, 2005, Vol. 18(1):35-42.

31) Kosiak M, Kubicek WG, Olson M, Danz JN, Kottke FJ. Evaluation of pressure as a factor in the production of ischial ulcers. Archives of physical and medical rehabilitation, 1958, Vol. 39(10):623-629.

32) Kosiak M. Etiology and pathology of ischemic ulcers. Archives of physical and medical rehabilitation, 1959, Vol. 40(9):62-69.

33) Kosiak M. Etiology of decubitus ulcers. Archives of physical and medical rehabilitation, 1961, Vol. 42:1929.

34) Bosboom EMH, Bouten VCV, Oomens CWJ, Baaijens FPT, Nicolay K. Quantifying pressure-sore related muscle damage using high-resolution MRI. Journal of applied physiology, 2003, Vol. 95:2235-2240.

35) Breuls RGM, Bouten CVC, Oomens CWJ, Bader DL, Baaijens FPT. Compression induced cell damage in engineered muscle tissue: An in vitro model to study pressure ulcer aetiology. Annals of biomedical engineering, 2003, Vol. 31:1357-1364.

36) Ceelen KK, Stekelenburg A, Mulders JLJ, Strijkers GJ, Baaijens FPT, Nicolay K, Oomens CWJ. Validation of a numerical model of skeletal muscle compression with MRI tagging: A contribution to pressure ulcers research. Journal of biomechanical engineering, 2008, Vol. 130: Epub 061015-1. 
37) Ceelen KK, Stekelenburg A, Loerakker S, Strijkers GJ, Bader DL, Nicolay K, Baaijens FP, Oomens CW. Compression-induced damage and internal tissue strains are related. Journal of biomechanics, 2008, Dec 5; 41(16):3399-404.

38) Daniel RK, Priest DL, Wheatley DC. Etiologic factors in pressure sores: an experimental model. Archives of physical and medical rehabilitation, 1981, Vol. 62:492-498.

39) Goldstein B, Sanders J. Skin response to repetitive mechanical stress: A new experimental model in pig. Archives of physical and medical rehabilitation, 1981, Vol. 79:265-272.

40) Brienza DM, Geyer MJ, Jan YA. A comparison of changes in rhythms of sacral blood flow in response to heating and indentation. Archives of physical and medical rehabilitation, 2005, Vol. 86:1245-1251.

41) Gefen A. How much time does it take to get a pressure ulcer? Integrated evidence from human, animal and in vitro studies. Ostomy wound management, 2008; 54 (10), 26-35.

42) Husain T. Experimental study of some pressure effects on tissue, with reference to the bed-sore problem. Journal of pathology and bacteriology, 1953, Vol. 66:347-363.

43) Dinsdale SM. Decubitus ulcers in swine: Light and electron microscopy study of pathogenesis. Archives of physical and medical rehabilitation, 1973, Vol. 54:51-56.

44) Dinsdale SM. Decubitus ulcers: Role of pressure and friction in causation. Archives of physical and medical rehabilitation, 1974, Vol. 55:147-152.

45) Nola GT, Vistness LM. Differential response of skin and muscle in the experimental production of pressure sores. Plastic and reconstructive surgery, 1980, Vol. 66:728-733.

46) Le KM, Madsen BL, Barth PW, Ksander AM, Angell JB, Vistnes LM. An in-depth look at pressure sores using monolithic pressure sensors. Plastic and reconstructive surgery, 1984, Vol. 74(6):745-754.

47) Reswick JB, Rogers JE. Experience at Rancho los Amigos hospital with devices and techniques to prevent pressure sores. In: Kennedi RM, Cowden JM, Scales JT (Eds.) Bedsore biomechanics, London, Macmillan 1976:301-310.

48) Geyer MJ, Brienza DM, Karg P, Trefler E, Kelsey S. A randomized control trial to evaluate pressurereducing seat cushions for elderly wheelchair users. Advances in skin \& wound care, 2001, Vol. 14(3):120129.

49) Ferguson-Pell M, Cardi MD. Prototype development and comparative evaluation of wheelchair pressure mapping system. Assistive technology, 1993, Vol. 5(2), 78-91.

50) Sprigle S, Dunlop W, Press L. Reliability of bench tests of interface pressure. Assistive technology, 2003, Vol. 15:49-57.

51) Todd BA, Thacker JG. Three-dimensional computer model of the human buttocks, in vivo. Journal of rehabilitation research and development, 1994, Vol. 31(4):111-119.

52) Dabnichki PA, Crocombe AD, Hughes SC. Deformation and stress analysis of supported buttock contact. Journal of engineering in medicine, 1994, Vol. 208:9-17.

53) Brosh T, Arcan M. Modeling the body/chair interaction- an integrative experimental-numerical approach. Clinical biomechanics, 2000, Vol. 15:217-219.

54) Ragan R, Kernozek TW, Bidar M, Matheson JW. Seat-interface pressures on various thickness of foam wheelchair cushions: a finite modeling approach. Archives of physical and medical rehabilitation, 2002, Vol. 83(6):872-875. 
55) Lin F, Moran B, Bankard J, Hendrix R, Makhsous M. A subject-specific FEM model for evaluating buttock tissue response under sitting load. Proceedings of the $26^{\text {th }}$ annual conference of IEEE, EMBS, sept. 2004 San Fransisco.

56) Oomens CWJ, Bressers OFJT, Bosboom EMH, Bouten CVC. Deformation analysis of a supported buttock contact. Vol. 50, 2001, Bioengineering Conference ASME 2001.

57) Oomens CWJ, Bressers OFJT, Bosboom EMH, Bouten CVC, Bader DL. Can loaded interface characteristics influence strain distributions in muscle adjacent to bony prominences? Computer methods in biomechanics and biomedical engineering, 2003, Vol. 6(3):177-180.

58) Linder-Ganz E, Gefen A. Mechanical compression induced pressure sores in rat hind limb: muscle stiffness, histology, and computational models. Journal of applied physiology, 2004, Vol. 96:2034-2049.

59) Linder-Ganz E, Engelberg S, Scheinowitz M, Gefen A. Pressure-time cell death threshold for albino skeletal muscles as related to pressure sore biomechanics. Journal of biomechanics, 2006;39(14):2725-32.

60) Gefen A, Gefen N, Linder-Ganz E, Margulies SS. In vivo stiffening under bone compression promotes seep pressure sores. ASME Journal of biomechanical engineering, 2005, Vol. 127:512-524.

61) Landis E M. Microinjection studies of capillary blood pressure in human skin. Heart, 1930; 15,207-228.

62) Goossens RHM, Zegers R, Hoek van Dijke GA, Snijders CJ. Influence of shear on skin oxygen tension. Clinical physiology, 1994, Vol. 14:111-118.

63) Goossens RH, Snijders CJ, Holscher TG, Heerens WC, Holman AE. Shear stress measured on beds and wheelchairs. Scandinavian journal of rehabilitation and medicine, 1997, Sep; 29(3):131-6.

64) Gilsdorf P, Patterson R, Fisher S, Appel N. Sitting forces and wheelchair mechanics. Journal of rehabilitation research and development, 1990, Summer; 27(3):239-46.

65) Hobson DA. Comparative effects of posture on pressure and shear at the body-seat interface. Journal of rehabilitation research and development, 1992, Vol. 29(4):21-31.

66) Bennet L, Kavner D, Lee BK, Trainor FA. Shear versus pressure as causative factors in skin blood flow occlusion. Archives of physical and medical rehabilitation, 1979, Vol. 60:309-314.

67) Ferguson-Pell M. An in-depth look at pressure sores using monolithic pressure sensors (Discussion). Plastic and reconstructive surgery, 1984, Vol. 74(6):755.

68) Sangeorzan BJ, Harrington RM, Wyss CR, Czerniecki JM, Matsen III FA. Circulatory and mechanical response of skin to loading. Journal of orthopedic research, 1989, Vol. 7:425-431.

69) Reddy NP, Patel H, Cochran GVB, Brunski JB. Model experiments to study the stress distributions in a seated buttock. Journal of biomechanics, 1982, Vol. 15(7):493-504.

70) Kuroda S, Akimoto M. Finite element analysis of undermining of pressure ulcer with a simple cylinder model. Journal of Nippon medical school, 2005, Jun; 72(3):174-178

71) Gefen A, Levine J. The false premise in measuring body-support interface pressures for preventing serious pressure ulcers. Journal of medical engineering and technology, 2007, Sep-Oct; 31(5):375-80.

72) Linder-Ganz E, Shabshin N, Itzchak Y, Yizhar Z, Siev-Ner I, Gefen A. Strains and stresses in sub-dermal tissues of the buttocks are greater in paraplegics than in healthy during sitting. Journal of biomechanics, 2008;41(3):567-80.

73) Gawlitta D, Lin W, Oomens CWJ, Baaijens FPT, Bader DL, Bouten CWC. The relative contribution of compression and hypoxia to development of muscle tissue damage: An in vitro study, Annals of biomedical engineering, 2007, Vol. 35 (2): 273-284. 
74) Bouten CV, Oomens CW, Baaijens FP, Bader DL. The etiology of pressure ulcers: Skin deep or muscle bound. Archives of physical and medical rehabilitation, 2003, Vol. 84:616-619.

75) Chow, W.W., Odell, E.I. (1978). Deformations and stresses in soft body tissues of a sitting person. Journal of Biomechanical Engineering, 100, 79-87.

76) Mak AF, Huang L, Wang Q. A biphasic poro-elastic analysis of the flow dependent subcutaneous tissue pressure and compaction due to epidermal loadings: issues in pressure sore. Journal of biomechanical Engineering, 1994, Nov; 116(4):421-9.

77) Salcido R, Fisher SB, Donofrio JC, Bieschke N, Knapp C, Liang R, LeGrand EK, Carney JM. An animal model and computer-controlled surface pressure delivery system for the production of pressure ulcers. Journal of rehabilitation research and development, 1995 Vol. 32(2):149-161.

78) Stekelenburg A, Gawlitta D, Bader DL, Oomens CWC. Deep tissue injury: How deep is our understanding? Archives of physical and medical rehabilitation, 2008, Vol. 89: 1410-1413.

79) Holloway jr. GA, Watkins DW. Laser Doppler measurement of cutaneous blood flow. The journal of investigative dermatology, 1977, Vol. 69:306-309.

80) Stern MD, Lappe DL, Bowen PD, Chimosky JE, Holloway jr. GA, Keiser HR, Bowman RL. Continuous measurement of tissue blood flow by laser Doppler spectroscopy. American journal of physiology, 1977, Vol. 232(4):441-448.

81) Watkins S, Holloway jr. GA. An instrument to measure cutaneous blood flow using the Doppler shift of laser light. IEEE transactions on biomedical engineering 1978, BME Vol 25(1):28-33.

82) Schubert V, Fagrell B. Local skin pressure and its effect on skin microcirculation as evaluated by laser Doppler fluxmetry. Clinical physiology, 1989, Vol. 9:535-545.

83) Schubert V, Fagrell B. Evaluation of the dynamic cutaneous post-ischemic hyperemia and thermal response in elderly subjects and in an area at risk for pressure sores. Clinical physiology, 1991, Vol. 11:169182.

84) Sachse RE, Fink SA, Klitzman B. Multimodality evaluation of pressure relief surfaces. Plastic and reconstructive surgery, 1998, Vol. 102:2381-2387.

85) Hermann EC, Knapp CF, Donofrio JC, Salcido R. Skin perfusion responses to surface-induced ischemia: Implications for the developing pressure ulcer. Journal of rehabilitation research and development, 1999, Vol. 26(2):109-120.

86) Thorfinn J, Sjöberg F, Lidman D. Sitting pressure and perfusion of buttock skin in paraplegic and tetraplegic patients, and in healthy subjects: a comparative study. Scandinavian journal of plastic surgery and hand surgery, 2002, Vol. 36:279-283.

87) Ek A, Lewis DH, Zetterqvist $\mathrm{H}$, Svensson $\mathrm{P}$, Skin blood flow in an area at risk for pressure sore. Scandinavian journal of rehabilitation medicine, 1984, Vol. 16:85-89

88) Colantuoni A, Bertuglia S, Intaglietta M. Micro vascular vasomotion: Origin of the laser Doppler flux motion. International journal of microcirculation, 1994, Vol. 14:151-158.

89) Newson TP, Rolfe P. Skin surface $\mathrm{PO}_{2}$ and blood flow measurements over the ischial tuberosity. Archives of physical and medical rehabilitation, 1982, Vol. 63:553-556.

90) Bader DL. The recovery characteristics of soft tissues following repeated loading. Journal of rehabilitation research and development, 1990, Vol. 27(2):141-150 
91) Bader DL, Gant CA. Changes in transcutaneous oxygen tension as a result of prolonged pressures at the sacrum. Clinical physics and physiological measurements, 1988, Vol. 9(1):33-40.

92) Bogie KM, Nuseibeh I, Bader DL. Transcutaneous gas tensions in the sacrum during the acute phase of spinal cord injury. Journal of engineering in medicine, 1992, Vol. 206(1):1-6.

93) Bogie KM, Nuseibeh I, Bader DL. Early progressive changes in tissue viability in the seated spinal cord injured subject. Paraplegia, 1995, Vol. 33:141-147

94) Knight SL, Taylor RP, Polliack A, Bader DL. Establishing predictive indicators for the status of loaded soft tissues. Journal of applied physiology, 2001, Vol. 90:2231-2237.

95) Makhsous M, Lin F, Patel JC, Hendrix RW, Zhang LQ, Rymer, WZ. Tissue perfusion and blood flow response in a wheelchair with adjustable ischial and back support. 27th Annual Meeting of the ASB; Toledo, September 25-27 2003.

96) Seiler WO, Stähelin HB. Skin oxygen tension as a function of imposed skin pressure: Implication for decubitus ulcer formation. Journal of the American geriatric society, 1979, Vol. 27(7); 298-301.

97) Ferguson-Pell M, Hagisawa S. An empirical technique to compensate for melanin when monitoring skin microcirculation using reflectance spectroscopy. Medical engineering and physics, 1995, Vol. 17(2):104-110.

98) Riordan B, Sprigle S, Linden M. Testing the validity of erythema detection algorithms. Journal of rehabilitation research and development, 2001, Vol. 38(1):13-22.

99) Sprigle S, Linden M, Riordan B. Characterizing reactive hyperemia via tissue reflectance spectroscopy in response to an ischemic load across gender, age, skin pigmentation and diabetes. Medical engineering and physics, 2002, Vol. 24 :651-661. 
Chapter 1 
CHAPTER 2

\section{THE CLINICAL USE OF INTERFACE PRESSURE TO PREDICT PRESSURE ULCER DEVELOPMENT: A SYSTEMATIC REVIEW}

J. Reenalda, M. Nederband, M. Jannink, M. IJzerman

Assistive Technology 2009; 21 (2): 76-85. 


\subsection{Abstract}

Pressure ulcers, or pressure related deep tissue injuries, are a large problem in subjects who use a wheelchair for their mobility. These ulcers originate beneath the bony prominences of the pelvis and progress outwards as a consequence of prolonged pressure. Interface pressure is used clinically to predict and prevent pressure ulcers. However, the relation between interface pressure and the development of pressure ulcers is not clear. A systematic review was performed to address the research question if interface pressure can be used to predict the development of pressure ulcers, or to determine the prognosis of an ulcer, once developed. Seven studies were identified that measured interface pressure and used the development or healing of pressure ulcers as an outcome measure. There appears to be a weak qualitative relation between interface pressure and the development of pressure ulcers. However, no conclusive clinical threshold for the interface pressure can be given. This, combined with the influence of individual characteristics like level of mobility, body composition, nutritional state and other comobordities, the low internal validity of interface pressure measurement for the prediction of pressure ulcers and an incongruent relation between pressure magnitude and duration, results in the fact that no quantification of the predictive or prognostic value of interface pressure can be given.

\subsection{Introduction}

Pressure ulcers often cause discomfort and pain to patients who use a wheelchair for their mobility for are confined to bed, and can be life threatening without treatment. The North American National Pressure Ulcer Advisory Panel (NPUAP) defines a pressure ulcer as "localized injury to the skin and/or underlying tissue, usually over a bony prominence, as a result of pressure, or pressure in combination with shear and/or friction" [1]. Prevalence of pressure ulcers is $18.1 \%$ in European standard and academic hospitals [2] and between 12 and $35 \%$ in Dutch hospitals and nursery homes [3]. Reported prevalence of pressure ulcers occurring in the ischial, sacral and gluteus region is about $46 \%$ [4]. Pressure ulcers in as a consequence of lying in bed develop mostly on the sacrum, trochanters and heels while pressure ulcers as a consequence of sitting in a chair or sitting in bed develop mostly on the ischial tuberosities and sacrum [5,6].

The etiology of pressure ulcers is multi factorial and does not depend solely on pressure. Factors, such as fecal and urinal incontinence, tissue maceration, malnutrition also play an important role in the development of pressure ulcers, because they modify the effect of 
The clinical use of interface pressure to predict pressure ulcer development

pressure on the tissue. Furthermore, the tolerance of the tissue to external load also depends on the duration of the exerted load [7]. High loads can be tolerated for very short periods of time while relatively low loads are acceptable for longer periods of time.

Recently the concept of pressure ulcers has been divided in pressure ulcers and friction ulcers based on their etiology. Pressure ulcers (or pressure related deep tissue injuries) are thought to originate mostly from sustained pressure during sitting while superficial friction ulcers are caused by friction, shear and trauma to the tissue [8-10]. Pressure ulcers originate subcutaneously and progress outwards while superficial friction ulcers develop in the skin and progress inwards. Although the effect of shear on the development of ulcers is well recognized, it received little research attention mainly due to the difficulties encountered when measuring shear reliably [11-16].

Internal load in the tissue, as a result of external load, causes cell deformation, occlusion of blood and lymphatic vessels and ischemia. Measuring these factors can be used to quantify the risk of pressure ulcers. However, because internal pressure cannot be measured reliably in vivo, to technical and ethical constraints [17-20], attempts have been made to understand the etiology and to quantify the risk of pressure ulcers based on Finite Element Modeling to estimate the internal load [9, 21-32]. In addition skin oxygenation and perfusion measurements have been used to understand the etiology and to quantify the risk of developing (skin) ulcers, based on the viability of the tissue [33-39]. However, these studies have not led to clinically usable thresholds or guidelines, besides the fact that the availability and ease of use of these devices in the clinical setting is limited.

The most used alternative measure is interface pressure, the pressure between skin and the sitting surface. This is mainly because the measurement of interface pressure is easy to administer, non-invasive and has straightforward data processing. Pressure mapping is used to determine the risk of pressure ulcer development, to analyze and understand different sitting postures within individuals, to educate about weight shifting techniques in order to alternate sitting load and to compare different support surfaces.

Unfortunately, despite substantial research effort, no clear cut-off point in interface pressure for the development of pressure ulcer has been established. Due to the lack of this clinical threshold, the golden standard in experimental research that can provide information about the risk of pressure ulcers is the actual development of pressure ulcers. A large amount of research has been published on the topic of prevention of pressure ulcers, using the incidence of 
pressure ulcers as an outcome measure. However, few studies have related the measurement of interface pressure to the incidence of pressure ulcers.

The measurement of interface pressure is widespread in research and clinical setting, based on the assumption that there is a relation between the interface pressure and the development or healing of pressure ulcers. However, a lot is unknown about this relation. Therefore a review of the literature is performed to determine if there is a clinical relation between the interface pressure and the incidence of pressure ulcers (deep tissue injury) in the sitting or lying subject. The main question in the current study that will be addressed is if interface pressure can be used for clinically predicting the development of pressure ulcers (deep tissue injury).

\subsection{Methods}

\subsubsection{Literature search}

A systematic literature search has been performed. Articles were sought in NCBI PubMed, CIRRIE and REHABDATA databases from 1970 to September 2006.

The following key words were included to identify articles that linked the measurement of interface pressure to the development of pressure ulcers as an outcome measure in a randomized clinical trial, controlled trial or clinical trial: Pressure ulcer(s) (MESH), Pressure

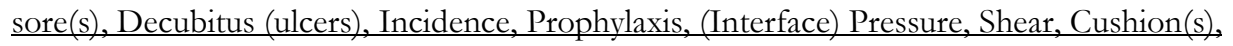
Mattress(es). Refer to appendix 1 for the complete search strategy.

In addition to searching the databases, the reference lists of the identified articles were checked for related articles.

\subsection{2 study selection}

The initial selection of articles was based on title and content of the abstract by two reviewers (JR, MJ). In the case of disagreement, a third reviewer (MN) was consulted. To be selected for review, a study had to:

- Use interface pressure measurement either as a predictive or a prognostic factor. This means that both the prediction of the development (predictive factor) as well as the prognosis of healing (prognostic factor) of pressure ulcer is of interest.

AND

- Use the development or healing of pressure ulcers as an outcome measure. 
No limitation as to the patient population and year of publication was imposed. In addition, no distinction in type of ulcer was made prior to inclusion.

\subsubsection{Methodological quality judgment}

An evaluation of the methodological characteristics of the identified studies was performed according to a framework modified from the work of Hudak, Cole \& Frank (1998) and Altman (2001). This framework consists of items regarding study population and patient selection, follow-up, outcome measures, treatment, predictive and prognostic factors and analysis. It has originally been developed for prognostic studies. See table 1 for details of this framework. Studies will be scored according to these items. A maximum of 17 points can be scored per study. Studies with nine points or more will be considered as having sufficient quality. Studies were scored by two independent reviewers (JR, MJ). If consensus was not reached, a third independent reviewer ( $\mathrm{MN}$ or $\mathrm{MIJ}$ ) was contacted to reach consensus about the items. 
Table 1: Evaluation of the methodological quality of the studies

\begin{tabular}{|c|c|c|c|c|c|c|c|c|}
\hline Study & & 1 & 2 & 3 & 4 & 5 & 6 & 7 \\
\hline Sample of patients & $\begin{array}{l}\text { Assembled at a common point of } \\
\text { the disease }\end{array}$ & Y & $\mathrm{Y}$ & $\mathrm{N}$ & $\mathrm{Y}$ & $\mathrm{Y}$ & $?$ & Y \\
\hline & Description of source population & Y & Y & $\mathrm{Y}$ & $\mathrm{Y}$ & Y & Y & Y \\
\hline & $\begin{array}{l}\text { Description of relevant inclusion } \\
\text { and exclusion criteria }\end{array}$ & Y & Y & $\mathrm{N}$ & Y & Y & Y & Y \\
\hline & $\begin{array}{l}\text { Adequate description of diagnostic } \\
\text { criteria }\end{array}$ & $\mathrm{Y}$ & Y & Y & Y & Y & Y & Y \\
\hline Follow up of patients & $\begin{array}{l}\text { Information completers versus loss } \\
\text { to follow-up/drop-outs }\end{array}$ & Y & Y & $?$ & Y & Y & Y & Y \\
\hline & $\begin{array}{l}\text { Percentage of loss to follow-up less } \\
\text { than } 20 \%\end{array}$ & $\mathrm{~N}$ & $\mathrm{Y}$ & $?$ & Y & Y & Y & Y \\
\hline & $\begin{array}{l}\text { Study duration sufficient for } \\
\text { pressure ulcer development }\end{array}$ & $\mathrm{Y}$ & Y & $?$ & Y & Y & Y & Y \\
\hline Sitting load & $\begin{array}{l}\text { Sitting load in cohort is fully } \\
\text { described and standardized }\end{array}$ & $\mathrm{Y}$ & Y & Y & Y & Y & Y & Y \\
\hline Predictive and prognostic factors & Factors fully defined & $\mathrm{Y}$ & $\mathrm{Y}$ & $\mathrm{Y}$ & $\mathrm{Y}$ & Y & Y & Y \\
\hline & Standardized or valid measurements & $\mathrm{Y}$ & Y & $\mathrm{Y}$ & $\mathrm{Y}$ & Y & Y & Y \\
\hline & Data presented per subject & $\mathrm{Y}$ & $\mathrm{N}$ & Y & $\mathrm{N}$ & $\mathrm{N}$ & $\mathrm{N}$ & $\mathrm{N}$ \\
\hline Outcome & Outcome fully defined & $\mathrm{Y}$ & Y & $\mathrm{Y}$ & $\mathrm{N}$ & $\mathrm{Y}$ & $\mathrm{N}$ & Y \\
\hline & Clinically relevant outcome measure & Y & Y & $\mathrm{N}$ & $\mathrm{N}$ & Y & $\mathrm{N}$ & Y \\
\hline & Standardized or valid measurements & Y & Y & $\mathrm{N}$ & $\mathrm{Y}$ & Y & $\mathrm{N}$ & Y \\
\hline Analysis & Statistical analysis performed & $\mathrm{Y}$ & Y & $\mathrm{N}$ & $\mathrm{N}$ & Y & Y & Y \\
\hline & Appropriate statistical analysis & $\mathrm{Y}$ & Y & $\mathrm{N}$ & $\mathrm{N}$ & Y & Y & Y \\
\hline & Corrected for other factors & $\mathrm{N}$ & $\mathrm{N}$ & $\mathrm{N}$ & $\mathrm{N}$ & $\mathrm{N}$ & $\mathrm{N}$ & $\mathrm{N}$ \\
\hline Total Score ${ }^{b}$ & & 15 & 15 & 7 & 12 & 15 & 11 & 15 \\
\hline
\end{tabular}

a $1=$ Brienza et al.(2001), 2= Conine et al. (1994), 3= Drummond et al. (1985), 4= Economides et al. (1995), 5=

Rosenthal et al. (2003), 6= Sideranko et al. (1992), 7= Tymec et al. (1997).

${ }^{\mathrm{b}}$ Yes $=1$ point, $\mathrm{No}=0$ points, $?=0$ points

\subsubsection{Data extraction and synthesis}

The content of the selected studies was analyzed by using a structured diagram, consisting of the following parameters: study type, descriptive features of the subject population, determination of interface pressure, outcome measures, study duration and conclusions. 
Analysis of the content was performed by two reviewers (JR, MJ); in case of discussion a third reviewer $(\mathrm{MN})$ was consulted.

\section{$2.4 \quad$ Results}

\subsubsection{Study Selection}

The search strategy resulted in a total of 1682 articles. An initial selection was made based on title, key-words and abstract. From the full-text screening of the selection only eight studies were identified that matched both inclusion criteria.

The identified articles were Brienza, Karg, Geyer, Kelsey \& Trefler, 2001; Conine, Hershler, Daechsel, Peel \& Pearson, 1994; Drummond, Narechania, Rosenthal, Breed, Lange \& Drummond, 1985; Economides, Skoutakis, Carter \& Smith, 1995; Geyer, Brienza, Karg, Trefler, \& Kelsey, 2001; Rosenthal, Felton, Nastasi, Naliboff, Harker \& Navach, 2003; Sideranko, Quinn, Burns \& Froman, 1992; Tymec, Pieper \& Vollman, 1997 [42-49]. Seven of the eight related the measurement of interface pressure to the probability of pressure ulcers while one study (Rosenthal et al. 2003) [47] investigated the prognosis of pressure ulcers once developed, expressed in time to healing, in relation to the interface pressure. Two studies (Brienza et al., 2001; Geyer et al., 2001) [42,46] used the same cohort and are therefore combined and referred to as Brienza et al. (2001). All studies are prospective except the study of Drummond et al. (1985) [44] which is retrospective. Four of the studies investigated the sitting subject (Brienza et al., 2001; Conine et al., 1994; Drummond et al., 1985; Rosenthal et al., 2003) [42-44, 47] while three of them investigated the lying subject (Economides et al., 1995; Sideranko et al., 1992 Tymec et al., 1997) [45, 48, 49].

\subsubsection{Methodological Quality judgment}

Studies were scored according to the framework for methodological quality. Table 1 displays the methodological criteria and the subsequent scores of the different studies. Except for the study of Drummond et al. (1985) [44], scoring less than 9 points all studies had sufficient methodological quality.

\section{Sample of patients}

Three different subject populations could be identified. Subjects in the reviewed studies were elderly at risk, free of pressure ulcers [42, 43, 49], patients that had already developed pressure ulcers of different grades [44, 45, 47] and surgical intensive care patients [48]. Reported sample sizes ranged from 12 [45] to 207 [47] subjects.

Follow up of patients 
Follow up of patients ranged from 48 hours to 12 months. Only one study [42] presented data per subjects. Drop out was reported in the studies with longer duration [42, 43, 47]. A common accepted value for loss to follow up is $20 \%$ of the subject's population. Only in the study of Brienza et al. [42] loss to follow-up was more than $20 \%$, however this was caused by death of subjects, established a priori as a valid study endpoint.

\section{Sitting load}

Full description and standardization of the study protocol is lacking in most articles. As a consequence, it is not possible to compare the dose-response relation between the different studies.

\section{Predictive and prognostic factor measurement}

Large heterogeneity exists in the measurement of interface pressure. Different pressure measurement devices from single cell pressure transducers $[43,45,48,49]$ to pressure mapping mats $[42,44,47]$ have been used. Interface pressure was measured at the seating surface by means of pressure mapping $[42,44,47]$, and by means of a single cell transducer in the sacrococcygeal area, ischial tuberosities and trochanters during sitting [43], at the (not further defined) site of myocutaneous flap surgery [45], at the sacrum and heels while lying [48, 49]. Mostly mean and peak interface pressures were reported as predictive or prognostic factors. A wide range of mean and peak interface pressure values was found. Generally, as a consequence of a smaller contact area, interface pressures in sitting are higher than during lying. Presentation of predictive and prognostic data was lacking in most studies. One study used a relative pressure distribution on the sitting surface as an outcome measure [44]. Data per subject was only presented in the study of Brienza et al. [42].

\section{Outcome measurement}

Included studies used the development or healing of pressure ulcers as an outcome measure. These outcome measures were measured by inspecting the skin manually and visually $[42,43$, $47,49]$ or from photographs [45]. Large heterogeneity also exists in the method of pressure ulcer measuring and staging in these studies. Furthermore, different staging systems for pressure ulcer staging have been used. Staging systems that were used are the NPUAP/AHCPR staging system [42, 49], the Exton-Smith scale [43], the Pressure Sore Status Score [47]. No staging of outcome measure was reported in three studies [44, 45, 48].

The temporal aspect of pressure ulcer development or healing was of interest in two studies. Tymec et al. [49] investigated the time to pressure ulcer development while Rosenthal et al. [47] investigated the time to pressure ulcer healing. 


\section{Analysis}

Parametric and non-parametric t-tests have been performed to statistically analyze the data.

However, not all studies used statistical analysis to interpret the data [44, 45]. Survival analysis was used to associate interface pressure to the time to development of pressure ulcers [49].

\subsection{General results}

Results regarding the relation between interface pressure and the development and healing of pressure ulcers can be found in table 2. Higher interface pressures seem to be related to a higher incidence of pressure ulcers. Two studies found that a higher interface pressure is related to a higher incidence of pressure ulcers [42, 43]. A relation between interface pressure distribution and pressure ulcer development was defined in a retrospective way [44], however, this study lacked methodological quality to draw clinical conclusion from. No relation between interface pressure and the development or healing of pressure ulcers was found in three other studies $[45,48,49]$.

When considering temporal aspects in the development or healing of pressure ulcers there appears to be a relation between the magnitude of the pressure and the time to development or healing of pressure ulcers. Considering time to development or healing of pressure ulcers, the magnitude of interface pressure was associated with the development of healing rate of pressure ulcers. Pressure ulcers at the feet developed sooner with higher interface pressure [49]. In agreement with this, lower interface pressure is associated with faster healing rates of pressure ulcers [47].

Table 2: Characteristics of the studies

\begin{tabular}{|l|l|l|l|l|l|l|}
\hline \multicolumn{1}{|c|}{ Study } & \multicolumn{2}{|c}{ Study type } & \multicolumn{1}{l}{$\begin{array}{l}\text { Determination } \\
\text { of IP }\end{array}$} & \multicolumn{1}{l}{$\begin{array}{l}\text { Outcome } \\
\text { staging method }\end{array}$} \\
\hline $\begin{array}{l}\text { Brienza et al. } \\
2001\end{array}$ & $\begin{array}{l}\text { RCT on } \\
\text { wheelchair } \\
\text { bound at risk } \\
\text { elderly, to } \\
\text { investigate the } \\
\text { relation between } \\
\text { PU incidence } \\
\text { and buttock- } \\
\text { wheelchair seat } \\
\text { cushion } \\
\text { interface }\end{array}$ & $\begin{array}{l}\text { FSA 15X15 } \\
\text { pressure mat }\end{array}$ & $\begin{array}{l}\text { PU Development } \\
\text { (NPUAP) }\end{array}$ & 12 Months & $\begin{array}{l}\text { Higher IP related } \\
\text { to higher } \\
\text { incidence of PU. }\end{array}$ \\
& & & & & \\
& & & & \\
\end{tabular}


Chapter 2

\begin{tabular}{|c|c|c|c|c|c|c|}
\hline $\begin{array}{l}\text { Conine et al. } \\
1994\end{array}$ & $\begin{array}{l}\text { RCT on } \\
\text { wheelchair } \\
\text { bound at risk } \\
\text { elderly, } \\
\text { comparison } \\
\text { Jay }{ }^{\circledR} \text { versus } \\
\text { foam cushions }\end{array}$ & 163 & $\begin{array}{l}\text { Scimedics single } \\
\text { cell pressure } \\
\text { evaluator }\end{array}$ & $\begin{array}{l}\text { PU Development } \\
\text { (Exton-Smith) }\end{array}$ & 3 Months & $\begin{array}{l}\text { Higher interface } \\
\text { pressure related to } \\
\text { higher incidence } \\
\text { of pressure ulcers. } \\
\text { The incidence of } \\
\text { PU was } \\
\text { significantly } \\
\text { among those } \\
\text { patients who } \\
\text { experienced peak } \\
\text { IP recorded at } 60 \\
\text { MMhg or higher. }\end{array}$ \\
\hline $\begin{array}{l}\text { Drummond et } \\
\text { al. } 1985\end{array}$ & $\begin{array}{l}\text { Cross-sectional } \\
\text { study on sitting } \\
\text { patients with } \\
\text { stage III or IV } \\
\text { PU }\end{array}$ & 16 & $\begin{array}{l}\text { Talley Pressure } \\
\text { scanner } \\
64 \text { cells }\end{array}$ & $\begin{array}{l}\text { Present PU's } \\
\text { (no staging) }\end{array}$ & $?$ & $\begin{array}{l}\text { A relation } \\
\text { between IP } \\
\text { distribution and } \\
\text { PU development } \\
\text { was found. SCI } \\
\text { experienced a } \\
\text { more posterior } \\
\text { distribution of } \\
\text { high IP under the } \\
\text { ischium and } \\
\text { sacrococcygeal } \\
\text { area. }\end{array}$ \\
\hline $\begin{array}{l}\text { Economides et } \\
\text { al. } 1995\end{array}$ & $\begin{array}{l}\text { RCT on patients } \\
\text { with previous } \\
\text { stage III or IV } \\
\text { PU after } \\
\text { myocutaneous } \\
\text { flap surgery. } \\
\text { Comparison of } \\
\text { Dry Flotation } \\
\text { and air-fluidized } \\
\text { mattresses. }\end{array}$ & 12 & $\begin{array}{l}\text { Scimedics single } \\
\text { cell pressure } \\
\text { evaluator, laser } \\
\text { Doppler } \\
\text { flowmetry }\end{array}$ & $\begin{array}{l}\text { Reoccurrence of } \\
\text { PU } \\
\text { (no staging). Flap } \\
\text { breakdown. }\end{array}$ & 14 days & $\begin{array}{l}\text { No relation } \\
\text { between IP and } \\
\text { PU development } \\
\text { after } \\
\text { myocutaneous } \\
\text { flap surgery. }\end{array}$ \\
\hline
\end{tabular}


The clinical use of interface pressure to predict pressure ulcer development

\begin{tabular}{|c|c|c|c|c|c|c|}
\hline $\begin{array}{l}\text { Rosenthal et al. } \\
2003\end{array}$ & $\begin{array}{l}\text { RCT on sitting } \\
\text { patients with a } \\
\text { stage III or IV } \\
\text { PU.. } \\
\text { Comparison of } \\
\text { a therapeutic } \\
\text { seat with low air } \\
\text { loss bed } \\
\text { treatment on } \\
\text { healing rates of } \\
\text { stage III and IV } \\
\text { PU. }\end{array}$ & 207 & $\begin{array}{l}\text { FSA } 15 \text { X } 15 \\
\text { pressure mat }\end{array}$ & $\begin{array}{l}\text { Healing of PU } \\
\text { (Pressure Sore } \\
\text { Status Score) }\end{array}$ & 6 Months & $\begin{array}{l}\text { Lower IP is } \\
\text { associated with } \\
\text { faster healing rates } \\
\text { of PU on the } \\
\text { Generic Total } \\
\text { Contact Seat. }\end{array}$ \\
\hline $\begin{array}{l}\text { Sideranko et al. } \\
1992\end{array}$ & $\begin{array}{l}\text { Observative } \\
\text { study on bed- } \\
\text { bound elderly } \\
\text { surgical patients. } \\
\text { Comparison of } \\
\text { alternating air, } \\
\text { static air and } \\
\text { water } \\
\text { mattresses. }\end{array}$ & 57 & $\begin{array}{l}\text { Single cell } \\
\text { pressure sensor }\end{array}$ & $\begin{array}{l}\text { Development of } \\
\text { PU } \\
\text { (no staging) }\end{array}$ & $\begin{array}{l}\text { Between } 3 \\
\text { and } 30 \\
\text { days }\end{array}$ & $\begin{array}{l}\text { No relation } \\
\text { between IP and } \\
\text { PU incidence }\end{array}$ \\
\hline $\begin{array}{l}\text { Tymec et al. } \\
1997\end{array}$ & $\begin{array}{l}\text { Observative } \\
\text { study on } \\
\text { immobile bed- } \\
\text { bound patients, } \\
\text { at risk for PU. } \\
\text { Comparison of } \\
\text { hospital pillows } \\
\text { vs. a commercial } \\
\text { heel elevation } \\
\text { device }\end{array}$ & 52 & $\begin{array}{l}\text { Gaymar electro } \\
\text { pneumatic } \\
\text { pressure } \\
\text { transducer }\end{array}$ & $\begin{array}{l}\text { Development of } \\
\text { PU } \\
\text { (Agency for Health } \\
\text { Care Policy and } \\
\text { Research) }\end{array}$ & 14 days & $\begin{array}{l}\text { No relation } \\
\text { between IP and } \\
\text { PU incidence. } \\
\text { PU's developed } \\
\text { sooner with } \\
\text { higher IP's. }\end{array}$ \\
\hline
\end{tabular}

\subsection{Discussion, general conclusions and Future Directions}

\subsubsection{Discussion}

Based on the present systematic review there seems to be a relation between interface pressure and pressure ulcer development or healing. However, this relation is qualitative and cannot be quantified in terms of interface pressure thresholds, temporal aspects of interface pressure in relation to pressure ulcer development and personal characteristics. Studies displayed large heterogeneity, resulting from different kinds of bias. This bias can be found in the heterogeneity in subjects and size of the subject population, lack of standardization of the research protocol, lack of standardization of the definition and measurement of the prognostic and predictive factors (interface pressure), and lack of standardization of the definition of 
outcome measurement (pressure ulcer development or healing), and will be discussed in the following section.

The definition of the subject population at risk for developing pressure ulcers, the lack of knowledge and validity on identifying patients at risk and the different individual pathways in the development of pressure ulcers demand large sample sized that are difficult to reach [50, 51]. Although the four methodologically most powerful studies (Brienza et al. 2001, Conine et al. 1994, Rosenthal et al. 2003, Tymec et al. 1997) [42, 43, 47, 49] had large subject populations, sample sizes in the others studies were relatively small. Sample sizes of the studies included in this review ranged from 12 to 207 subjects.

The lack of standardized protocols within and between the different studies limits the comparison of the different studies and results in a poor external validity. Studies included in the present review have used a variety of different measurement devices, ranging from single cell pressure transducers to pressure mapping device with 225 cells, and generally fail to clearly describe there measurement routine. In addition, the accuracy and stability of the pressure measurement devices is limited. It has been noted that pressure measurement devices display substantial hysteresis and creep [52], although the pressure measurement technique is improving [53]. As a result, the quantification and standardization of the load is difficult. This might explain some of the differences found between the studies and accounts for the fact that their subsequent pressure values can not be compared easily. The ISO seating standards group is currently working on standardization of the clinical application of interface pressure measurement techniques. This standardization will facilitate the comparison of data from different studies.

To quantify the interface pressure, mostly maximum and average pressures were used.

Unfortunately, the expression of the interface pressure values in average or maximum values has low test-retest reliability $[54,55]$. The recently developed dispersion index [55] and the pressure distribution value of Staarink [56] are relative measures of the distribution of the pressure on the total contact surface. The dispersion index has a good reliability and has been proposed as a standardized measure of the interface pressure.

The definition of the outcome measure differs between the included studies because no standardized pressure ulcer staging method has been used. Used staging methods were NPUAP/AHCPR staging system [42, 49] the Exton-Smith scale [43], the Pressure Sore Status Score [47]. No staging of outcome measure was reported in three studies [44, 45, 48]. The lack 
of a standardized and generally accepted way of determining and staging pressure ulcers makes the comparison of data between the studies difficult.

In addition, recently the distinction between shear/friction ulcers and pressure ulcer has been made based on their different etiology. This is in congruence with early animal experiments showing that as a consequence of prolonged load, pressure ulcers develop subcutaneously beneath a bony prominence [57]. Unfortunately, none of the studies in this review makes the distinction between the different types of ulcers. Considering the research question, only pressure ulcers (deep tissue injuries) can be used as an outcome measure to explore the relation between interface pressure and pressure ulcer development. If developed ulcers are divided in superficial friction ulcers and pressure ulcers, the qualitative relation that has been found in this review might be troubled.

Finite element studies, animal studies and studies with test-buttocks have shown that interface pressure is not equal to internal pressure $[18,21,23-25,27-31,56,58]$. Internal pressure, however, is a key factor in the development of pressure ulcers because it is the stress and deformation of the subcutaneous tissue that causes pressure ulcers. Because the relation between interface pressure and internal pressure is not linear, it is not possible to extrapolate interface pressures to internal pressures. It is stated that even with a soft cushion leading to a high reduction in the measured interface pressure, the deformation at the skeletal muscle near the bone can be high enough to form a risk for the development of pressure ulcers [29] and Finite Element Modeling furthermore showed that subjects with comparable external pressures had significantly different internal stresses and strains [26]. This has consequences for the clinical practice of measuring interface pressure in order to prevent pressure ulcers. For quantification of the risk of pressure ulcer development, the validity of interface pressure measurement in relation to the development of pressure ulcers is low.

Although a relation has been found, results are not congruent and considering the aforementioned arguments, interface pressure measurement might not be sufficient as a risk indicator for the development of pressure ulcers. Realizing the fact that pressure ulcers develop internally due to prolonged pressure and deformation, parameters that are a more direct derivative of the internal pressure are tissue oxygenation and perfusion. It has been noted that blood flow is a direct factor in the development of pressure ulcers because it is the blood that provides the tissue with the critical nutrients necessary for its survival [59]. As such, tissue oxygenation and perfusion play an important role in the development of pressure ulcers and are essential in the viability of the tissue. Some research has been performed on tissue 
oxygenation and perfusion in the field of pressure ulcers. However, this is limited to the oxygenation and perfusion of the skin only, since penetration depth of the measurement devices is limited to one to two millimeters, and at present has not led to clinical usable thresholds for the quantification of the risk of developing deep tissue injury [33-39]. To gain more insight in the relation between tissue oxygenation and perfusion and development of deep tissue injury, more research is needed.

2.6.2 General conclusions and future direction

A qualitative relation between interface pressure and the incidence and time to development or healing of pressure ulcers has been found. Higher interface pressures are related to a higher incidence of pressure ulcers. However, no conclusive clinical threshold for the interface pressure can be given. This, combined with the influence of individual characteristics like level of mobility, body composition, nutritional state and other comobordities, the low internal validity of interface pressure measurement for the prediction of pressure ulcers and an incongruent relation between pressure magnitude and duration, results in the fact that no quantification of the predictive or prognostic value of interface pressure can be given. More fundamental research on the etiology and development of pressure ulcers is needed to gain more understanding in the development of pressure ulcers and the relationship between interface pressure and pressure ulcers incidence. In addition larger randomized clinical trials are needed to establish a relation between the predictive/prognostic factors and pressure ulcers development. These trials should use standardized measurement protocols, and standardized definitions of the predictive/prognostic factors and the definition of the outcome measure. It is furthermore important to account for the influence of individual mediating factors that might have a clear impact on the individual etiology. 
The clinical use of interface pressure to predict pressure ulcer development

\subsection{References}

1) Black, J., Baharestani, M., Cuddigan, J., Dorner, B., Edsberg, L., Langemo, D., Posthauer, M.E., Ratliff, C., Taler, G., NPUAP. National Pressure Ulcer Advisory Panel's updated pressure ulcer staging system. Urologic Nursing, 2007, 27(2), 144-150.

2) Vanderwee, K., Clark, M., Dealey, C., Gunningberg, L., Defloor, T. Pressure ulcer prevalence in Europe: a pilot study. Journal of Evaluation in Clinical Practice, 2007, 13, 227-235.

3) Health Council of the Netherlands. Pressure Ulcers. The Hague: Health Council of the Netherlands, publication no. 1999/23.

4) Swaine, J., Young, C. Sitting Acquired Pressure Ulcers: Collecting incidence data in Tasmania. In Trefler, E. (Ed.) Proceedings of the 21th International Seating Symposium, Orlando Florida, 2005, Pittsburgh PA, pp 109-110.

5) Yarkony, G.M. Pressure ulcers: A review. Archives of Physical and Medical Rehabilitation, 1994, 75 (8), 908-917.

6) Byrne, D.W., Salzberg, C.A. Major risk factors for pressure ulcers in the spinal cord disabled: a literature review. Spinal Cord, 1996, 34, 255-263

7) Husain, T. Experimental study of some pressure effects on tissue, with reference to the bed-sore problem. Journal of Pathology and Bacteriology, 1953, 66, 347-363.

8) Bouten, C.V.C., Bosboom, E.M.H., Oomens, C.W.J. The etiology of pressure sores: A tissue and cell mechanics approach. In: Biomedical aspects of manual wheelchair propulsion. L.H.V. Van der Woude et al. (Eds.) IOS Press, 1999, (pp. 52-62).

9) Bouten, C.V.C., Oomens, C.W.J., Baaijens, F.P.T., Bader, D.L. The etiology of pressure ulcers: Skin deep or muscle bound. Archives of Physical and Medical Rehabilitation, 2003: 84, 616-619.

10) Quintavalle, P.R., Lyder, C.H., Mertz, P.J., Phillips-Jones, C., Dyson, M. Use of high-resolution, highfrequency diagnostic ultrasound to investigate the pathogenesis of pressure ulcer development. Advances in Skin Wound Care, 2006, 19(9), 498-505.

11) Bennet L., Kavner D., Lee B.K., Trainor F.A. Shear versus pressure as causative factors in skin blood flow occlusion. Archives of physical and medical rehabilitation, 1979, 60, 309-314.

12) Dinsdale, S. Decubitus ulcers in swine: Role of pressure and friction in causation. Archives of Physical and Medical Rehabilitation, 1975, 55, 147-152.

13) Gilsdorf, P., Patterson, R., Fisher, S., Appel, N. Sitting forces and wheelchair mechanics. Journal of Rehabilitation Research and Development, 1990, 27(3), 239-246.

14) Goossens, R.H., Zegers, R., Hoek van Dijke, G.A., Snijders, C.J. Influence of shear on skin oxygen tension. Clinical Physiology, 1994, 14(1), 111-118.

15) Goossens, R.H., Snijders, C.J., Holscher, T.G., Heerens, W.C., Holman, A.E. Shear stress measured on beds and wheelchairs. Scandinavian Journal of Rehabilitation Medicine, 1979, 29(3), 131-136.

16) Hobson, D.A. Comparative effects of posture on pressure and shear at the body-seat interface. Journal of Rehabilitation Research and Development, 1992, 29(4), 21-31.

17) Kosiak, M. Etiology and pathology of ischemic ulcers. Archives of Physical and Medical Rehabilitation, 1959, 40(9), 62-69.

18) Le, K.M., Madsen, B.L., Barth, P.W., Ksander, A.M., Angell, J.B., Vistnes, L.M. An in-depth look at pressure sores using monolithic pressure sensors. Plastic and Reconstructive Surgery, 1984: 74(6), 745-754. 
19) Ferguson-Pell, M. An in-depth look at pressure sores using monolithic pressure sensors (Discussion). Plastic and Reconstructive Surgery, 1984: 74(6), 755.

20) Bosboom, E.M.H., Bouten, V.C.V., Oomens, C.W.J., Baaijens, F.P.T., Nicolay, K. Quantifying pressuresore related muscle damage using high-resolution MRI. Journal of Applied Physiology, 2003: 95, 22352240.

21) Brosh, T., Arcan, M. Modeling the body/chair interaction- an integrative experimental-numerical approach. Clinical Biomechanics, 2000: 15, 217-219.

22) Chow, W.W., Odell, E.I. Deformations and stresses in soft body tissues of a sitting person. Journal of Biomechanical Engineering, 1978, 100, 79-87.

23) Gefen, A., Gefen, N., Linder-Ganz, E., Margulies, S.S. In vivo stiffening under bone compression promotes seep pressure sores. ASME Journal of Biomechanical Engineering, 2005: 127, 512-524.

24) Lin, F., Moran, B., Bankard, J., Hendrix, R., Makhsous, M. A subject-specific FEM model for evaluating buttock tissue response under sitting load. In Proceedings of the $26^{\text {th }}$ annual conference of IEEE, EMBS, 2004: San Francisco, USA.

25) Linder-Ganz E, Engelberg S, Scheinowitz M, Gefen A. Pressure-time cell death threshold for albino skeletal muscles as related to pressure sore biomechanics. Journal of Biomechanics, 2005: 39(14):27252732.

26) Linder-Ganz, E., Shabshin, N., Itzchak, Y., Gefen, A. Assessment of mechanical conditions in sub-dermal tissues during sitting: A combined experimental-MRI and finite element approach. Journal of Biomechanics, 2006: 40(7):1443-1154.

27) Linder-Ganz, E., Gefen, A. Mechanical compression induced pressure sores in rat hind limb: muscle stiffness, histology, and computational models. Journal of Applied Physiology, 2004: 96, 2034-2049.

28) Oomens, C.W.J., Bressers, O.F.J.T., Bosboom, E.M.H., Bouten, C.V.C.. Deformation analysis of a supported buttock contact. In proceedings of the Bioengineering Conference ASME 2001, pp 853-854.

29) Oomens, C.W.J., Bressers, O.F.J.T., Bosboom, E.M.H., Bouten, C.V.C., Bader, D.L. Can loaded interface characteristics influence strain distributions in muscle adjacent to bony prominences? Computer Methods in Biomechanics and Biomedical Engineering, 2003: 6(3), 177-180.

30) Ragan, R., Kernozek, T.W., Bidar, M., Matheson, J.W. Seat-interface pressures on various thickness of foam wheelchair cushions: a finite modeling approach. Archives of Physical and Medical Rehabilitation, 200: 83(6), 872-875.

31) Todd, B.A., Thacker, J.G. Three-dimensional computer model of the human buttocks, in vivo. Journal of Rehabilitation Research and Development, 1994: 31(4), 111-119.

32) Mak, A.F., Huang, L., Wang, Q. A biphasic poroelastic analysis of the flow dependent subcutaneous tissue pressure and compaction due to epidermal loadings: issues in pressure sore. Journal of Biomechanical Engineering, 1994: 116(4), 421-9.

33) Schubert, V., Fagrell, B. Local skin pressure and its effect on skin microcirculation as evaluated by laser Doppler fluxmetry. Clinical Physiology, 1989: 9, 535-545.

34) Schubert, V., Fagrell, B. Evaluation of the dynamic cutaneous post-ischemic hyperemia and thermal response in elderly subjects and in an area at risk for pressure sores. Clinical Physiology, 1991: 11, 169-182.

35) Sachse, R.E., Fink, S.A., Klitzman, B. Multimodality evaluation of pressure relief surfaces. Plastic and Reconstructive Surgery, 1998: 102, 2381-2387. 
36) Hermann, E.C., Knapp, C.F., Donofrio, J.C., Salcido, R. Skin perfusion responses to surface-induced ischemia: Implications for the developing pressure ulcer. Journal of Rehabilitation Research and Development, 1999: 26(2), 109-120.

37) Salcido, R., Fisher, S.B., Donofrio, J.C., Bieschke, N., Knapp, C., Liang, R., LeGrand, E.K., Carney, J.M. An animal model and computer-controlled surface pressure delivery system for the production of pressure ulcers. Journal of Rehabilitation Research and Development, 1995: 32(2), 149-161.

38) Thorfinn, J., Sjöberg, F., Lidman, D. Sitting pressure and perfusion of buttock skin in paraplegic and tetraplegic patients, and in healthy subjects: a comparative study. Scandinavian Journal of Plastic Surgery and Hand Surgery, 2002: 36, 279-283.

39) Völker, H.U., Röper, G., Sterk, J., Willy, C. Long-term invasive measurement of subcutaneous oxygen partial pressure above the sacrum on lying healthy volunteers. Wound Repair and Regeneration, 2006: 14(5), 542-547.

40) Hudak, P.L., Cole, D.C., Frank, J.W. Perspectives on prognosis of soft tissue musculoskeletal disorders. International Journal of Rehabilitation Research, 1998: 21, 29-40.

41) Altman, D.G. Systematic reviews of evaluations of prognostic variables. British Medical Journal, 2001: 323 , 224-228.

42) Brienza, D.M., Karg, P.E., Geyer, M.J., Kelsey, S., Trefler, E. The relationship between pressure ulcer incidence and buttock-seat cushion interface pressure in at-risk elderly wheelchair users. Archives of Physical and Medical Rehabilitation, 2001: 4, 529-33.

43) Conine, T.A., Hershler, C., Daechsel, D., Peel, C., Pearson, A. Pressure ulcer prophylaxis in elderly patients using polyurethane foam or Jay ${ }^{\circledR}$ wheelchair cushions. International Journal of Rehabilitation Research, 1994: 17, 123-137.

44) Drummond, D.S., Narechania, R.G., Rosenthal, A.N., Breed, A.L., Lange, T.A., Drummond, D.K. A study of pressure distributions measured during balanced and unbalanced sitting. The Journal of Bone and Joint Surgery, 1985: 64-A(7), 1034-1039.

45) Economides, N.G., Skoutakis, V.A., Carter, C.A., Smith, V.H. Evaluation of the effectiveness of two support surfaces following myocutaneous flap surgery. Advances in Wound care, 1995: 8(1), 49-54.

46) Geyer, M.J., Brienza, D.M., Karg, P., Trefler, E., Kelsey, S. A randomized control trial to evaluate pressurereducing seat cushions for elderly wheelchair users. Advances in Skin Wound Care, 2001: 14(3), 120-129.

47) Rosenthal, M.J., Felton, R.M., Nastasi, A.E., Naliboff, B.D., Harker, J., Navach, J.H. Healing of advanced pressure ulcers by a generic total contact seat: 2 randomized comparisons with low air loss bed treatments. Archives of Physical and Medical Rehabilitation, 2003: 84, 1733-1742.

48) Sideranko, A., Quinn, A., Burns, K., Froman, R.D. Effects of position and mattress overlay on sacral and heel pressure in a clinical population. Research in Nursing and Health, 1992: 15, 245-251.

49) Tymec, A.C., Pieper, B., Vollman, K. A comparison of two pressure-relieving devices on the prevention of heel pressure ulcers. Advances in Wound Care, 1997: 10(1), 39-44.

50) Gebhardt, K. S. Pressure ulcer research: Where do we go from here? British Journal of Nursing, 2004 (Tissue viability supplement), 13(19), 14-18.

51) Cuddigan, J., Berlowitz, D.R., Ayello, E.A. and NPUAP. Pressure ulcers in America: Prevalence, incidence and implications for the future. An executive summary of the National Pressure Ulcer Advisory Panel Monograph. Advances in Skin Wound Care, 2001: 14(4), 208-215. 
52) Ferguson-Pell, M., Cardi, M.D. Prototype development and comparative evaluation of wheelchair pressure mapping system. Assistive Technology, 1993: (5), 78-91.

53) Ferguson-Pell, M., Hagisawa, S., Bain, D. Evaluation of a sensor for low interface pressure applications. Medical Engineering and Physics, 2000: (22), 657-663.

54) Stinson, M., Porter, A., Eakin, P. Measuring interface pressure: a laboratory based investigation into the effects of repositioning and sitting. American Journal of Occupational Therapy, 2002: 56(2), 185-190.

55) Sprigle, S., Dunlop, W., Press, L. Reliability of bench tests of interface pressure. Assistive Technology, 2003: 15, 49-57.

56) Staarink, H.A.M. Sitting posture, comfort and pressure. Delft University Press, 1995: Delft, the Netherlands.

57) Sangeorzan BJ, Harrington RM, Wyss CR, Czerniecki JM, Matsen III FA. Circulatory and mechanical response of skin to loading. Journal of orthopedic research, 1989: Vol. 7:425-431.

58) Dabnichki, P.A., Crocombe, A.D., Hughes, S.C. Deformation and stress analysis of supported buttock contact. Journal of Engineering in Medicine, 1994: 208, 9-17.

59) Brienza, D.M., Geyer, M.J., Jan, Y. A comparison of the changes in rhythms of sacral blood skin blood flow in response to eating and indentation. Archives of Physical and Medical Rehabilitation, 2005: 86,12451251. 


\subsubsection{APPENDIX 1: SEARCH STRATEGY FOR PUBMED*}

\section{Clinical}

1) Pressure ulcer $(\mathrm{M})$

2) Pressure sore

3) Decubitus ulcer

4) Shear ulcer

5) \#1 OR \#2 OR \#3 OR \#4

\section{Measurements}
6) Incidence
7) Prophylaxis
8) Controlled trial
9) Clinical trial
10) \#6 OR \#7 OR \#8 OR \#9

\section{Technical}

11) Pressure

12) Interface pressure

13) Shear

14) Cushion

15) Cushions

16) Mattress

17) Mattresses

18) \#11 OR \#12 OR \#13 OR \#14 OR \#15 OR \#16 OR \#17

Combination clinical, measurements and technical

19) \# 18 AND \#10 AND \#5

* This strategy provided the basis for adjustments to other databases.

* M indicates Mesh subject heading 
Chapter 2 
CHAPTER 3

\section{ANALYSIS OF HEALTHY SITTING BEHAVIOR: INTERFACE PRESSURE DISTRIBUTION AND SUBCUTANEOUS TISSUE OXYGENATION}

J. Reenalda, P. van Geffen, M. Nederband, M. Jannink,

M. IJzerman, H. Rietman

Journal of Rehabilitation Research and Development , 2009; 46 (5) 


\subsection{Abstract}

Pressure ulcers are a large problem in individuals who use a wheelchair for their mobility and suffer from limited trunk stability and motor function. Due to the fact that no relation between interface pressure and pressure ulcer development has been established, and no clinical threshold for pressure ulcer development can be given, it is important to look at the sitting behavior of healthy individuals. Healthy individuals do not develop pressure ulcers due to continuously shifting posture.

An experiment with 25 healthy male subjects was performed with the objective of analyzing the sitting behavior of healthy subjects by using a combination of interface pressure measurement and the measurement of sub-cutaneous tissue oxygenation by means of the Oxygen to See (O2C).

Healthy subjects shift posture on average $7.8+/-5.2$ times an hour. These posture shifts are merely a combination of posture shifts in the frontal and sagital plane. Subcutaneous oxygen saturation increases on average $2.2 \%$ with each posture adjustment, indicating a positive effect of posture shifts on tissue viability. The results of this study can be used as a reference for seating interventions aimed at preventing pressure ulcers. It is recommended to change the sitting load at least every 8 minutes.

\subsection{Introduction}

A pressure ulcer is defined as "localized injury to the skin and/or underlying tissue, usually over a bony prominence, as a result of pressure, or pressure in combination with shear and/or friction" [1]. Pressure ulcers are a large problem in individuals who use a wheelchair for their mobility. These individuals, especially those with limited trunk stability and limited motor function, sit in a wheelchair for long consecutive periods of time, mostly in one single posture. As a consequence, pressure ulcers can develop due to an unbalanced match between the external load and the ability of the skin and subcutaneous tissue to withstand load. Prevalence values of pressure ulcers are high and have been reported to be $15.5 \%$ in US healthcare facilities, with $28 \%$ of the pressure ulcers located at the sacrum and $17.2 \%$ at the buttocks [2]. Prevalence values of $18.1 \%$ have been reported in European standard and academic hospitals [3].

A distinction can be made between superficial and deep pressure ulcers, both having a different etiology [4-6]. It is understood that deep pressure ulcers result from prolonged pressure and usually develop near the bony prominences where internal pressures are high. It 
has been suggested that superficial ulcers do not start to develop as a result of pressure but are more dependent of shear and trauma to the tissue [7]. Unfortunately, no specific prevalence values for superficial or deep pressure ulcers are available.

Current clinical practice of assessing the risk of pressure ulcers focuses on the interface pressure (the pressure between seat and body), during static load in one presumed optimal posture. To quantify the risk of developing pressure ulcers during static load and to assess the influence of a specific seating device, a relevant measure of this risk is necessary. Despite the fact that much research has been performed in the field of the etiology and prevention of pressure ulcers, a threshold value for the development of deep pressure ulcers, in terms of magnitude or duration, is still lacking. Moreover, the relation between interface pressure and the probability of pressure ulcer development is not consistent [8]. In addition, the developed pressure time curves $[9,10]$ predict that pressure ulcers will develop eventually, even with an optimal pressure distribution. This has been confirmed by finite element modeling techniques and it has been demonstrated that with evenly distributed pressures at the sitting interface high pressure peaks can occur near the bony prominence [11-13].

It is intuitively obvious that individuals with intact sensory and motor function do not develop pressure ulcers due to a continuous variation in sitting posture, even if they sit on very uncomfortable seats for prolonged periods of time. Extrapolating this sitting behavior to the current practice for spinal cord injured wheelchair users, resulted in guidelines to lift every 20 minutes or to be repositioned every 2 hours (AHRQ guidelines) [14]. However lifting creates severe loads on shoulders and arms and the ability to reposition is often limited in wheelchair users. Therefore, attempts have been made to minimize the load on the tissue by means of dynamic cushions and seating devices that create an alternating load in order to increase tissue oxygenation. It was demonstrated that these seating systems were able to positively influence the interface pressure and the skin oxygenation $[15,16]$. Other methods, such as electric Gluteal muscle stimulation also showed effectiveness in decreasing the interface pressure, which might restore blood flow [17]. However, it is not clear what the optimal frequency of these seating interventions is in order to increase the viability of the tissue.

The sitting behavior of healthy individuals can serve as a guide to these seating interventions. This seating behavior prevents tissue damages like pressure ulcers and can serve as a reference value for the sitting behavior that should be adopted by the spinal cord injured. Furthermore, knowledge of healthy sitting behavior could also be valuable in the development of dynamic seating devices that can alter the load on the tissue in order to prevent pressure ulcers. An 
analysis of healthy sitting behavior has been carried out by Linder-Ganz et al. [18] who concluded that healthy subjects change their posture approximately every 9 minutes in the sagital plane and approximately every 6 minutes in the frontal plane, as measured with pressure sensors and trunk movement analysis. Unfortunately, this study focused only on trunk movements and the external load on the tissue, as quantified by the interface pressure. However, an important determinant of deep pressure ulcer development is the internal pressure beneath the ischial tuberosities. Finite Element Modeling [11-13] and test-buttock experiments with pressure sensors $[19,20]$ have shown that the internal pressure exceeds the external pressure, and peaks in the muscle tissue due to compression of tissue beneath the bony prominences. Deep pressure ulcers originate in the muscle layer beneath the ischial tuberosities. Local subcutaneous tissue oxygenation is a direct derivative of the viability of the muscle tissue and is directly influenced by the internal pressure, which causes compression and occlusion. At present, up to a measurement depth of approximately 8 millimeters, the Oxygen to See (O2C, LEA Medizintechnik, Giessen Germany) is the only device that is capable of the non-invasive measurement of (sub-) cutaneous tissue oxygenation.

Due to the fact that no relation between interface pressure and pressure ulcer development has been established, and as such no clinical threshold for pressure ulcer development can be given, reference guidelines for dynamic sitting behavior could be obtained from knowledge of the sitting behavior of healthy subjects. Therefore, the objective of this research paper is to describe healthy dynamic sitting behavior in terms of variation in pressure distribution and to investigate the effects of such sitting behavior on the sub-cutaneous tissue oxygenation as a function of time. 


\subsection{Methods}

A cross-sectional study was performed. The study design was approved by the local Medical and Ethical Committee.

\subsubsection{Subjects}

A total of 25 healthy subjects was recruited (mean age $26 \pm 3.9$ years, mean height $1.9 \pm 0.07$ meters, mean weight $80.2 \pm 9.5$ kilograms, mean BMI $22.7 \pm 2.2$ ). All subjects were male, between the ages of 18 and 50 years. Exclusion criteria were vascular diseases that could disturb blood flow (like diabetes) and the presence of pressure ulcers or other skin diseases. This was checked prior to the study by the medical staff.

\subsubsection{Equipment}

A standard IBIS comfort wheelchair was used for this study. The cushion of the IBIS Comfort wheelchair was replaced with a custom made cushion (Welzorg Special Products, Oldenzaal, the Netherlands). The wheelchair was equipped with a Tekscan Conformat Pressure Mapping device (Tekscan Inc, Boston Massachusetts, USA), in order to measure the pressure distribution on the sitting surface. This pressure mapping device consists of 1024 pressure sensors that are connected in a flexible way, in order to minimize the hammocking effect. Sample rate of the pressure mat was set at $1 \mathrm{~Hz}$. The pressure mapping device was calibrated according to the manufacturers' guidelines on a weekly basis.

Tissue perfusion and oxygenation was measured with the Oxygen-to-See $(\mathrm{O} 2 \mathrm{C})$. The $\mathrm{O} 2 \mathrm{C}$ is a diagnostic device that uses Laser Doppler flowmetry and diffuse-reflectance spectroscopy for the non-invasive determination of oxygen supply in blood perfused tissue (LEA Medizintechnik Giessen, Germany). The O2C transmits continuous wave laser light (830 nm and $30 \mathrm{~mW}$ ) and white light (500-800 nm, $1 \mathrm{~nm}$ resolution, $20 \mathrm{~W})$ to tissue where it is scattered and collected on the skin surface at fibers in the probe. The sample frequency of the $\mathrm{O} 2 \mathrm{C}$ is $0.5 \mathrm{~Hz}$; therefore it is capable of measuring the dynamic response in blood flow. The data are analyzed by comparing with prerecorded deoxygenated and oxygenated hemoglobin spectra. The $\mathrm{O} 2 \mathrm{C}$ has four output parameters [21] of which only the oxygenation $\mathrm{SO}_{2}(\%)$, which is a relative measure and reflects the oxygen saturation of hemoglobin, was used in this study. The fiber-optic probes used by O2C incorporate both the Laser-Doppler method and broadband light spectroscopy techniques and measures at a maximum depth of approximately $8 \mathrm{~mm}$. The probe was attached to the skin with surgical tape. The probe for subcutaneous measurement was attached beneath the right tuberosity. 


\subsubsection{Experimental design}

Subjects reported to the laboratory once and were instructed beforehand by means of a letter about the experimental procedure. They also signed an informed consent.

Prior to the study, the probes of the $\mathrm{O} 2 \mathrm{C}$ were securely attached to the skin with adhesive medical tapes right beneath the ischial tuberosities. The probes were custom-made to prevent interference with the seating interface. As a result there were no confounding effects of the probes on the measurements. To prevent probe dislocation relative to the ischial tuberosity as a result of soft tissue displacement when seating, the ischial tuberosity was localized by means of palpation with the subject lying on his side with his hips and knees flexed 90 degrees to imitate the sitting position. The adhesive tape prevented the probe to displace as a result of posture shifts during the study. After attachment of the probe, the subject was transferred to the experimental wheelchair. Foot support was adjusted according to the subject characteristics. Subjects were instructed to sit as comfortably and naturally as possible. After instruction the measurement started and lasted for 60 minutes. A television, showing a movie, was placed at the horizontal level to distract the subjects. Temperature in the room was controlled at 21 degrees Celsius.

\subsubsection{Outcome measures}

Interface pressure, as measured with the pressure mapping device, is expressed in the Dispersion Index (DI) [22]. DI is a relative measure of the load on the sitting surface and is defined as the load on one of tuberal zones divided by the total load on the sitting surface as measured with the pressure mapping device. Advantage of expressing the pressure data in a relative measure like DI is that reliability issues like creep and drift are bypassed. Raw data from the pressure mapping device was exported in the ASCII format. A Matlab script was used to define pressure peaks in a region that was expected to surround the ischial tuberosities and this region was defined by a zone of $6 \times 6$ pressure sensors $(9 \times 9 \mathrm{~cm})$ in order to calculate the dispersion index. A lower DI value means that the load is more evenly distributed (i.e. dispersed) on the total sitting contact surface as opposed to being located at two points (e.g. the ischial tuberosities). The DI value is dependent of the total contact surface and, therefore, DI values are not comparable inter-individually.

Although the $\mathrm{O} 2 \mathrm{C}$ provides information about the tissue oxygenation as well as tissue perfusion, hemoglobin content and velocity, only oxygenation values $\left(\% \mathrm{SO}_{2}\right)$ were used in this experiment. The tissue oxygenation is a direct indicator of the viability of the tissue and is a result of the tissue perfusion. It is expected from physiological consideration that $\mathrm{SO}_{2}$ will 
decrease gradually due to occlusion of the blood vessels as a result of the external load,

followed by a sharp increase after a posture shift as a results of the reflow of blood. A $5^{\text {th }}$ order

Butterworth filter with a cut-off frequency of $0.1 \mathrm{~Hz}$ was used to filter the DI and $\mathrm{SO}_{2}$ data for random noise.

\subsubsection{Data analysis}

In order to establish a pattern of healthy sitting behavior the frequency of the posture shifts and the resulting change in subcutaneous tissue oxygenation are of interest.

Posture shifts were defined by analyzing the DI data of both ischial tuberosities. In order to calculate posture shifts in the sagital plane, the sum of the DI values of the right and left ischial tuberosities was calculated. For movement in the frontal plane, the ratio of the mean DI values of the left and right ischial tuberosities was calculated. Threshold values for sagital and frontal movements of $\pm 10 \%$ were defined. When the signal exceeds the threshold, a posture shift is identified. Posture shifts that occurred within one minute were regarded as one single posture shift. Posture shifts were counted and related to their respective variation in $\mathrm{SO}_{2}$ values. Average $\mathrm{SO}_{2}$ values of the time frames of 1 minute before and 1 minute after the posture shift were calculated. The difference between these two average values was defined as the variation in tissue oxygenation as a result of a single posture shift.

Average values of the variation in oxygenation as a result of the total number of posture shifts were calculated per subject, along with posture shifts in the sagital and frontal plane respectively.

\subsection{Results}

Based on changes in pressure distribution, healthy subjects change their posture on average 7.8 +/- 5.2 times per hour. These posture shifts were mostly a combination of posture shifts employed in the sagital and frontal plane. Posture shifts were composed mostly of approximately 80\% movements in the sagital plane and 20\% movements in the frontal plane. The posture shifts correspond to an average increase in subcutaneous tissue oxygenation of 2.2 $+/-2.4 \%$. Figure 1 gives a typical example of the DI and $\mathrm{SO}_{2}$ values of one research subject during the measurement period with the identified posture shifts. It can be seen in figure 1 that this subject employs 8 posture shifts (t1-t8) during the measurement period of 60 minutes, based on the DI values as indicated in the upper row. Tissue oxygenation values are displayed in the lower row. Clearly visible is the physiologically expected pattern of gradually decreasing subcutaneous $\mathrm{SO}_{2}$ values, which increase rapidly after a posture shift. 


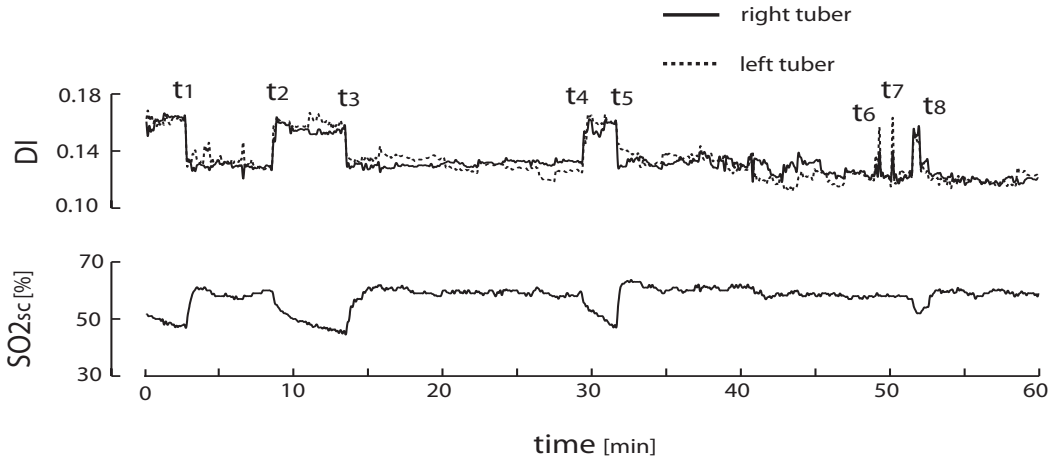

Figure 1: Typical examples of DI and $\mathrm{SO}_{2}$ with the identified posture shifts

Tissue oxygenation data was complete for all but one subject. Table 1 describes the average values for $\mathrm{SO}_{2}$, the number of posture shifts and their corresponding change in $\mathrm{SO}_{2}$ and identified patterns in tissue oxygenation for all subjects. This includes average values for the different patterns in tissue oxygenation values.

In the subcutaneous tissue oxygenation data, three patterns can be identified: the physiologically expected pattern, the physiologically inconsistent pattern and the stable pattern in which no reaction in oxygenation is observed. The physiologically expected pattern is characterized by a slow decrease in tissue oxygenation followed by a rapid increase as a result of a posture shift. By contrast, the physiologically inconsistent pattern is characterized by very low tissue oxygenation values of $11 \%$ on average and shows a slow increase in tissue oxygenation values followed by a rapid decrease as a result of a posture shift. The number of posture shifts is comparable to the number of posture shifts as observed in the physiologically expected pattern. The third pattern is characterized by a stable tissue oxygenation value and a lack of posture shifts. 


$\begin{array}{cl}\text { Subject } & \text { Pattern } \\ 1 & \text { Physiological } \\ 2 & \text { Physiological } \\ 3 & \text { Physiological } \\ 4 & \text { Physiological } \\ 5 & \text { Physiological } \\ 6 & \text { Physiological } \\ 7 & \text { Inconsistent } \\ 8 & \text { Stable } \\ 9 & \text { Physiological } \\ 10 & \text { Physiological } \\ 11 & \text { Physiological } \\ 12 & \text { Physiological } \\ 13 & \text { NA } \\ 14 & \text { Physiological } \\ 15 & \text { Physiological } \\ 16 & \text { Physiological } \\ 17 & \text { Physiological } \\ 18 & \text { Physiological } \\ 19 & \text { Physiological } \\ 20 & \text { Physiological } \\ 21 & \text { Stable } \\ 22 & \text { Stable } \\ 23 & \text { Physiological } \\ 24 & \text { Inconsistent } \\ 25 & \text { Physiological }\end{array}$

$\begin{array}{ccc}\text { avg SO2 (\%) } & \text { \# posture shifts } & \boldsymbol{\Delta} \text { SO2 (\%) } \\ 58.0 & 14 & 0.7 \\ 48.9 & 9 & 0.8 \\ 57.4 & 10 & 2.2 \\ 53.0 & 6 & 1.3 \\ 32.3 & 14 & 3.7 \\ 50.1 & 15 & 5.4 \\ 10.4 & 11 & 1.4 \\ 40.1 & 2 & 0.0 \\ 38.2 & 5 & 3.0 \\ 16.0 & 4 & 1.1 \\ 54.7 & 1 & 3.6 \\ 56.6 & 3 & 8.7 \\ \text { NA } & 1 & \text { NA } \\ 33.5 & 4 & 2.4 \\ 37.1 & 2 & 0.2 \\ 28.0 & 12 & 1.8 \\ 48.2 & 8 & 4.9 \\ 57.9 & 7 & 0.1 \\ 59.9 & 4 & 0.8 \\ 28.3 & 2 & 1.1 \\ 32.7 & 0 & 0.0 \\ 59.4 & 1 & 0.0 \\ 61.3 & 20 & 0.9 \\ 11.9 & 5 & 0.0 \\ 32.6 & 9 & 2.1\end{array}$

Average values for each pattern

\begin{tabular}{|c|c|c|c|}
\hline $\begin{array}{l}\text { Physiological } \\
\qquad N=19\end{array}$ & 44.9 & $7,8 \pm 5,2$ & $2,2 \pm 2,4$ \\
\hline $\begin{array}{c}\text { Inconsistent } \\
\mathrm{N}=2\end{array}$ & 11.14 & $8.0 \pm 4.2$ & $0.7 \pm 1.1$ \\
\hline $\begin{array}{l}\text { Stable } \\
\mathrm{N}=3\end{array}$ & 44.4 & $1.0 \pm 1.0$ & $0.0 \pm 0.0$ \\
\hline
\end{tabular}

Table 1: Average values for $\mathrm{SO}_{2}$ (avg. $\mathrm{SO}_{2}$ ), the number of posture shifts (\# posture shifts) and their corresponding change in $\mathrm{SO}_{2}\left(\triangle \mathrm{SO}_{2}\right)$ for all subjects $(P P)$, including the identified reaction pattern in tissue oxygenation.

The physiologically expected pattern is displayed by 19 out of the 24 subjects. The

physiologically inconsistent pattern is displayed by only two out of 24 subjects, and is excluded from analysis due to the extremely low oxygenation values. These values are commonly stated as extremely hypoxic and therefore regarded as highly predictive of the onset of tissue failure [23]. The third pattern is characterized by a stable tissue oxygenation value and can be 
identified in three subjects. Due to the lack of posture shifts and the stable oxygenation values, these subjects are also excluded from further analyses.

No differences in BMI values could be found between the three groups. As a result, analyses are performed on the 19 subjects displaying the physiologically expected pattern. Typical examples of four subjects displaying the physiologically expected pattern can be found in figure 2 .

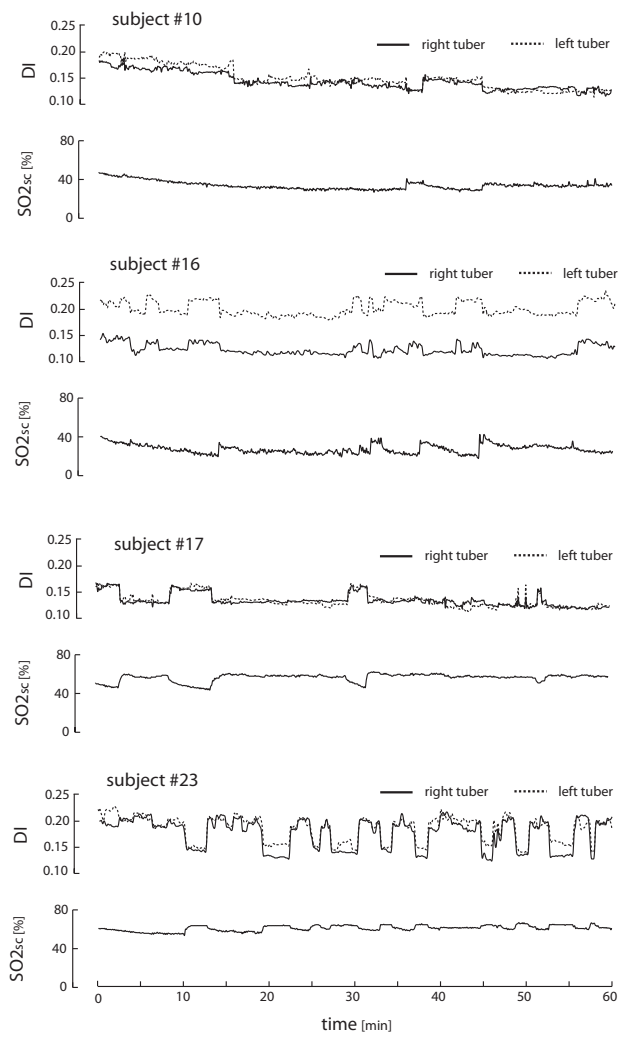

Figure 2: Typical examples of DI and $\mathrm{SO}_{2}$ against time of four subjects (subject \# 10, 16, 17, 23) displaying the physiologically expected pattern

\subsection{Discussion}

Healthy subjects change their sitting position on average $7.6+/-5.6$ times per hour.

Subcutaneous oxygen saturation increases on average $2.2 \%$ with each posture adjustment, indicating the positive effects of posture shifts on tissue viability. Posture shifts in our study were composed mostly of approximately $80 \%$ movements in the sagital plane and $20 \%$ 
movements in the frontal plane. The results of this study can be used as a reference for dynamic seating devices aimed at preventing pressure ulcers in individuals with limited sensory and motor function who use a wheelchair for their mobility. The magnitude of the posture shifts is of the same order as the magnitude of the results of the study of Linder-Ganz et al. [18]. In that study it was found that healthy subjects change their posture approximately every 9 minutes in the sagital plane (6.7 times per hour) and approximately every 6 minutes in the frontal plane (10 times an hour), as measured with pressure sensors and movement analysis. Compared to the study of Linder-Ganz et al. subjects in the present study moved more frequently in the sagital plane $(80 \%)$ and less frequently in the frontal plane $(20 \%)$. LinderGanz et al. based their analysis of healthy sitting behavior on pressure measurement (in order to define posture shifts in the frontal plane) and trunk motion analysis (in order to define posture shifts in the sagital plane). The study of Linder-Ganz et al. only quantified variation in external pressure without taking the internal pressure into account. The present study used measurement of the dispersion index to quantify posture shifts and used the measurement of sub-cutaneous tissue oxygenation, as a determinant of the internal pressure. In the majority of the subjects, the posture shifts were accompanied by an increase in subcutaneous oxygen saturation. As a result of the posture shifts, subcutaneous oxygen saturation increases on average $2.2 \%$, which indicates the positive effects of posture shifts on tissue viability. It has yet to be studied if the value of $2.2 \%$ is sufficient to maintain tissue viability in subjects with limited motor functions who use a wheelchair for their mobility.

A more in-depth look at the subcutaneous tissue oxygenation reveals three distinct patterns that could be identified. The first pattern follows a physiological pathway which was expected in advance and, indeed, is exhibited by most subjects. Due to the external load, the buttock tissue is compressed against the bony structures of the pelvis. As a result of this, the internal load increases. This has previously been shown with FEM and experiments with test-buttocks $[11-13,19,20]$. The increase in internal load causes compression of the tissue and occlusion of the blood and lymphatic vessels, resulting in a decrease in tissue oxygenation. Posture shifts can cause relief of the tissue and a restoration of the blood flow, thereby elevating the tissue oxygenation values. This process continues and repeats during prolonged sitting. The second observed pattern is physiologically inconsistent. Few subjects $(n=2)$ that display this pattern have very low average values of tissue oxygen saturation of approximately $11 \%$. This is a value that is commonly stated as extremely hypoxic and is regarded as highly predictive of the onset of tissue failure [23]. Considering these extremely low oxygenation 
values it is likely that these values are the result of measurement errors. Therefore these subjects were excluded from the analysis.

In the third pattern, as exhibited by three subjects, average tissue saturation values are comparable to the average values in the physiologically expected group, however no changes in pressure distribution and tissue oxygenation could be found. An explanation for this phenomenon could be that these subjects do have internal tissue characteristics, reflected in a different anatomy and geometry. This may have prevented the muscle tissue from deformation or occlusion, although no relation with BMI of the subjects could be established. However, a more plausible explanation could be that, just as in the case of the physiologically inconsistent pattern, measurement errors are responsible for these results. Despite the care with which the probes were placed, misplacement of the probes might have caused these unexpected values. The present study uses a relative measure of the interface pressure to describe the pressure distribution. It has been shown that maximum pressures and average pressures do posses low test-retest reliability [24]. The dispersion index has been proposed as a relative measure to describe the distribution of pressure on the tuberal regions compared to the total contact surface and has been shown to have good reliability [24]. There appears to be a weak qualitative relation between interface pressure and the development of pressure ulcers [8]. As a result, no conclusive clinical threshold for the interface pressure can be given. In addition individual characteristics like level of mobility, body composition, nutritional state and other comobordities do play a role. Furthermore, the measurement of interface pressure has low internal validity for the prediction of pressure ulcers and there is an incongruent relation between pressure magnitude and duration. This results in the fact that no quantification of the predictive or prognostic value of interface pressure can be given [8]. To overcome this problem, the present study uses the measurement of subcutaneous tissue perfusion and oxygen saturation with the $\mathrm{O} 2 \mathrm{C}$. At present, the $\mathrm{O} 2 \mathrm{C}$ is the only device capable of measuring the perfusion and oxygenation of the subcutaneous tissue non-invasively up to a maximum depth of approximately 8 millimeters. Muscle blood flow has been reliably measured by means of the Xenon Clearance method [4]. However this technique is invasive and requires injections with radio-active tracer material. Other measurement techniques used in the field of pressure ulcer research, like laser Doppler flowmetry [25, 26], transcutaneous oxygen tension [15, 16] others) and tissue reflectance spectrophotometry [27, 29], do not possess penetration depths sufficient to reach the muscle tissue and are confined to measure the perfusion and oxygen saturation of the skin only. However, muscle tissue is most sensitive to developing pressure ulcers because 
of its high metabolic demand [29]. In addition, FEM has shown that internal stresses are highest in the muscle tissue right beneath the bone. During sitting the $\mathrm{m}$. Gluteus Maximus is located at the depth pf approximately 7 to 15 millimeters, depending on the anatomy and geometry of the other tissue structures. This means that in this study part of the signal from the subcutaneous measurement is coming from the $\mathrm{m}$. Gluteus Maximus, and part of the signal is coming from other subcutaneous structures. To obtain data from the muscle only, an even larger penetration depth is necessary which cannot be reached non-invasively at present. In this study a subject population of young healthy males was used. This provides a homogeneous subject population but had drawbacks of the universal applicability. As a result of immobilization and atrophy, differences in skin anatomy and vascularization exist between subjects with and without a spinal cord injury [30]. Consequently, the ability of the tissue of subjects with SCI to withstand external load will likely be reduced. In order to imitate the seating situation of individuals that use a wheelchair for their mobility, the healthy subjects in this study sat in a wheelchair during the measurement period. However this implicated also that the displayed sitting behavior might not have fully reflected their normal sitting behavior in their seat of choice. Caution must therefore be taken when generalizing the results of this study to the spinal cord injured population.

The results of the present study suggest that healthy subjects move on average 7.8 times an hour in order to relieve the subcutaneous tissue and increase tissue viability. Posture shifts were composed mostly of approximately $80 \%$ movements in the sagital plane and 20\% movements in the frontal plane. It can be concluded from these results that shifting posture at least every eight minutes should be advisable for subjects that use a wheelchair for their mobility in order to maintain tissue viability. The results of this study can be used as a reference value for dynamic seating devices or seating interventions aimed at alternating the seating load in order to prevent pressure ulcers in subjects that use a wheelchair for their mobility. Future studies should address the effect of using this reference value for healthy sitting behavior on the subcutaneous tissue oxygenation of wheelchair users with limited mobility. Subcutaneous oxygen saturation increases on average $2.2 \%$ with each posture adjustment, indicating the positive effects of posture shift on tissue viability. Future studies should address the relevance of this value for the spinal cord injured population. 


\subsection{References}

1. Black J, Baharestani M, Cuddigan J, Dorner B, Edsberg L, Langemo D, Posthauer ME, Ratliff C, Taler G, NPUAP. National Pressure Ulcer Advisory Panel's updated pressure ulcer staging system. Urologic Nursing, 2007, 27(2), 144-150.

2. Vangilder C, Macfarlane GD, Meyer S. Results of nine international pressure ulcer prevalence surveys. Ostomy Wound Manage 2008, 54(2): 40-54.

3. Vanderwee K, Clark M, Dealey C, Gunningberg L, Defloor T. Pressure ulcers prevalence in Europe: A pilot study. Journal of the Evaluation of Clinical Practice. 2007, 13(2), 227-235.

4. Levine SP, Kett RL, Gross MD, Wilson BA, Cederna PS, Juni JE. Blood flow in the gluteus maximus of seated individuals during electrical muscle stimulation. Archives of Physical Medicine and Rehabilitation.1990; 71(9):682-6.

5. Bouten CVC, Bosboom EMH, Oomens CWJ. The etiology of pressure sores: A tissue and cell mechanics approach. In: Biomedical aspects of manual wheelchair propulsion. L.H.V. Van der Woude et al. (Eds.) IOS Press, (1999) (pp. 52-62).

6. Bouten CVC, Oomens CWJ, Baaijens FPT, Bader DL. The etiology of pressure ulcers: Skin deep or muscle bound. Archives of Physical and Medical Rehabilitation, 2003, 84, 616-619.

7. Brienza D. Pressure ulcers, more questions than answers. Proceedings of the $23^{\text {rd }}$ International Seating Symposium, Orlando, Fl 2007.

8. Reenalda J, Nederhand M, Jannink M, IJzerman M. The clinical use of interface pressure to predict pressure ulcer development: A systematic review. Assistive Technology, 2009, in press

9. Kosiak M. Etiology and pathology of ischemic ulcers. Archives of Physical and Medical Rehabilitation, 1959, 40(9), 62-69.

10. Reswick JB, Rogers JE. Experience at Rancho los Amigos hospital with devices and techniques to prevent pressure sores. In: Kennedi RM, Cowden JM, Scales JT (Eds.) Bedsore biomechanics, London, Macmillan (1976):301-310

11. Oomens CWJ, Bressers OFJT, Bosboom EMH, Bouten CVC, Bader DL. Can loaded interface characteristics influence strain distributions in muscle adjacent to bony prominences? Computer Methods in Biomechanics and Biomedical Engineering, 2003; 6(3): 177-180.

12. Linder-Ganz E, Engelberg S, Scheinowitz M, Gefen A. Pressure-time cell death threshold for albino skeletal muscles as related to pressure sore biomechanics. Journal of Biomechanics, 2005, 39(14):27252732 .

13. Linder-Ganz E, Shabshin N, Itzchak Y, Gefen A. Assessment of mechanical conditions in sub-dermal tissues during sitting: a combined experimental-MRI and finite element approach. Journal of Biomechanics, 2007, 40, 1443-54.

14. Agency for Health Care Policy and Research (AHCPR)/ Treatment of pressure ulcers, in: Clinical Practice guidelines no.15 US Department of health and Human Services, Publication no. 95-0652, 1994.

15. Bader DL. The recovery characteristics of soft tissues following repeated loading. Journal of Rehabilitation Research and Development, 1990, 27, 141-50

16. Makhsous M, Lin F, Hendrix RW, Hepler M, Zhang LQ. Sitting with adjustable ischial and back supports: biomechanical changes. Spine, 2003, 28, 1113-21; discussion 1121-2. 
17. Van Londen A, Herwegh M, Van der Zee CH, Daffertshofer A, Smit CA, Niezen A, Janssen TW. The effect of surface electric stimulation of the gluteal muscles on the interface pressure in seated people with spinal cord injury. Archives of Physical and Medical Rehabilitation 2008, 89(9):1724-1732.

18. Linder-Ganz E, Scheinowitz M, Yizhar Z, Margulies SS, Gefen A. How do normals move during prolonged wheelchair-sitting? Technology and Health Care, 2007, 15(3), 198-202.

19. Staarink, H.A.M. (1995). Sitting posture, comfort and pressure. Delft University Press, Delft, the Netherlands.

20. Gefen A, Levine J. The false premise in measuring body-support interface pressures for preventing serious pressure ulcers. Journal of Medical Engineering and Technology. 2007, 31(5): 375-380.

21. Beckert S, Witte MB, Königsrainer A, Coerper S. The Impact of the Micro-Lightguide O2C for the Quantification of Tissue Ischemia in Diabetic Foot Ulcers, Diabetes Care, 2004; vol. 27, nr. 12: 2863-2867.

22. Sprigle S, Press L, Davis K. Development of uniform terminology and procedures to describe wheelchair cushion characteristics Journal of Rehabilitation Research and Development, 2001, 38(4), 449-461.

23. Hölzle F, Swaid S, Nolte D, Wolff K. Nutritive perfusion at donor site after micro vascular fibula transfer.

24. Sprigle S, Dunlop W, Press L. Reliability of bench tests of interface pressure. Assistive Technology, 2003, $15,49-57$

25. Mayrovitz HN, Smith JR. Adaptive skin blood flow increases during hip-down lying in elderly women. Advisory Wound Care. 1999 Jul-Aug;12(6):295-301

26. Mayrovitz HN, Macdonald J, Smith JR. Blood perfusion hyperemia in response to graded loading of human heels assessed by laser-Doppler imaging. Clinical Physiology. 1999 Sep; 19(5):351-9.

27. Sprigle S, Linden M, Riordan B. Characterizing reactive hyperemia via tissue reflectance spectroscopy in response to an ischemic load across gender, age, skin pigmentation and diabetes. Medical Engineering in Physiology. 2002, 24(10):651-661.

28. Sprigle S, Linden M, Riordan B. Analysis of localized erythema using clinical indicators and spectroscopy. Ostomy Wound Manage. 2003, 49(3):42-52.

29. Salcido R, Fisher SB, Donofrio JC, Bieschke N, Knapp C, Liang R, LeGrand EK, Carney JM. An animal model and computer-controlled surface pressure delivery system for the production of pressure ulcers. Journal of Rehabilitation Research and Development, 1995, 32(2), 149-161.

30. Li Z, Leung JY, Tam EW, Mak AF. Wavelet analysis of skin blood oscillations in persons with spinal cord injury and able-bodied subjects. Archives of Physical and Medical Rehabilitation. 2006, 87(9):1207-2012 
Chapter 3 
CHAPTER 4

\section{EFFECTS OF ACTUATED POSTURAL CHANGE ON (SUB-) CUTANEOUS TISSUE OXYGENATION}

J. Reenalda, P. van Geffen, M. Nederband, M. Jannink,

M IJzerman, H. Rietman

This chapter has been submitted in its present form. 


\subsection{Abstract}

Postural variations are proposed as a method to alternate the sitting load in order to prevent pressure ulcers. An experiment was performed in 14 healthy male subjects (age [25] \pm [3] years, weight [77.9] $\pm[7.5] \mathrm{kg}$, height [1.86] $\pm[0.04] \mathrm{m}$ ) to investigate the influence of different sitting postures and pelvic orientations, imposed with the Dynasit chair, on the (sub-)cutaneous tissue oxygenation.

Starting with an initial reference sitting position (seat 5 degrees, back 15 degrees and neutral pelvic tilt), changing the back angle by 5 degrees to 15 degrees, the seat angle with steps of 10 degrees from 5 to 15 to 25 degrees and the pelvic orientation with steps of 10 degrees to 40 degrees forward showed significant and trend effects on cutaneous and subcutaneous tissue oxygenation. It was found that the cutaneous tissue oxygenation peaked at $62.9 \%$, which is $14,1 \%$ points higher than the reference sitting posture. The average subcutaneous tissue oxygenation reached a peak of $62.8 \%$, which is $2.8 \%$ points higher than the reference sitting position. It can be concluded that postural adjustments, as imposed with the Dynasit chair, can have positive effects on the cutaneous and subcutaneous tissue oxygenation.

\section{$4.2 \quad$ Introduction}

Postural variations are proposed as a method to alternate the sitting load in order to prevent pressure ulcers. Individuals that use a wheelchair for their mobility often suffer from limited motor function and trunk stability because of a lack in postural variation. Important factors determining the sitting posture are the orientation of the trunk, pelvis and thighs. In addition, the pelvic angle is important because it directly affects the lumbar spine curvature and the load at the seating surface [1]. Pressure ulcer incidence rates vary considerably by clinical setting, ranging from $0.4 \%$ to $38 \%$ in acute care, from $2.2 \%$ to $23.9 \%$ in long-term care, and from $0 \%$ to $17 \%$ in home care [2]. Prevalence values of pressure ulcers in the spinal cord injured (US veteran) population are reported as high as 39\% [3]. These high prevalence values of pressure ulcers stress the need for prevention Current clinical practice of postural variation in order to prevent pressure ulcers for individuals that use a wheelchair for their mobility is to reposition every 20 minutes. Individuals who cannot reposition due to limited motor control should be repositioned by outside assistance at least every hour (The Agency for Healthcare Research and Quality [4]. Repositioning can occur by lifting, by leaning forward or sideward or by changing the orientation of the pelvis.

Especially the anterior tilt of the pelvis is proposed to relieve the ischial tuberosities. The effect 
of these postural adjustments, as employed in the clinical setting, on sitting load were investigated in previous research $[5,6,7]$. Postural changes in the frontal and the sagital plane could reduce the maximum interface pressure by as much as $12 \%$ and $32 \%$ respectively [5]. In addition, positive effects of different seat inclinations ("squeezing"), a technique commonly used to minimize tissue load, were found on the interface pressure distribution, as expressed in the dispersion index (DI) [6]. Furthermore, significant effects of Seat Tilt Angle (STA) and Seat to Back Angle (SBA) were found on interface pressure parameters [7].

In previous research, an experimental chair (the Dynasit chair), containing a mechanical concept for postural variation and independent pelvic rotation, was developed in order to investigate alternating seating and dynamic seating patterns. The experimental device is developed with a pivot point of the seat right beneath the ischial tuberosities and a pivot point of the backrest at the height of the $3^{\text {rd }}$ and $4^{\text {th }}$ lumbar vertebrae to uncouple the trunk, pelvis and thighs. In this way, independent actuation of the different body segments is possible. The independent actuation of the different body segments results in the minimization of shear forces during repositioning [8]. It has been shown that shear forces are an important factor in the development of superficial ulcers [9-14]. Experiments with the Dynasit chair showed that the Dynasit chair is capable of imposing different body positions [15]. In addition, previous experiments partly confirmed the effects of postural changes on the sitting load. The load at the sacrum could be regulated by independent pelvic rotation. However, it was found that actuated independent pelvic rotation in the sagital plane was insufficient to alter the DI of the ischial tuberosities $[15,16]$. By rotating the pelvis over the ischial tuberosities the tuberal regions are loaded continuously. As a result no changes in pressure distribution could be witnessed, because the load only shifts within the tuberal region $[15,16]$.

The previous studies used the interface pressure as a representative of the buttock load. However, it has been shown that there appears to be a weak qualitative relation between interface pressure and the development of pressure ulcers but no conclusive clinical threshold for the interface pressure can be given [17]. As a result, no quantification of the predictive or prognostic value of interface pressure can be given. In addition, it has been shown with Finite Element Modeling (FEM) that there is no linear relation between the external load exerted on the body and the internal load in the tissue. High pressure peaks are calculated in the muscular layers beneath the bony prominences. These pressure peaks, causing high internal stresses and strains, can occur even with an evenly distributed pressure distribution at the sitting interface 
[18-20]. These high internal stresses and strains result in compression and deformation of the muscle tissue, which, due to its higher metabolic demand, is most vulnerable for developing pressure ulcers as a result of occlusion of blood vessels [21]. It has been noted that tissue perfusion and oxygenation is a factor in the development of subcutaneous pressure ulcers because it is the blood that provides the tissue with the critical nutrients necessary for its survival [22]. The measurement of the subcutaneous tissue perfusion and oxygenation can therefore be of added value to the quantification of the load on the tissue during sitting and repositioning.

It is plausible that chair configurations that can regulate pelvic orientation, independent from the trunk and the thighs, are important to regulate the sitting load and therefore to prevent pressure ulcers. Because the effect of postural variation on the (sub-)cutaneous tissue oxygenation is not known, a cross-sectional study was performed with the objective of investigating the effects of a combination of actuated postural changes and actuated pelvic rotation in the sagital plane on the oxygenation of the (sub-)cutaneous tissue in healthy male subjects. In the present study it is assumed that in addition to the previous studies, the Dynasit chair is capable of regulating the (sub-)cutaneous tissue oxygenation beneath the ischial tuberosities.

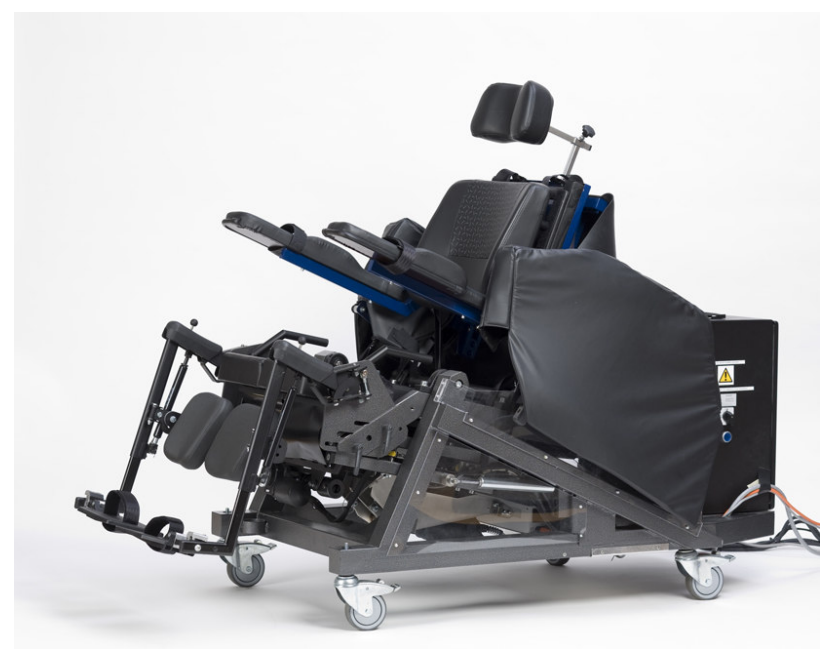

Figure 1: The Dynasit chair

\subsection{Methodology}

\subsubsection{Subjects}

Fourteen healthy male (age [25] $\pm[3]$ years, weight [77.9] $\pm[7.5] \mathrm{kg}$, height [1.86] $\pm[0.04] \mathrm{m}$ ) subjects were recruited for this study. All subjects were male, between the age of 18 and 50 
years old, free of any vascular diseases that could disturb blood flow and free of any pressure ulcers or other skin diseases. Prior to the study, all subjects signed an 'informed consent'. The study was approved by the local Medical and Ethical Committee. We certify that all applicable institutional and governmental regulations concerning the ethical use of human volunteers were followed during the course of this study.

\subsubsection{Equipment}

To investigate the effects of different sitting postures and pelvic orientations on the (sub-) cutaneous tissue oxygenation, an experimental simulator chair (the Dynasit chair, figure 1) was used. With the Dynasit chair it is possible to adjust the seat angle, back angle and pelvic angle in the sagital plane. The concept for actuated posture adjustmens in the sagital plane is based on a paralellogram and is shown in figure 2. The parallelogram is hid behind the safety covers in figure 1. The orientation and configuration of the parallelogram imposes pelvic tilt and was actuated from the back seat. Proper pelvic alignment makes independent pelvis rotation possible. The back support of the chair was fixed on this parallelogram and was mounted on a sledge to allow up- and downward translations when the pelvis was not properly aligned. The weight of the back support was counterbalanced. The seat was able to rotate on an axis aligned under the ischial tuberosities. The rotation point of the backrest was individually adjustable and was set at the height of the $3^{\text {rd }}$ and $4^{\text {th }}$ lumbar vertebrae.
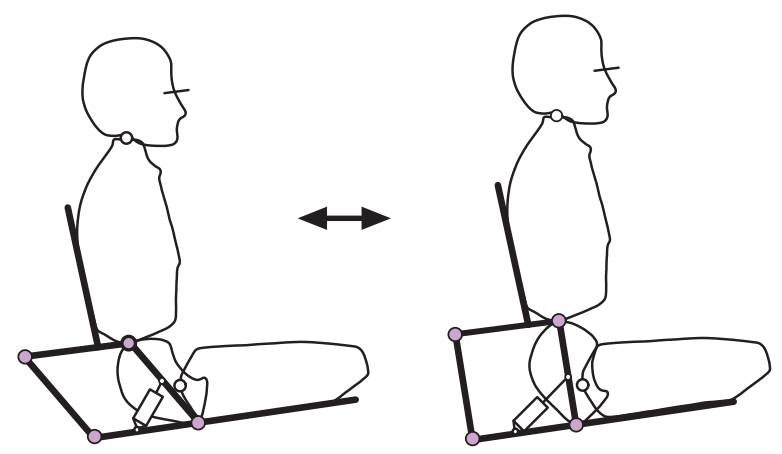

Figure 2: Concept for postural adjustment and independent pelvic actuation

Tissue oxygenation $\left(\mathrm{SO}_{2}\right.$, which reflects the oxygen saturation of hemoglobin) was measured with the Oxygen-to-See (O2C, LEA Medizintechnik Giessen, Germany). The O2C uses laser Doppler flowmetry and diffuse reflectance spectroscopy for non-invasive determination of oxygen supply in tissue perfused with blood. At present, the $\mathrm{O} 2 \mathrm{C}$ is the only device capable of 
non-invasively measuring the subcutaneous tissue oxygenation up to a measurement depth of 8 $\mathrm{mm}$, reaching the muscle tissue. The $\mathrm{O} 2 \mathrm{C}$ transmits continuous wave laser light $(830 \mathrm{~nm}$ and $30 \mathrm{~mW}$ ) and white light (500-800 nm, $1 \mathrm{~nm}$ resolution, $20 \mathrm{~W})$. The sample frequency of the $\mathrm{O} 2 \mathrm{C}$ is $0.5 \mathrm{~Hz}$, which makes it suitable to measure the dynamic response in blood flow in reaction to the changing seating load. The fiber-optic probes were custom-made to prevent interference with the seating interface. No confounding effects of the probes on the measurements are expected. The probes were attached to the skin with surgical tapes to prevent displacement during the study.

\subsubsection{Study design}

Subjects reported to the laboratory once. The depth and height of the back support, seat and the leg rests were individually adjustable. The distance between the seat and back could be changed by adjusting the height of the parallelogram. The depth of the seat and forests were adjusted for optimal pressure distribution. The thighs were fully supported except for the back of the knees. The footrests were set perpendicular to the seat and so that only the weights of the lower legs were supported. The height of the parallelogram and depth of the back support was individually adjusted to centre the pivot point of the back support within the lumbar region at a level of the third lumbar vertebrae. Within the initial chair configuration, the seat plane was tilted 5 degrees backward. The parallelogram and back rest angles were set to respectively to 25 and 10 degrees relative to the seat. Subjects were asked to keep their arms folded, maintain a vertical head orientation and adopt a passive sitting posture to prevent redundant muscle activity. From the initial reference chair configuration, a total of 29 different sitting postures, representing 6 different sitting configurations with 5 different pelvic orientations were imposed. All trials lasted 1 minute. Table 1 represents the 30 different sitting postures with their corresponding back-, seat- and pelvic angles. 
Table 1: Sitting conditions, imposed posture with their back-, seat-, and pelvic angles (in degrees)

\begin{tabular}{|c|c|ccccc|}
\hline \multicolumn{6}{|l|}{ Static Measurements } \\
\hline Back $\left(^{\circ}\right)$ & Seat $\left(^{\circ}\right)$ & \multicolumn{5}{|c|}{ Pelvis Sagittal $\left(^{\circ}\right)$} \\
& & 0 & 10 & 20 & 30 & 40 \\
\cline { 3 - 7 } & 5 & 1 & 2 & 3 & 4 & 5 \\
10 & 15 & 10 & 9 & 8 & 7 & 6 \\
& 25 & 11 & 12 & 13 & 14 & 15 \\
\hline \multirow{3}{*}{15} & 25 & 20 & 19 & 18 & 17 & 16 \\
& 15 & 21 & 22 & 23 & 24 & 25 \\
& 5 & 30 & 29 & 28 & 27 & 26 \\
\hline
\end{tabular}

\subsubsection{Data analysis}

Average cutaneous and sub-cutaneous $\mathrm{SO}_{2}$ values were calculated for the last 30 seconds of each condition. It is assumed that steady state tissue oxygenation is reached at least 30 second after postural alteration. Paired t-tests with a two-way confidence interval set at $95 \%$ were used to test statistical differences between the different conditions and between the conditions.

\subsection{Results}

All 14 Subjects completed the experiment. Average cutaneous and sub-cutaneous oxygenation values for the different sitting postures can be found in Figure 3 and Figure 4 respectively. Changing the back angle by 5 degrees from 10 to 15 degrees, the seat angle from 5 to 15 to 25 degrees and the pelvic orientation with steps of 10 degrees from 0 to 40 degrees showed significant and trend effects on cutaneous and subcutaneous tissue oxygenation. Significant differences $(\mathrm{p}<0.05)$ in cutaneous oxygenation compared to the reference sitting position (posture 1) could be found in a negative direction indicating lower oxygenation values, for sitting postures $4 *$ and $5 *$, and in a positive direction, indicating higher oxygenation values, for sitting postures $16^{*}, 17^{*}, 18^{*}, 25^{*}, 29^{*}$ and $30^{*}$. For subcutaneous tissue oxygenation, significant differences $(\mathrm{p}<0.05)$ compared to the reference sitting position were found in a negative direction for sitting postures $3^{*}$ and $4^{*}$, and in a positive direction for sitting posture $28^{*}, 29^{*}$ and $30^{*}$.

It was found that average cutaneous tissue oxygenation peaked at $62.9 \%$ in sitting posture $30 *$ with a back angle of 15 degrees, a seat angle of 5 degrees and a neutral pelvic orientation. This $14,1 \%$ points higher than the reference sitting posture. A minimum tissue oxygenation of $35.5 \%$ was reached in sitting posture $4 *$ with a back angle of 10 degrees, a seat angle of 5 
degrees and a pelvic angle of 30 degrees. The average subcutaneous tissue oxygenation reached its peak of $63.3 \%$ in sitting posture 29* (back angle of 15 degrees, a seat angle of 25 degrees and an anterior tilt of the pelvis of 10 degrees). This is $2.8 \%$ points higher than the reference sitting position. Comparable to the cutaneous tissue oxygenation, a minimum in subcutaneous tissue oxygenation was reached at $56.2 \%$ in sitting posture $4 *$ (back angle of 10 degrees, a seat angle of 5 degrees and an anterior tilt of the pelvis of 40 degrees).

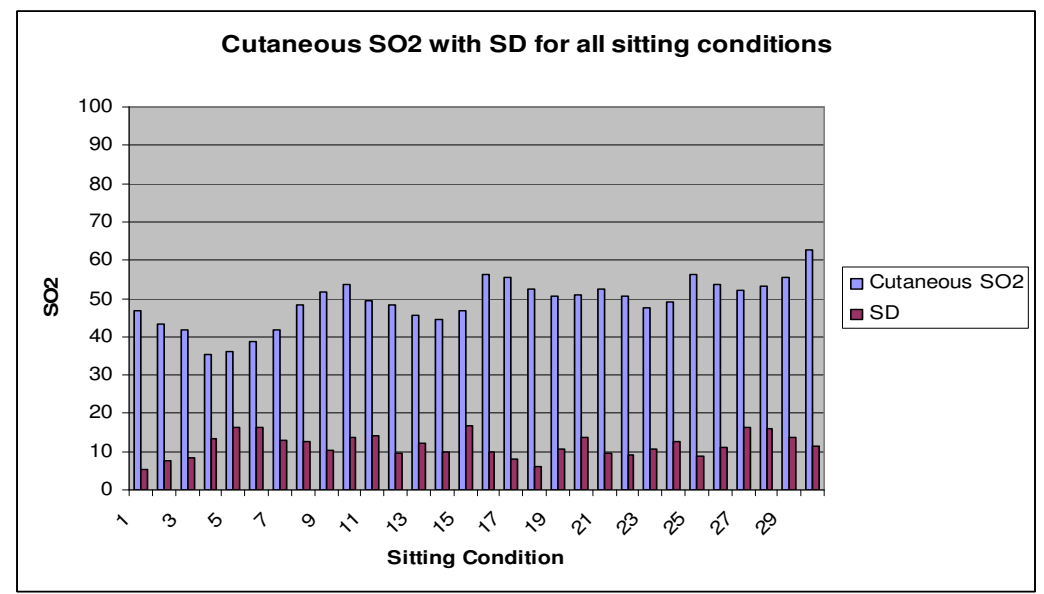

Figure 3: Average cutaneous SO2 values with SD

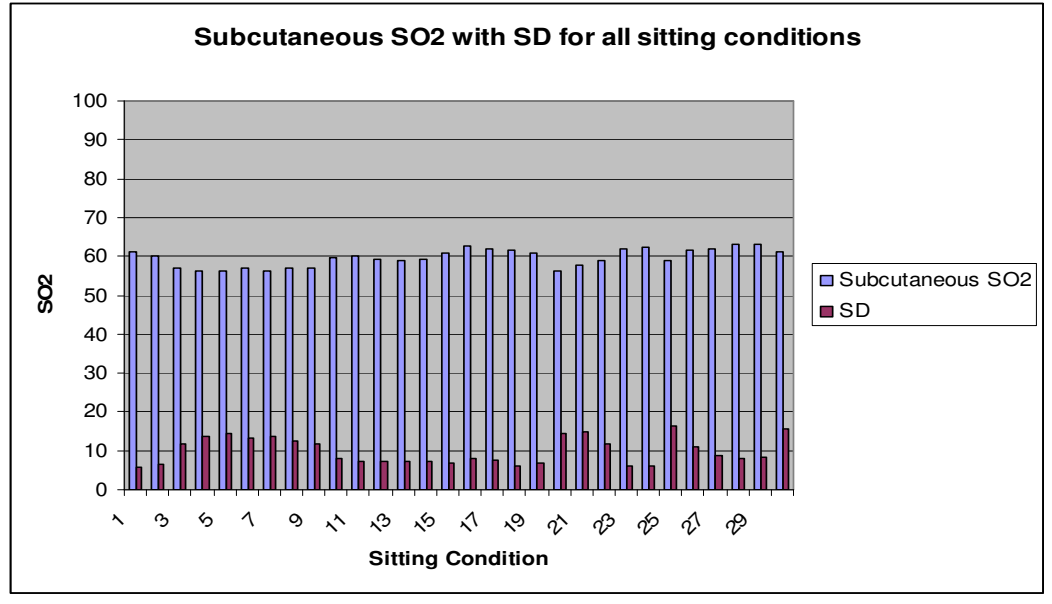

Figure 4: Average subcutaneous SO2 values with SD 


\subsection{Discussion}

The present study shows that postural variation with steps of one minute, as imposed by the Dynasit chair, has effects on the cutaneous and subcutaneous tissue oxygenation of healthy subjects. Changing the back angle of the seat by 5 degrees from 10 to 15 degrees, the seat angle from 5 to 15 to 25 degrees and the pelvic orientation with steps of 10 degrees from 0 to 40 degrees showed effects on cutaneous and subcutaneous tissue oxygenation. It was found that average cutaneous tissue oxygenation peaked in sitting posture $30 *$ at $62.9 \%$, while a minimum tissue oxygenation of $35.5 \%$ was reached in sitting posture $4 *$. The average subcutaneous tissue oxygenation reached its peak of $63.3 \%$ in sitting posture $29 *$. In sitting posture $4 *$ a minimum was reached of $56.2 \%$.

Previous studies found positive effects of postural variation, either by postural changes employed by the individual or by changing the chair configuration, on the sitting load as expressed in the maximal interface pressure and the interface pressure distribution. In addition the ability of the Dynasit chair to alter seating load was demonstrated [15, 16]. However, by dynamically rotating the pelvis in the sagital plane, it was not possible to adjust the load on the ischial tuberosities. Realizing the non-linear relation between the externally applied load on the tissue and the resulting internal load, it is not clear what the clinical relevance is of these values. Therefore, the measurement of the (sub-)cutaneous tissue oxygenation has been presented as an alternative. The present study showed the ability of the Dynasit chair to manipulate the internal tissue load as expressed by the tissue oxygenation. While it might not be possible to regulate the pressure distribution under the ischial tuberosities, it seems possible to regulate the tissue load as expressed in the oxygenation of the (sub-)cutaneous tissue, by adjusting the sitting posture and pelvic orientation with the Dynasit chair. This observation is in line with results from Finite element studies, animal studies and studies with test-buttocks that have shown that the load exerted at the interface is not equal to the internal pressure and stresses and strains in the subcutaneous tissue layers internal pressure [18, 23-28].

Minimum cutaneous and subcutaneous tissue oxygenation values were reached in sitting posture $4 *$. This posture is similar to the initial sitting position, however with an anterior pelvic tilt of 30 degrees. This anterior pelvic tilt increases the load on the ischial tuberosities as reflected in the tissue oxygenation. It can therefore be concluded that a sitting posture with a back angle of 10 degrees, a seat angle of 5 degrees and anterior pelvic tilt of 30 degrees results in the lowest oxygenation values and is therefore a posture to be avoided. The clinically proposed anterior pelvic tilt to relieve the ischial tuberosities might therefore be contra 
productive and might result in lower oxygenation values. A larger anterior pelvic tilt of 40 degrees resulted in slightly higher oxygenation values, but still significantly lower than the reference sitting posture. A plausible explanation for this might be that the larger anterior pelvic tilt of 10 degrees causes more load transfer to the legs and as a result a more forward oriented centre of mass, hereby slightly unloading the ischial tuberosities.

Compared to the reference sitting posture, changing the back angle to 15 degrees resulted in the highest oxygenation values. Maximum cutaneous tissue oxygenation was reached in sitting posture 29*, a posture with a back angle of 15 degrees, a seat angle of 5 degrees and a neutral pelvic orientation of 0 degrees. Maximum subcutaneous tissue oxygenation values were reached in sitting posture $30^{*}$, which is almost the same sitting posture except for an anterior pelvic tilt of 10 degrees. This small difference might indicate a distinction between the cutaneous and subcutaneous tissue load and stresses the importance of investigating the subcutaneous tissue viability in relation to the development of pressure ulcers. In order to achieve the lowest internal load and the highest oxygenation values, a sitting posture with a seat angle of 5 degrees, a back angle of 15 degrees and a neutral or 10 degrees anterior tilted pelvis is recommended.

It can be concluded that actuated postural changes, as imposed by the Dynasit chair, are effective to change (sub-)cutaneous tissue oxygenation, either in a positive or negative direction. Care has to be taken to choose the sitting posture that actually results in an increase in tissue oxygenation. Sitting posture with an anterior tilted pelvis are to be avoided. The highest oxygenation values are achieved in a sitting posture with a slightly reclined back and a neutral pelvic orientation. The Dynasit chair is therefore capable of elevating the cutaneous and subcutaneous tissue oxygenation by imposing selected sitting postures. Larger sample sizes are needed to control for inter-individual variation in tissue oxygenation and hence increase the statistical power of the experiment. Future experiments are needed to validate the Dynasit chair in individuals with spinal cord injury at risk of developing pressure ulcers. 


\subsection{References}

1. Hobson DA, Tooms RE. Seated lumbar/pelvic alignment. A comparison between spinal cord-injured and noninjured groups. Spine. 1992 Mar;17(3):293-8

2. Lyder CH. Pressure ulcer prevention and management. Journal of the American medical association, 2003, Jan 8;289(2):223-6. Maurer C L, Sprigle S. Effect of seat inclination on seated pressures of individuals with spinal cord injury. Physical Therapy, 2004 Mar; 84(3):255-61.

3. Garber SL, Rintala DH. Pressure ulcers in veterans with spinal cord injury: a retrospective study. Journal of Rehabilitation Research and Development. 2003 Sep-Oct;40(5):433-41.

4. Agency for Health Care Policy and Research (AHCPR). Treatment of pressure ulcers, in: Clinical Practice guidelines no.15 US Department of health and Human Services, Publication no. 95-0652, 1994.

5. Hobson D. Comparative effects of posture on pressure and shear at the body-seat interface. Journal of Rehabilitation Research and Development, 1992 Fall; 29(4):21-31.

6. Maurer C L, Sprigle S. Effect of seat inclination on seated pressures of individuals with spinal cord injury. Physical Therapy, 2004 Mar;84(3):255-61.

7. Assaoui R, Lacoste M, Dansereau J. Analysis of sliding and pressure distribution during a repositioning of persons in a simulator chair. IEEE Transactions on Neural Systems and Rehabilitation Engineering. 2001 Jun; 9(2):215-24.

8. Van Geffen P, Molier BI, Reenalda J, Veltink PH, Koopman BF. Body segments decoupling in sitting: control of body posture from automatic chair adjustments. Journal of Biomechanics 2008 Dec 5;41(16):3419-25. Epub 2008 Nov 8.

9. Dinsdale SM. Decubitus ulcers in swine: Light and electron microscopy study of pathogenesis. Archives of physical and medical rehabilitation, 1973, Vol. 54:51-56.

10. Dinsdale SM. Decubitus ulcers: Role of pressure and friction in causation. Archives of physical and medical rehabilitation, 1974, Vol. 55:147-152.

11. Bennet L, Kavner D, Lee BK, Trainor FA. Shear versus pressure as causative factors in skin blood flow occlusion. Archives of physical and medical rehabilitation, 1979, Vol. 60:309-314.

12. Goossens RHM, Zegers R, Hoek van Dijke GA, Snijders CJ. Influence of shear on skin oxygen tension. Clinical physiology, 1994, Vol. 14:111-118.

13. Goossens RH, Snijders CJ, Holscher TG, Heerens WC, Holman AE. Shear stress measured on beds and wheelchairs. Scandinavian journal of rehabilitation and medicine, 1997, Sep; 29(3):131-6.

14. Goldstein B, Sanders J. Skin response to repetitive mechanical stress: A new experimental model in pig. Archives of physical and medical rehabilitation, 1981, Vol. 79:265-272.

15. Van Geffen P, Reenalda J, Veltink PH, Koopman BF. Effects of sagittal postural adjustments on seat reaction load. Journal of Biomechanics 2008 Jul 19;41(10):2237-45.

16. Reenalda J, van Geffen P, Nederhand M, Veltink P, Koopman B, Jannink M, IJzerman M, Rietman H. Effects of Actuated Pelvic Rotation on Sitting Forces and Pressure Distribution. Proceedings of the 2008 RESNA Conference, Arlington VA.]

17. Reenalda J, van Geffen P, Nederhand M, Jannink M, IJzerman M. The clinical use of interface pressure: A systematic review. Assistive Technology, 2009, 21 (2): 76-85. 
18. Oomens, C.W.J., Bressers, O.F.J.T., Bosboom, E.M.H., Bouten, C.V.C., Bader, D.L. Can loaded interface characteristics influence strain distributions in muscle adjacent to bony prominences? Computer Methods in Biomechanics and Biomedical Engineering, 2003, 6(3), 177-180.

19. Linder-Ganz E, Engelberg S, Scheinowitz M, Gefen A. Pressure-time cell death threshold for albino skeletal muscles as related to pressure sore biomechanics. Journal of Biomechanics, 2005, 39(14):27252732.

20. Linder-Ganz, E., Shabshin, N., Itzchak, Y., Gefen, A. Assessment of mechanical conditions in sub-dermal tissues during sitting: A combined experimental-MRI and finite element approach. Journal of Biomechanics, 2006, 40(7):1443-1154

21. Salcido R, Fisher SB, Donofrio JC, Bieschke N, Knapp C, Liang R, LeGrand EK, Carney JM. An animal model and computer-controlled surface pressure delivery, 1995, 19(5):351-9.

22. Brienza, D.M., Geyer, M.J., Jan, Y. A comparison of the changes in rhythms of sacral blood skin blood flow in response to eating and indentation. Archives of Physical and Medical Rehabilitation, 2005, 86, 1245-1251.

23. Le, K.M., Madsen, B.L., Barth, P.W., Ksander, A.M., Angell, J.B., Vistnes, L.M. An in-depth look at pressure sores using monolithic pressure sensors. Plastic and Reconstructive Surgery, 1984, 74(6), 745-754.

24. Brosh, T., Arcan, M. Modeling the body/chair interaction- an integrative experimental-numerical approach. Clinical Biomechanics, 2000, 15, 217-219.

25. Ragan, R., Kernozek, T.W., Bidar, M., Matheson, J.W. Seat-interface pressures on various thickness of foam wheelchair cushions: a finite modeling approach. Archives of Physical and Medical Rehabilitation, 2002, 83(6), 872-875.

26. Lin, F., Moran, B., Bankard, J., Hendrix, R., Makhsous, M. A subject-specific FEM model for evaluating buttock tissue response under sitting load. In Proceedings of the $26^{\text {th }}$ annual conference of IEEE, EMBS, 2004, San Francisco.

27. Oomens, C.W.J., Bressers, O.F.J.T., Bosboom, E.M.H., Bouten, C.V.C. Deformation analysis of a supported buttock contact. In proceedings of the Bioengineering Conference ASME 2001, pp 853-854.

28. Gefen, A., Gefen, N., Linder-Ganz, E., Margulies, S.S. In vivo stiffening under bone compression promotes seep pressure sores. ASME Journal of Biomechanical Engineering, 2005, 127, 512-524. 


\title{
CHAPTER 5
}

\section{EFFECT OF ACTUATED TUBERAL SUPPORT ON TISSUE LOAD AND ON TISSUE PERFUSION AND OXYGENATION}

\author{
J. Reenalda, P. van Geffen, M. Jannink, M. Nederhand, \\ M. IJzerman, H. Rietman
}

This chapter is accepted pending revision in its present form by the Journal of Rehabilitation Research and Development, official journal of the Veterans Association of Research and Development (VARD). 


\subsection{Abstract}

Pressure ulcers are a large problem in subjects who use a wheelchair for their mobility. Seating patterns with alternating pressures have been suggested as a solution to seating related problems such as pressure ulcers.

With the Dynasit chair it is possible to regulate the load on seating surface by actuated pelvic movement in the sagital plane. A mechanical concept for actuated tuberal relief was developed and integrated into the seating device in order to regulate tuberal load and investigate seating patterns with alternating pressures. Actuated tuberal support was provided by two tuberal support elements in the seat, that could be lowered 40 millimeters to create complete unloading of the tuberal zones.

An experiment was performed in healthy subjects $(n=15)$ with the objective of determining the effect of alternating tuberal support patterns on cutaneous and subcutaneous tissue perfusion and oxygenation as measured with the Oxygen-to-See (O2C).

During unsupported sitting, tissue perfusion and oxygenation values were significantly higher than during the baseline condition $(\mathrm{p}<0.05)$. During alternate support, tissue perfusion and oxygenation values were significantly higher than during constant support $(p<0.05)$. It can be concluded that the system for actuated tuberal support is effective in alternating the seating load in healthy subjects, resulting in elevated tissue perfusion and oxygenation values.

\subsection{Introduction}

Pressure ulcers are defined as "localized injury to the skin and/or underlying tissue, usually over a bony prominence, as a result of pressure, or pressure in combination with shear and/or friction" [1]. They are a large problem in subjects who use a wheelchair for their mobility, like patients with a spinal cord injury or with muscle dystrophy. Reported prevalence of pressure ulcers occurring in the ischial, sacral and gluteus region, most likely a result of sitting load, is about $46 \%$ in a general hospital [2]. Pressure ulcers are thought to develop as a consequence of an unbalanced match between the load and the load ability of the skin and subcutaneous tissue in long term sitting.

Current clinical practice of preventing pressure ulcers in wheelchair bound subjects focuses on lowering the interface pressure during static load in one optimal posture. However, the subject will still sit in that particular posture for a prolonged period of time. Considering the developed pressure time curves [3-4] pressure ulcers will develop eventually, if the adopted posture will be maintained for too long, even with low interface pressures. In addition, it has been shown with 
Finite Element modeling that even with an evenly distributed pressure distribution at the sitting interface, high peak pressures and high internal stresses and strains can occur near the bony prominence [5-6]. It has been hypothesized that relieving the load on a periodically basis should give the tissue the opportunity to recover from the applied load. Current clinical practice for patients with a spinal cord injury is to lift every 20 minutes or to be repositioned every two hours. However, a theoretical basis for this period of time does not exist. In addition, with impaired motor function of the upper body or with limited availability of nursing staff, it is not possible to maintain this behavior. The inability for patients with for example spinal cord injury or muscular dystrophy to reposition themselves implies that adequate postural or support change is only possible by automatic chair adjustments or by the help of others. Seating patterns with alternating pressures have been suggested as a solution to seating related problems such as low back pain [7] and pressure ulcers [8-12]. Aim of these seating patterns with alternating pressures is to alternate the load over different areas of the seating surface, allowing the tissue to recover when less loaded or unloaded. Bader showed a positive effect of alternating the seating load on skin perfusion ( $\mathrm{tcPO}$ and $\left.\mathrm{tc} \mathrm{PCO}_{2}\right)$ and interface pressure by means of a dynamic cushion. Makhsous et al. [9-10] demonstrated positive effects of alternating the seating load, using an automated seating system, containing adjustable ischial and back supports, on skin perfusion and interface pressure. In addition they showed that the automated seating system allowed substantial oxygen and carbon dioxide recovery compared to a traditional push-up routine. Unfortunately, little is known about optimal alternating patterns and the effects of these seating patterns with alternating pressures on subcutaneous tissue perfusion and oxygenation. The subcutaneous tissue perfusion and oxygenation is most relevant for the development of pressure related deep tissue injury [1]. These types of pressure ulcers develop in the subcutaneous tissue (mostly muscle tissue) beneath the bony prominences and progress outwards. Perfusion and oxygenation is of interest in the tissue layers that are compressed against the bone, resulting in high internals stresses and strains [13-15].

In previous research an experimental seating device, the Dynasit chair, capable of imposing different sitting postures and pelvic orientations has been described [16-18]. With this experimental seating system it is possible to regulate the load on the sacrum by actuated pelvic movement in the sagital plane. However, in this concept, the pelvis rotates over the ischial tuberosities as a pivot point. As a consequence, due to continuous loading, the regulation of the tuberal load is difficult. Therefore, addictively, a mechanical concept for actuated tuberal 
relief was developed in order to regulate the tuberal load and to investigate alternating tuberal support. Objective of this study is to determine the effects of alternating tuberal support on tissue load, and cutaneous and subcutaneous tissue perfusion and oxygenation.

\subsection{Methods}

\subsubsection{Subjects}

Fifteen healthy male subjects (age $23 \pm 2$ years, weight $75 \pm 8 \mathrm{~kg}$, length $1.84 \pm 0.05 \mathrm{~m}$ ) were recruited for this study. All subjects were between the age of 18 and 50 years, free of any vascular diseases that could disturb blood flow and free of any pressure ulcers or other skin diseases. The study design was approved by the local Medical and Ethical Committee of ' $t$ Roessingh Centre for Rehabilitation, Enschede, the Netherlands. Prior to the experiment, all subjects read and signed an 'informed consent' in which the objective and experimental protocol was explained.

\subsubsection{Experimental setup}

Experiments were performed with an instrumented simulator chair containing a concept for actuated tuberal support (fig 1A). Aligned with the seat pivot point and spaced according to an average inter-tuberal distance of $120 \mathrm{~mm}$ [19], two adjustable force sensing support elements were integrated in the seat plane (fig1B). For accurate 3D measurements of seat reaction load, 6 more uni-axial load cells (FUTEK®, California, USA) were integrated in the seating surface. The cushion placed over the seat contained a wooden under plate with $100 \mathrm{~mm}$ of industrial foam commonly used in wheelchair ergonomics. Round cut-outs ( $\varnothing 90 \mathrm{~mm}$ ), each covered with foam with characteristics similar to the total support area, were made above the two adjustable support elements to imply tuberal actuation. Both support elements were independently adjustable and designed to relief pressure meaning that they only allowed tuberal actuation below the support surface. 

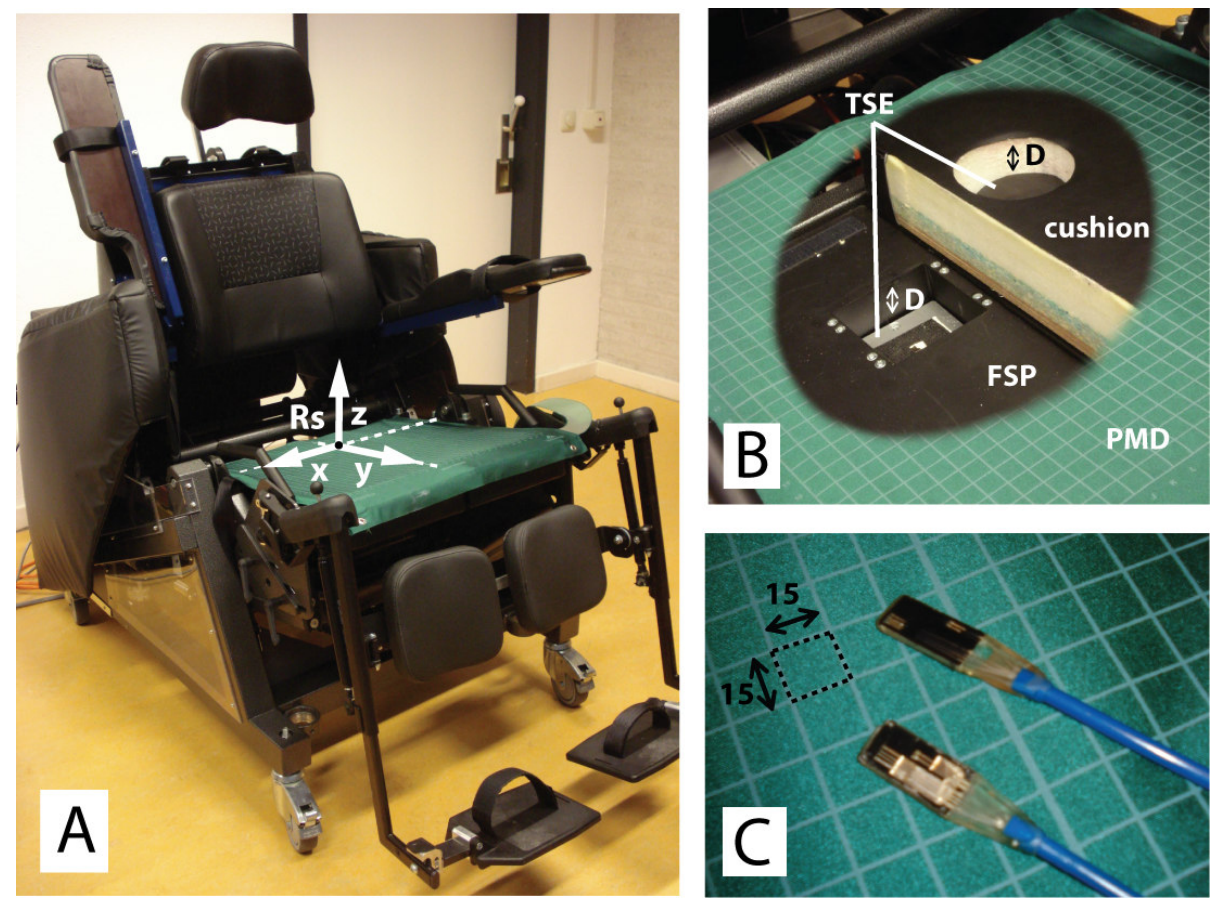

Figure 1: Experimental seating device with reference frame (Rs) for force sensing (A) containing a concept for actuated tuberal support (B) (With Tuberal Support Element (TSE), distance (D), Force Sensing Platform (FSP) and Pressure Mapping Device (PMD)). O2C probes are shown in $(C)$, distance in $\mathrm{mm}$.

Tissue perfusion and oxygenation was measured with the Oxygen-to-See $(\mathrm{O} 2 \mathrm{C})$. The $(\mathrm{O} 2 \mathrm{C})$ is a diagnostic device that uses Laser Doppler flowmetry and diffuse reflectance spectroscopy for non-invasive determination of oxygen supply in blood perfused tissue (LEA Medizintechnik Giessen, Germany). The O2C transmits continuous wave laser light (830 $\mathrm{nm}$ and $30 \mathrm{~mW}$ ) and white light (500-800 nm, $1 \mathrm{~nm}$ resolution, $20 \mathrm{~W}$ ) to tissue where it is scattered and collected on the skin surface at fibers in the probe (Fig 1C). The sample frequency of the O2C is $0.5 \mathrm{~Hz}$; therefore it is capable of measuring the dynamic response in blood flow. The data are analyzed by comparison with prerecorded deoxygenated and oxygenated hemoglobin spectra. 
The O2C has four output parameters [20] of which the perfusion (Flow, F) and oxygenation $\left(\mathrm{SO}_{2}\right)$ were used:

- $\quad \mathrm{F}(\mathrm{AU})$, which is in relative units, and reflects the blood flow in the microcirculation.

- $\mathrm{SO}_{2}(\%)$, which is a relative measure, and reflects the oxygen saturation of hemoglobin.

The fiber-optic probes used with the O2C incorporate both the Laser-Doppler method and broadband light spectroscopy techniques. Two probes were used with different measurement depths. The superficial probes measures at a maximum depth of approximately $1 \mathrm{~mm}$ and the deep probe measures at a maximum depth of approximately 7 to $8 \mathrm{~mm}$. The probes were attached to the skin with surgical tape. The probe for superficial measurement was placed beneath the left tuberosity and the probe for subcutaneous measurement was attached beneath the right tuberosity.

\subsubsection{Experimental Protocol}

Prior to the experiment, an empty seated force calibration measurement was performed. Subjects were seated with their tuberosities on top of the tuberal support elements. Pressure mapping (Tekscan Conformat, Tekscan inc. Boston Massachusetts) was applied for proper tuberal positioning. The seat and footrests were individually adjusted for optimal pressure distribution. The thighs were fully supported except for the back of the knees. Within the initial chair configuration, the seat- and backrest angles were set to $10^{\circ}$ and $20^{\circ}$ respectively. The footrests were set perpendicular to the seat and so that only the weights of the lower legs were supported. The experimental seating device was adjusted individually to centre the pivot point of the back support within the lumbar region at a level of the third lumbar vertebrae.

The experiment started with a base-line measurement of 20 minutes in which the subject was instructed to sit continuously, without moving, with his arms on the armrest and his back in contact with the back-support. In this situation the tubera were supported normally with the tuberal support elements raised creating a flat sitting surface. After this period the tuberal support elements were lowered $40 \mathrm{~mm}$, resulting in complete relieving of the tuberal load for five minutes. This situation was repeated with five minutes of supported sitting in between, where the tuberal support elements were raised, comparable to the base-line measurement. In addition five different actuation frequencies were imposed $(1 / 120 \mathrm{~Hz}, 1 / 60 \mathrm{~Hz}, 1 / 30 \mathrm{~Hz}$, $1 / 15 \mathrm{~Hz}$ and $1 / 10 \mathrm{~Hz}$ ) (Figure 2). 


\subsubsection{Data analysis}

The values of Skin perfusion (Fskin), subcutaneous tissue perfusion (Fsub), skin oxygenation $\left(\mathrm{SO}_{2}\right.$ skin) and subcutaneous tissue oxygenation $\left(\mathrm{SO}_{2}\right.$ sub) during the supported base-line measurement were regarded as initial values. $\mathrm{F}$ skin, $\mathrm{F}$ sub, $\mathrm{SO}_{2}$ skin and $\mathrm{SO}_{2}$ sub values for the other sitting conditions were normalized in order to compare them inter-individually. Values were normalized by calculating the ratio between the present value minus the initial value and the maximal value minus the initial value (e.g. $\mathrm{nSO}_{2} \mathrm{sub}=\left(\mathrm{SO}_{2}\right.$ sub$\mathrm{SO}_{2}$ initial $) /\left(\mathrm{SO}_{2}\right.$ max-SO $\mathrm{S}_{2}$ initial $\left.)\right)$. Normalized values are between 0.0 and 1.0. Figure 2 shows a typical example of the $\mathrm{SO}_{2}$ sub values of one subject during the experimental protocol and the method of identifying the initial and maximal values in order to normalize the data.

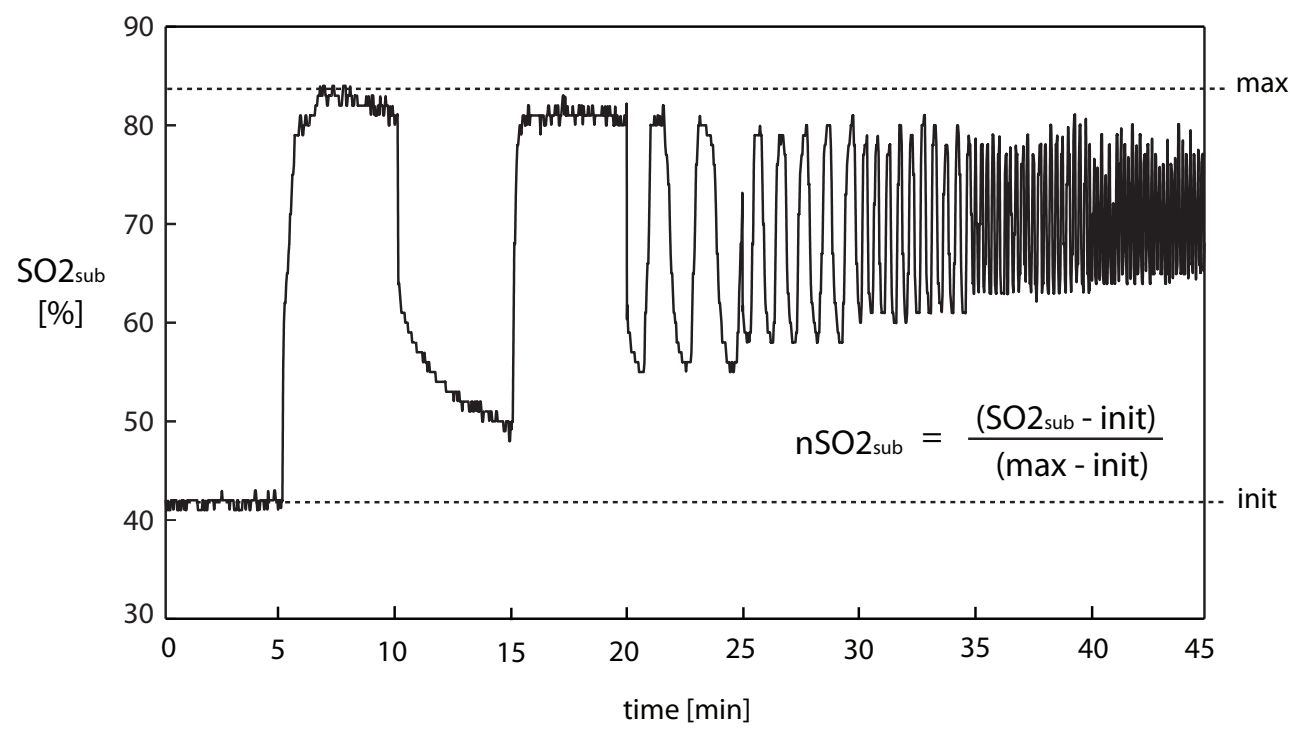

Figure 2: Typical example of the non-normalized $\mathrm{SO}_{2}$ sub values of 1 subject and the identifying of the initial and maximal values in order to normalize the data.

Average values for all sitting conditions were calculated for all subjects for the normalized $\mathrm{F}$ skin, $\mathrm{F}$ sub, $\mathrm{SO}_{2}$ skin and $\mathrm{SO}_{2}$ sub for all sitting conditions. One-way ANOVA was used to statistically compare the different sitting conditions. 


\section{$5.4 \quad$ Results}

All 15 Subjects completed the experiment. As measured with the force sensors in the seat and the actuator heads of the tuberal support elements, lowering the actuators with 40 millimeters $(\mathrm{D}=-40)$, creates a complete unloading of the tuberal zones. Load is displaced to the remaining contact area of the seat and to the backrest in some way.

\subsubsection{Perfusion and oxygenation}

Based on the perfusion and oxygenation patterns during the alternating protocols, subjects can be divided in responders and non-responders. Five out of 15 subjects showed no statistical significant difference between the alternating conditions and the base-line measurements and as such no response in tissue perfusion ( $\mathrm{F}$ skin and $\mathrm{F}$ sub) and oxygenation $\left(\mathrm{SO}_{2}\right.$ skin and $\mathrm{SO}_{2}$ sub) to the manipulation of the tuberal support. This group is classified as the non-responding group and excluded from further analysis. The rationale for excluding these subjects can be found in the discussion section. The subjects that showed response to the tuberal actuation are classified as the responding group. No differences in Body Mass Index (BMI) could be found between the responders and non-responders. Initial cutaneous and subcutaneous perfusion and cutaneous oxygenation values during the base-line measurement were significantly higher for the non-responder group compared to the responder group. No differences were found in initial subcutaneous oxygenation values between the two groups (figure 3). A typical example of the Perfusion and Oxygenation values as a consequence of actuation with a distance $\mathrm{D}$ of a responder and a non-responder can be found in figure 4.
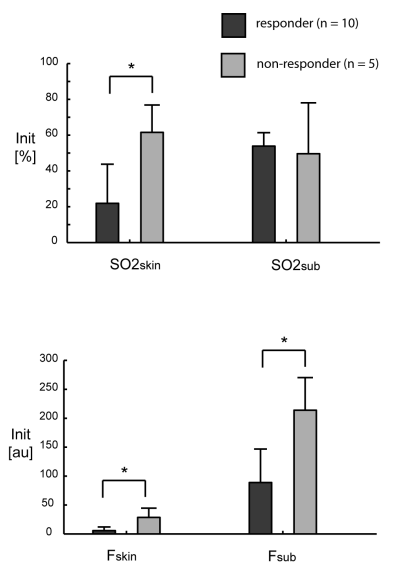

Figure 3: Initial values for responders and non responders for $\mathrm{SO}_{2}$ skin and $\mathrm{SO}_{2}$ sub and $\mathrm{F}$ skin and $\mathrm{F}$ sub 


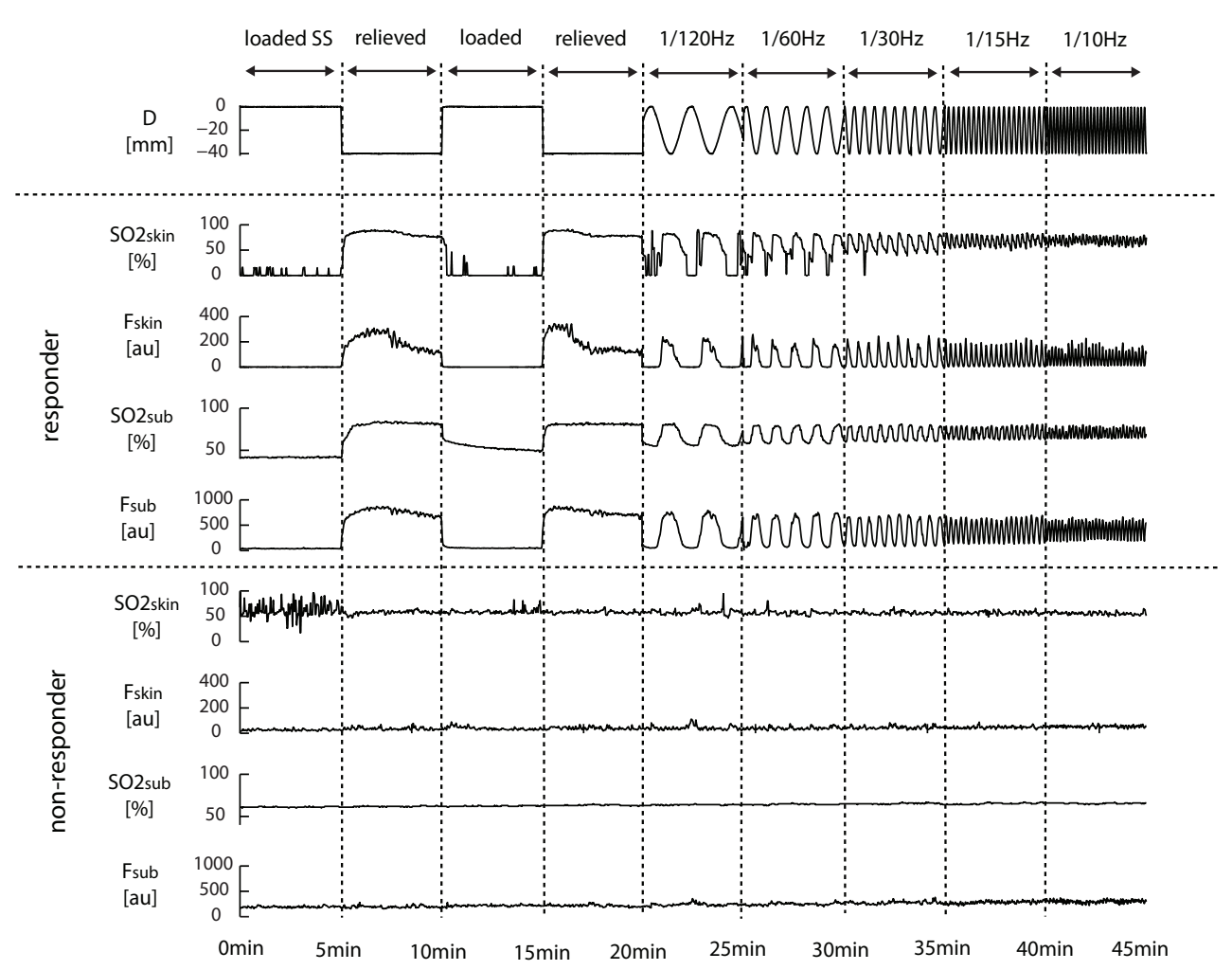

Figure 4: Protocol and typical examples. Distance of actuation (D), tissue oxygen saturation of the skin (SO2skin) and subcutaneous tissue $\left(\mathrm{SO}_{2}\right.$ sub) and perfusion of the skin (F skin) and subcutaneous tissue ( $\mathrm{F}$ sub) of a responder and a non-responder

\subsubsection{Patterns of loading and unloading}

During unsupported sitting, normalized (sub-)cutaneous tissue perfusion and oxygenation values are significantly higher than during supported sitting ( $\mathrm{p}<0.05$ ) (fig 5). In addition, (sub-) cutaneous perfusion and oxygenation during the different actuation frequencies are significantly different from the initial supported base-line condition $(p<0.05)$. During alternate support, average cutaneous and sub-cutaneous tissue perfusion and oxygenation values are significantly higher than during constant support $(\mathrm{p}<0.05)$. No significant differences could be found between the different alternating frequencies, although a trend is visible for higher cutaneous tissue oxygenation and higher sub-cutaneous tissue perfusion values for higher actuation frequencies. 


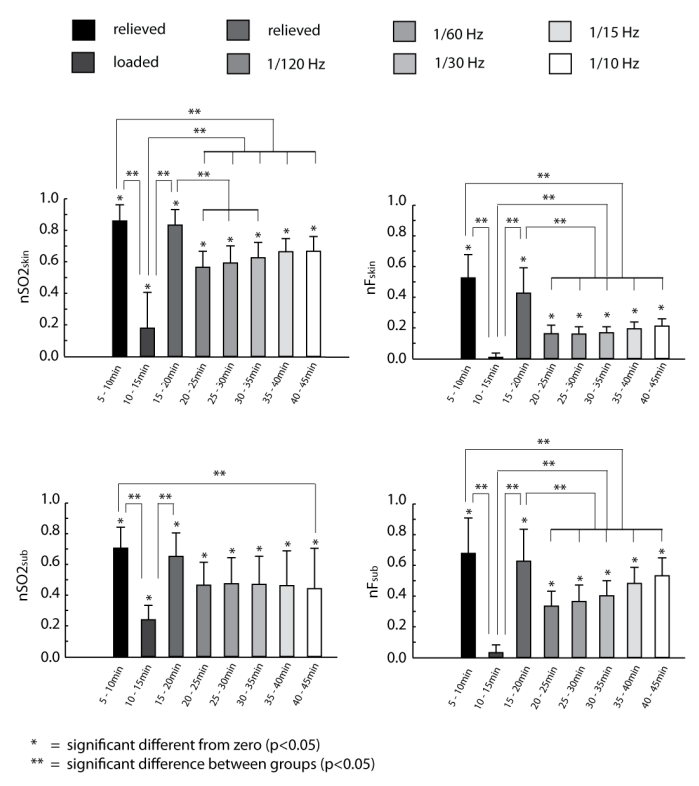

Figure 5: Normalized $\mathrm{SO}_{2}$ skin, $\mathrm{SO}_{2}$ sub, F skin and $\mathrm{F}$ sub values as a result of different alternating protocols, $\mathrm{N}=10$ (Responders only). Significant differences calculated between groups with $p<0.05$.

\subsection{Discussion and conclusions}

It can be concluded that the developed system for actuated tuberal support is effective in alternating the seating load in healthy subjects, resulting in elevated cutaneous and subcutaneous tissue perfusion and oxygenation values.

In general two distinct reaction patterns could be observed. Ten out of 15 subjects responded directly in tissue perfusion and oxygenation to the actuation beneath the tubera in such a way that oxygenation and perfusion are inversely related to the applied load. However 5 out of the 15 subjects showed minimal response to the actuation, as characterized by no significant differences between the actuated sitting conditions and the supported base-line measurement. These groups can respectively be classified as responders and non-responders. A similar pattern was observed by Bader [8]. Bader investigated the effects of an alternating dynamic cushion on the skin perfusion of healthy subjects and patients (multiples sclerosis, syringomyella and spinal cord injury), as measured with trans-cutaneous oxygen tension. All but one disabled subjects showed a similar non-responding pattern, where no adequate tissue relief was provided by the dynamic cushion used in the study. The time permitted for tissue 
recovery was inadequate and would inevitably lead to diminished oxygen levels on repeated loading and eventual tissue ischemia. Bader suggests that the non-responders among are at higher risk for developing pressure ulcers, due to an impaired physiological control mechanism, causing diminishing oxygenation values during constant support and no restoration of oxygenation values during unloading and eventually leading to tissue ischemia. However, distinction between the study of Bader and the present study is that in the present study only healthy subjects were investigated. According to Bader's study, they should all display a responding pattern, because all healthy subjects in that study showed response in tissue oxygenation to the dynamic cushion. An explanation for this difference might be that in the present study initial (sub-) cutaneous tissue perfusion and cutaneous oxygenation values during the supported base-line measurement were significantly higher for the non-responders compared to the responders. This might be explained by inter-subject variation in pressure distributing properties of the subcutaneous tissue resulting in the fact that the external load is distributed in a different way to the internal tissue in the responders. Unfortunately, no relation with Body Mass Index could be found between the groups, stressing the importance of intrinsic factors in the development of pressure ulcers and might explain why some subjects can sit for prolonged periods of time without moving while others cannot. On the other hand, $\mathrm{SO}_{2}$ sub values at base-line did not differ between the responders and responders. With the $\mathrm{SO}_{2}$ sub being an important determinant of the viability of tissues at particular risk of developing pressure ulcers; it might be contra-intuitive to state that the non-responders do have intrinsic factors that prevent them from developing pressure ulcers during prolonged sitting. Therefore, a more plausible explanation might be that the displacement of the probe during the measurement caused a different measurement area that consisted mostly of less blood perfused fatty tissue, resulting in false tissue perfusion and oxygenation values. Because of this rationale, the non-responders are excluded from the analysis.

A sharp rise in oxygenation and perfusion values was seen during unsupported sitting. In addition, in the support condition following actuated unloading, flow and saturation values do not fall to their initial values. The actuation of the tuberal support in an alternating way causes an increase in all values. Significant differences were found between the normalized perfusion and oxygenation values of the alternating frequencies versus the supported condition. Furthermore, there is a trend visible that the frequency of the alternating tuberal support seems to be related to the normalized cutaneous oxygenation and subcutaneous perfusion values. Although not statistically significant is seems that a higher actuation frequency results in higher 
cutaneous oxygenation and sub-cutaneous perfusion values. A plausible explanation for this phenomenon is that the metabolic process of decreasing perfusion and oxygenation values as a result of loading is slower than the mechanical process of increasing perfusion and oxygenation after unloading. It can be seen that after unloading flow and saturation increase very rapidly. When loaded, flow values decrease rapidly; however, the decrease in saturation values is a slower process. A plausible explanation for the rapid response in flow values is that the flow of blood during loading and unloading is a mechanical process. During loading, vessels are occluded with limited flow as a result. After unloading external pressure on the vessels is relieved allowing the blood to flow again. Due to the temporary ischemia and build-up of blood pressure an overshoot of blood flow will occur, characterized as reactive hyperemia. This is a mechanical process and therefore very rapid. Contrary, the decrease in saturation values as a result of loading is a metabolic process in which the available oxygen is consumed relatively slowly by the surrounding tissues. During unloading the saturation values rise as rapidly as the perfusion values. As a result higher actuation frequencies cause a total increase over time in the perfusion and oxygenation values due to the overshoot in perfusion and oxygenation values.

An important distinction between the present study and the studies of Bader [8] and Makhsous et al. [9-10], in which the effect of a dynamic cushion on tissue oxygenation is investigated, is the measurement device. Both studies used transcutaneous oxygen tension measurement, system only capable of measuring up till $1 \mathrm{~mm}$ of depth. The $\mathrm{O} 2 \mathrm{C}$ used in the present study is capable of measuring at a two depths. The superficial probe measures tissue oxygenation at a depth of 1 to $2 \mathrm{~mm}$ and the deep probe measures tissue oxygenation at a maximum depth of 8 $\mathrm{mm}$. In this way tissue oxygenation for both types of ulcers, skin ulcer and pressure related deep tissue injury can be studied. Differences in perfusion and oxygenation values could be observed between the skin and subcutaneous tissue stressing the different etiology of superficial ulcers and pressure related deep tissue injury [13-15].. This can be caused by the different vessels that are measured at different measurement depth. In deeper tissue, larger vessels are measured in order to get valuable data [20-21]. The distance between the illuminating (source) fiber and the detecting fiber determines the possible measurement depth of the probes. The larger the separation between the source and detector becomes, the larger the 'banana-shaped' path of the photons will be and also the depth of the photons which have been scattered back will be. Light that is detected by the O2C mainly reflects information coming from small arterioles, capillaries and venules. As $85 \%$ of the hemoglobin located in the 
capillary-venous compartment of the microcirculation, the measurements with the $\mathrm{O} 2 \mathrm{C}$ reflect mainly the capillary venous oxygen saturation.

Besides the limited measurement depth, $\mathrm{tcPO}_{2}$ sensors need to be heated to 40 degrees Celsius in order to evoke maximal vasodilatation. This is necessary for oxygen exchange from skin to sensor. This heating, however, disturbs the physiological processes, associated with perfusion and oxygenation [22]. The maximum vasodilatation caused by the heating bypasses normal physiological responses and protection mechanisms. No heating is necessary for simultaneous measurement of oxygenation and perfusion with the $\mathrm{O} 2 \mathrm{C}$.

The subject population in this study consisted of young healthy male subjects. This subject group was chosen because of their homogeneity in order to determine the exact effects of the different tuberal support condition. However different skin and tissue characteristics of subjects with spinal cord injury, caused by atrophy due to immobility and changes in vascularization, can cause different reactions in oxygenation and perfusion to loading and unloading. Future experiments will address the effects of tuberal support actuation on tissue oxygenation and perfusion in subjects with limited upper motor function at risk of developing pressure ulcers.

It can be concluded that the developed system for actuated tuberal support is effective in alternating the seating load in healthy subjects, resulting in elevated cutaneous and subcutaneous tissue perfusion and oxygenation values. Future experiments should address the effects of combined actuated pelvic rotation and tuberal unloading, creating a dynamic sitting pattern, on the tissue oxygenation and saturation of the spinal cord injured. 


\subsection{References}

1. Black J, Baharestani M, Cuddigan J, Dorner B, Edsberg L, Langemo D, Posthauer ME, Ratliff C, Taler G, NPUAP. National Pressure Ulcer Advisory Panel's updated pressure ulcer staging system. Urologic Nursing, 2007; 27(2): 144-150.

2. Swaine J, Young C. Sitting Acquired Pressure Ulcers: Collecting incidence data in Tasmania. In Proceedings of the 21th International Seating Symposium, Orlando Florida, 2005: pp 109-110.

3. Kosiak M. Etiology and pathology of ischemic ulcers. Archives of Physical and Medical Rehabilitation, 1959; 40(9): 62-69.

4. Reswick JB, Rogers JE. Experience at Rancho los Amigos hospital with devices and techniques to prevent pressure sores. In: Kennedi RM, Cowden JM, Scales JT (Eds.) Bedsore biomechanics, London, Macmillan, 1976:301-310.

5. Oomens CWJ, Bressers OFJT, Bosboom EMH, Bouten CVC, Bader DL. Can loaded interface characteristics influence strain distributions in muscle adjacent to bony prominences? Computer Methods in Biomechanics and Biomedical Engineering, 2003; 6(3): 177-180.

6. Linder-Ganz E, Engelberg S, Scheinowitz M, Gefen A. Pressure-time cell death threshold for albino skeletal muscles as related to pressure sore biomechanics. Journal of Biomechanics, 2005; 39(14):27252732 .

7. Makhsous M, Hendrix R, Crowther Z, Nam E, Lin F. Reducing whole-body vibration and musculoskeletal injury with a new car seat design. Ergonomics, 2005; Jul 15; 48(9):1183-99.

8. Bader DL. The recovery characteristics of soft tissues following repeated loading. Journal of Rehabilitation Research and Development, 1990; 27: 141-50.

9. Makhsous M, Lin F, Hendrix RW, Hepler M,Zhang L Q. Sitting with adjustable ischial and back supports: biomechanical changes. Spine, 2003; 28: 1113-21; discussion 1121-2.

10. Makhsous M, Priebe M, Bankard J, Rowles D, Zeigler M, Chen D, Lin F. Measuring tissue perfusion during pressure relief maneuvers: insights into preventing pressure ulcers. J Spinal Cord Med. 2007; 30(5):497-507.

11. Makhsous M, Rowles DM, Rymer WZ, Bankard J, Nam EK, Chen D, Lin. Periodically relieving ischial sitting load to decrease the risk of pressure ulcers. Arch Phys Med Rehabil. 2007; Jul; 88(7):862-70.

12. Stockton L, Rithalia S. Is dynamic seating a modality worth considering in the prevention of pressure ulcers? Journal of tissue viability, 2007; 17(1): 15-21.

13. Levine SP, Kett RL, Gross MD, Wilson BA, Cederna PS, Juni JE. Blood flow in the gluteus maximus of seated individuals during electrical muscle stimulation. Arch Phys Med Rehabil. 1990; Aug; 71(9):682-6.

14. Bouten CVC, Bosboom EMH, Oomens CWJ. (1999). The etiology of pressure sores: A tissue and cell mechanics approach. In: Biomedical aspects of manual wheelchair propulsion. L.H.V. Van der Woude et al. (Eds.) IOS Press, 1999: (pp. 52-62).

15. Bouten CVC, Oomens CWJ, Baaijens FPT, Bader DL. The etiology of pressure ulcers: Skin deep or muscle bound. Archives of Physical and Medical Rehabilitation, 1990; 84: 616-619. 
16. Van Geffen P, Reenalda J. DYNASIT An Assistive Seating System that Controls Sitting Posture and Regulates Body Load Associated with Sitting Related Mobility Problems. In Proceedings of the RESNA 2008 conference, Arlington VA.

17. Van Geffen P, Reenalda J, Veltink P, Koopman FJM. Effects of sagittal postural adjustments on seat reaction load, Journal of Biomechanics, 2008; 5: p2237-2245.

18. Reenalda J, Van Geffen P, Nederhand M, Jannink M, Veltink P, Koopman B, IJzerman M, Rietman H. Effects of Actuated Pelvic Rotation on Sitting Forces and Pressure Distribution, In proceedings of the RESNA 2008 conference, Arlington VA, pp xx-xx.

19. Linder-Ganz E, Shabshin N, Itzchak Y,Gefen A. Assessment of mechanical conditions in sub-dermal tissues during sitting: a combined experimental-MRI and finite element approach. Journal of Biomechanics, 2007; 40: 1443-54

20. Beckert S, Witte MB, Königsrainer A, Coerper S. The Impact of the Micro-Lightguide O2C for the Quantification of Tissue Ischemia in Diabetic Foot Ulcers, Diabetes Care, 2004; vol. 27, nr. 12: 2863-2867.

21. Ghanzanfari M. Reproducibility of non invasive Blood Flow Measurements using Laser Doppler Spectroscopy. Phys Med Rehab Kuror. 2002; 12: 330-336.

22. Sheffield PJ. Measuring tissue oxygen tension: a review. Undersea Hyperbaric Medicine 1998 Fall; 25(3):179-88. 
Chapter 5 
CHAPTER 6

\section{EFFECTS OF DYNAMIC SITTING INTERVENTIONS ON TISSUE OXYGENATION IN INDIVIDUALS WITH SPINAL CORD DISORDERS}

J. Reenalda, P. van Geffen, G. Snoek, M. Jannink,

M. IJzerman, H. Rietman

This chapter is accepted pending revision in its present form by Spinal Cord. 


\subsection{Abstract}

Objective of this study is to investigate the possibility of imposing dynamic sitting behavior on individuals with spinal cord disorders by using the Dynasit chair and to investigate its effect on the (sub-) cutaneous tissue oxygenation. The Dynasit chair, an experimental simulator chair, containing mechanical concepts for postural adjustments, regulation of tuberal load and pelvic rotation, was developed to allow individuals with a spinal cord disorder to sit in a dynamic way. An explorative study was performed in which a dynamic sitting pattern was imposed. The sitting pattern consisted of series of actuated changes in posture, tuberal load and pelvic orientation. Effects of these changes on cutaneous and subcutaneous buttock tissue oxygenation were investigated by transcutaneous measurement of tissue oxygenation. Nonparametric statistical analyses were performed on 9 subjects that completed the study. Results showed significant positive effects $(p<0.05)$ of actuated changes in tuberal load on the cutaneous and subcutaneous tissue oxygenation. The Dynasit chair is effective in imposing dynamic sitting behavior in individuals with a spinal cord disorder and consequently might reduce the chance of tissue degradation.

\subsection{Introduction}

Superficial and deep pressure ulcers (PU) are common in individuals with spinal cord injury (SCI) that use a wheelchair for their mobility. It is understood that deep pressure ulcers result from prolonged pressure and develop usually near the bony prominences where internal pressures are high. At present it is suggested that superficial ulcers do not initiate as a result of pressure but are more the consequence of shear and trauma to the tissue [1]. Prevalence of pressure ulcers in the spinal cord injured (US veteran) population are reported as high as 39\% [2]. This high prevalence indicates the need for prevention of pressure ulcer development. In order to prevent PU development, the Agency for Healthcare Research and Quality (AHRQ, AHCPR guidelines 1994) [3] recommends that wheelchair users shift their sitting posture at least once per hour. In addition, subjects who have sufficient upper body motor function are advised to shift their posture every fifteen minutes. However, two studies have measured the posture shift frequency of individuals that use a wheelchair for their mobility and it was concluded that there is a wide variety in pressure relief intervals between subjects and that sitting times exceed the AHRQ guidelines [4, 5].

Because Individuals with SCI lack the sensory ability to register the need to reposition and the motor function to reposition; they are often dependent on nursing staff to reposition them. 
This is a time consuming and cost ineffective activity. Therefore, to reduce demands on nursing staff and increase patient autonomy, seating devices have been developed that create dynamic alternating seating patterns which mimic the reposition behavior as recommended by the AHRQ. Both a dynamic cushion [6] and a dynamic seating device [7] have been studied as mechanisms to reduce tissue load. Positive effects of seating patterns with alternating loads were found on the skin oxygen tension of the buttock tissue. No conclusive results were found regarding the optimal actuation frequencies of the dynamic seating patterns under consideration.

Known is that subjects without restrictions in sensory function and motor function do not develop PU, even if they sit for prolonged periods. Due to a continuous variation in sitting posture, and consequently sitting load, they maintain tissue viability and as such do not develop PU. Recently some data about sitting behavior of healthy subjects has become available that can be helpful in defining optimal dynamic seating patterns. Linder-Ganz et al. [8] and Reenalda et al. [9] investigated the sitting behavior of healthy subjects by measuring their posture shifts. Linder-Ganz et al. [8] found that healthy subjects change their posture approximately every 9 minutes in the sagital plane and approximately every 6 minutes in the frontal plane, as measured with pressure sensors and trunk movement analysis. Reenalda et al. [9] found slightly higher values based on the measurement of interface pressure and subcutaneous tissue oxygenation and concluded that healthy subjects change their posture at least every eight minutes. This sitting behavior can serve as a basis for dynamic seating patterns with alternating loads.

The notion that individuals with a spinal cord disorder perform less posture shifts, and healthy individuals perform more posture shifts, than the AHRQ guidelines indicates the need for seating intervention. In order to impose dynamic sitting behavior to individuals with impaired sensory and motor function, a fully adjustable computer-aided (Matlab/Simulink ${ }^{\circledR}$ environment) simulator chair (the Dynasit chair), was developed (See Figure 1). Previous studies have shown that the Dynasit chair is capable of controlling the body posture of sitting subjects [10[, regulating the sitting load [11, 12], and elevating the subcutaneous tissue oxygenation below the ischial tuberosities [13]. However, these experiments with the Dynasit chair were only performed on healthy individuals. In the present study we focus on individuals with a spinal cord disorder with impaired sensory and motor function that use a wheelchair for their mobility. The objective of the present study is to investigate the effect of dynamic sitting behavior on the cutaneous and subcutaneous tissue oxygenation in individuals with spinal cord 
disorders. It is expected that the Dynasit chair is capable of imposing dynamic sitting behavior and increasing the tissue oxygenation.

\subsection{Methods}

\subsubsection{Subjects}

An explorative cross-sectional study was performed in ten male subjects with a spinal cord disorder (age [58] $\pm[7.4]$ years, weight [94.2] \pm [16.6] kg, height [1.82] \pm [0.09] m). Subject characteristics can be found in table 1 . Subjects were all in the chronic phase of their spinal cord disorder and free of pressure ulcers for at least two years. Inspection of vascularization by medical staff revealed no abnormalities.

A dynamic sitting pattern was induced by means of the Dynasit chair. The study was approved by the local Medical and Ethical Committee. We certify that all applicable institutional and governmental regulations concerning the ethical use of human volunteers were followed during the course of this study.

Table 1: Subject characteristics. Nine subjects were diagnosed with a spinal cord injury, while one subject was diagnosed with spinal cord disease. AIS = ASIA Impairment Scale

\begin{tabular}{|c|c|c|c|c|c|c|c|}
\hline Subject & Age & Height & Weight & Sexe & Lesion level & Lesion type & AIS \\
\hline & (years) & $(\mathrm{m})$ & $(\mathrm{kg})$ & & & & \\
\hline 1 & 65 & 1,85 & 95 & $\mathrm{~m}$ & Th5 & incomplete & C \\
\hline 2 & 52 & 1,93 & 110 & $\mathrm{~m}$ & Th11 & complete & A \\
\hline 3 & 63 & 1,72 & 96 & $\mathrm{~m}$ & C5 & complete & A \\
\hline 4 & 55 & 1,76 & 76 & $\mathrm{~m}$ & \multicolumn{2}{|c|}{ Paraplegia due to Strümpel's disease } & \\
\hline 5 & 53 & 1,78 & 82 & $\mathrm{~m}$ & Th10 & incomplete & C \\
\hline 6 & 52 & 1,88 & 100 & $\mathrm{~m}$ & Th9 & complete & A \\
\hline 7 & 56 & 1,78 & 75 & $\mathrm{~m}$ & Th12 & complete & A \\
\hline 8 & 66 & 1,77 & 67 & $\mathrm{~m}$ & C4 & incomplete & C \\
\hline 9 & 46 & 1,8 & 75 & $\mathrm{~m}$ & Th5 & complete & A \\
\hline 10 & 68 & 1,74 & 97 & $\mathrm{~m}$ & Th4 & incomplete & B \\
\hline
\end{tabular}

\subsubsection{Adjustable chair for postural actuation}

Experiments were performed with the Dynasit chair which allows for sagital postural actuation and actuated pelvic rotation independent from the backrest and seat support. In addition, the chair contains a concept for actuated tuberal support. Seat and back angle are independently adjustable and by adjusting the configuration the pelvis is actuated to rotate in the sagital plane 
without affecting the orientation of the trunk and thighs (see Figure. 1). The fact that the pivot point of the seat is located right beneath the ischial tuberosities and the pivot point of the backrest is located at the $3^{\text {rd }}$ lumbar vertebrae results in independent movement of the pelvis which minimizes eventual shear forces during actuation.

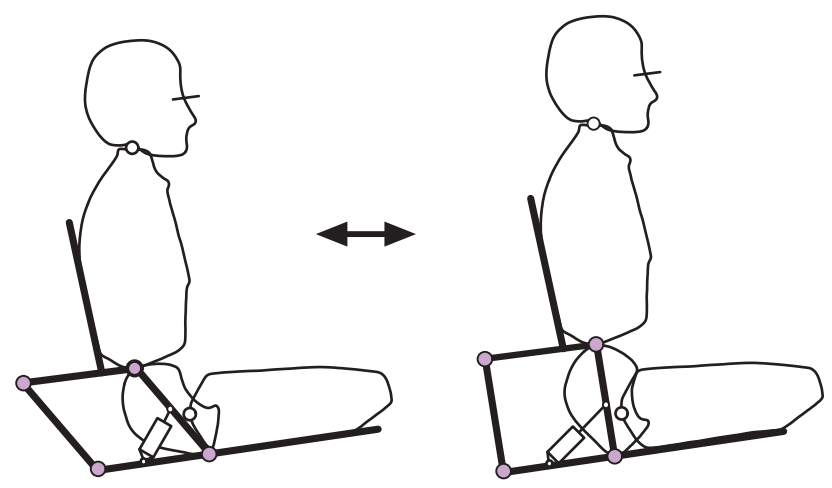

Figure 1: Concept for postural actuation and pelvic rotation in the sagital plane

Aligned with the seat pivot point and with an inter-tuberal distance of $120 \mathrm{~mm}{ }^{13}$, two adjustable support elements were integrated in the seat plane (see Figure 2). The chair was equipped with a cushion, consisting of a wooden base plate with $100 \mathrm{~mm}$ of industrial foam as is commonly used in wheelchair cushions. Drill holes $(\varnothing 90 \mathrm{~mm})$ were made above the two adjustable support elements to allow for tuberal actuation. The actuators were covered with industrial foam. 

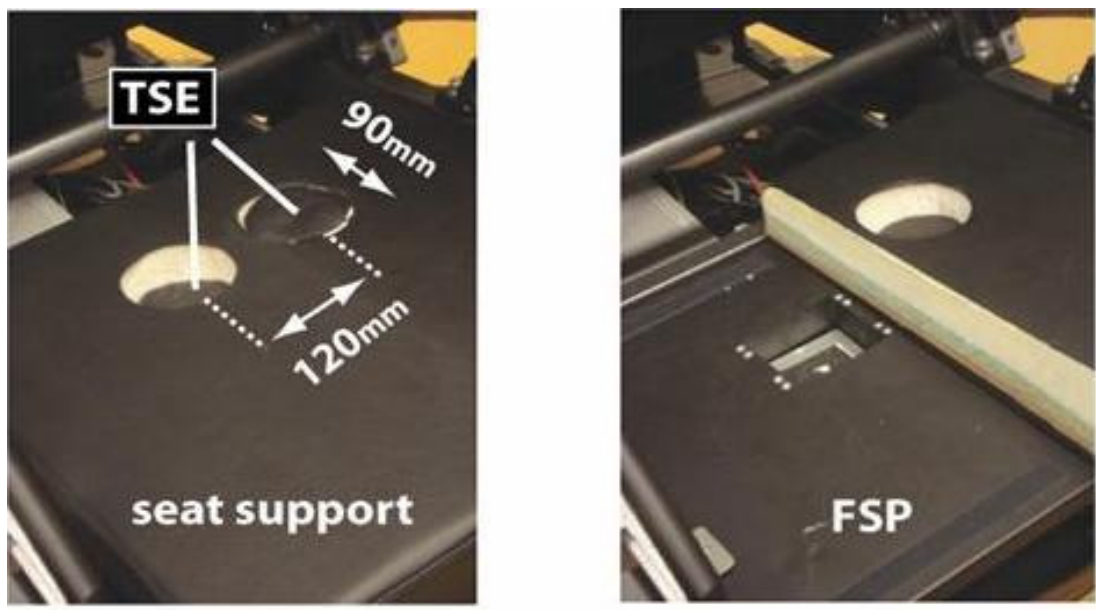

Figure 2: The left part of figure 2 shows the cushion (seat support) of the Dynasit chair in which two round cutouts (Ø $90 \mathrm{~mm})$ were made two allow for actuation of the adjustable tuberal support elements (TSE). These tuberal support elements, constructed with an inter-tuberal distance of $120 \mathrm{~mm}$ were covered with industrial foam. One TSE is lowered, the other is at level with the seat support. The right part of figure 2 shows the base of the seat of the Dynasit chair (FSP)(at the left), in which the adjustable tuberal support elements are integrated (TSE), and part of the cushion (at the right). Both Tuberal Support Elements are lowered.

\subsubsection{Tissue oxygenation}

Tissue oxygenation $\left(\mathrm{SO}_{2}\right.$, which reflects the oxygen saturation of hemoglobin) was measured with the Oxygen-to-See (O2C, LEA Medizintechnik Giessen, Germany). The O2C uses laser Doppler flowmetry and diffuse reflectance spectroscopy for non-invasive determination of oxygen supply in tissue perfused with blood. At present, the $\mathrm{O} 2 \mathrm{C}$ is the only device capable of non-invasively measuring the subcutaneous tissue oxygenation up to a measurement depth of 8 $\mathrm{mm}$, reaching the muscle tissue. The $\mathrm{O} 2 \mathrm{C}$ transmits continuous wave laser light $(830 \mathrm{~nm}$ and $30 \mathrm{~mW}$ ) and white light (500-800 nm, $1 \mathrm{~nm}$ resolution, $20 \mathrm{~W}$ ). The sample frequency of the O2C is $0.5 \mathrm{~Hz}$, which makes it suitable to measure the dynamic response in blood flow in reaction to the changing seating load. The fiber-optic probes were custom-made to prevent interference with the seating interface. No confounding effects of the probes on the measurements are expected. The probes were attached to the skin with surgical tapes to prevent displacement during the study.

\subsubsection{Experimental setup and measurement procedures}

Before and after the study, the skin of the buttocks of the subjects was inspected for tissue breakdown by a qualified and specialized nurse. An experimental protocol was developed in 
which the sitting load was altered every five minutes by actuation of the experimental chair. This frequency was obtained from a previous study in which healthy sitting behavior was analyzed and a change in sitting posture was found every eight minutes [9]. However, sitting periods of 8 minutes would result in extensive sitting time; therefore sitting periods of 5 minutes were chosen. Three types of actuation were imposed with the Dynasit chair in a nonrandomized non-controlled order: $[\mathrm{A}]$ change in sitting posture by adjusting the configuration of the seat and back of the chair, [B] static tubera actuation (STA) by means of the tuberal support elements, and [C] dynamic actuation of the pelvis (DA). The experimental protocol is displayed in figure 3 .

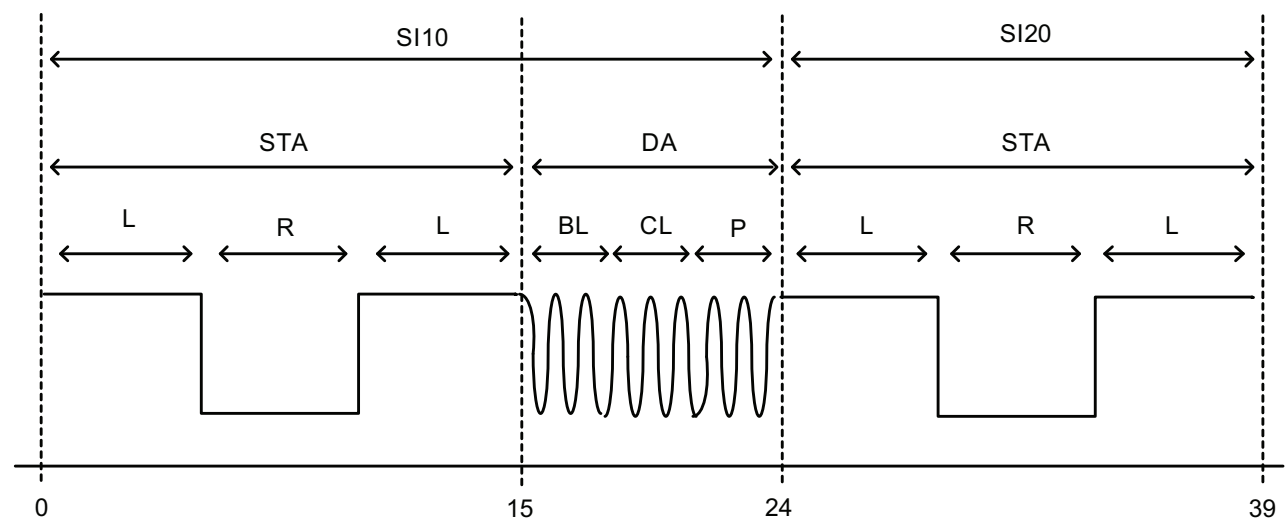

time (min)

Figure 3: Experimental protocol (SI10, Seat Inclination 10 degrees; SI20, Seat Inclination 20 degrees; STA, Static Tuberal Actuation; DA, Dynamic Actuation; L, Loaded; R, Relieved; BL, Bi-lateral; CL, Contra-lateral; P, Pelvic). See text for further explanation of the experimental protocol.

After an unloaded base-line measurement, the experiment started with STA in SI10 (seat inclination of 10 degrees). In these conditions the tuberal zones were loaded (L) and relieved (R) in alternating periods of 5 minutes. Following STA the effect of dynamic actuation of the pelvis (DA) on tissue oxygenation was investigated. In the bi-lateral condition (DA, BL), actuation of both tuberal support elements in phase were performed with an actuation frequency of $1 / 30 \mathrm{~Hz}$. In the contra-lateral condition (DA, CL) actuation of both tuberal support elements in contra-phase was performed with an actuation frequency of $1 / 30 \mathrm{~Hz}$. In the dynamic pelvic adjustment condition (DA, P) the pelvis is actuated in the sagital plane by 
dynamically changing the configuration of the chair, as can be seen in Figure 1. In addition, sitting posture was changed to SI20 (seat inclination of 20 degrees) after the DA and the STA with loaded and relieved conditions was repeated. The total experimental protocol lasted 39 minutes.

\subsubsection{Data analysis}

Given the repeated measures design and the low number of participants, non-parametric permutation tests for paired replicates were used to investigate the ability of the Dynasit chair to impose dynamic sitting behavior. The Wilcoxson signed rank test for paired replicated was used to statistically compare the average values of the different sitting conditions $[A, B, C]$ with the base-line measurement and with the first loaded condition (STA SI10). In addition this test was performed to statistically analyze differences within the groups (STA SI10 and SI20 and DA SI10). The significance interval was set at 95\%. Because of the explorative nature of this study, no correction for possible spurious significance levels was required [15].

\subsection{Results}

Inspection of the skin of the subjects after completion of the experiment revealed no abnormalities.

All 10 subjects completed the experiment. However, tissue oxygenation data was incomplete for one subject (nr. 10) as a result of technical problems; therefore analysis has been performed on the remaining nine subjects. Average values for (sub-) cutaneous oxygenation and their statistical significance relative to the base-line measurement and the different sitting conditions are given in Figure 4. 


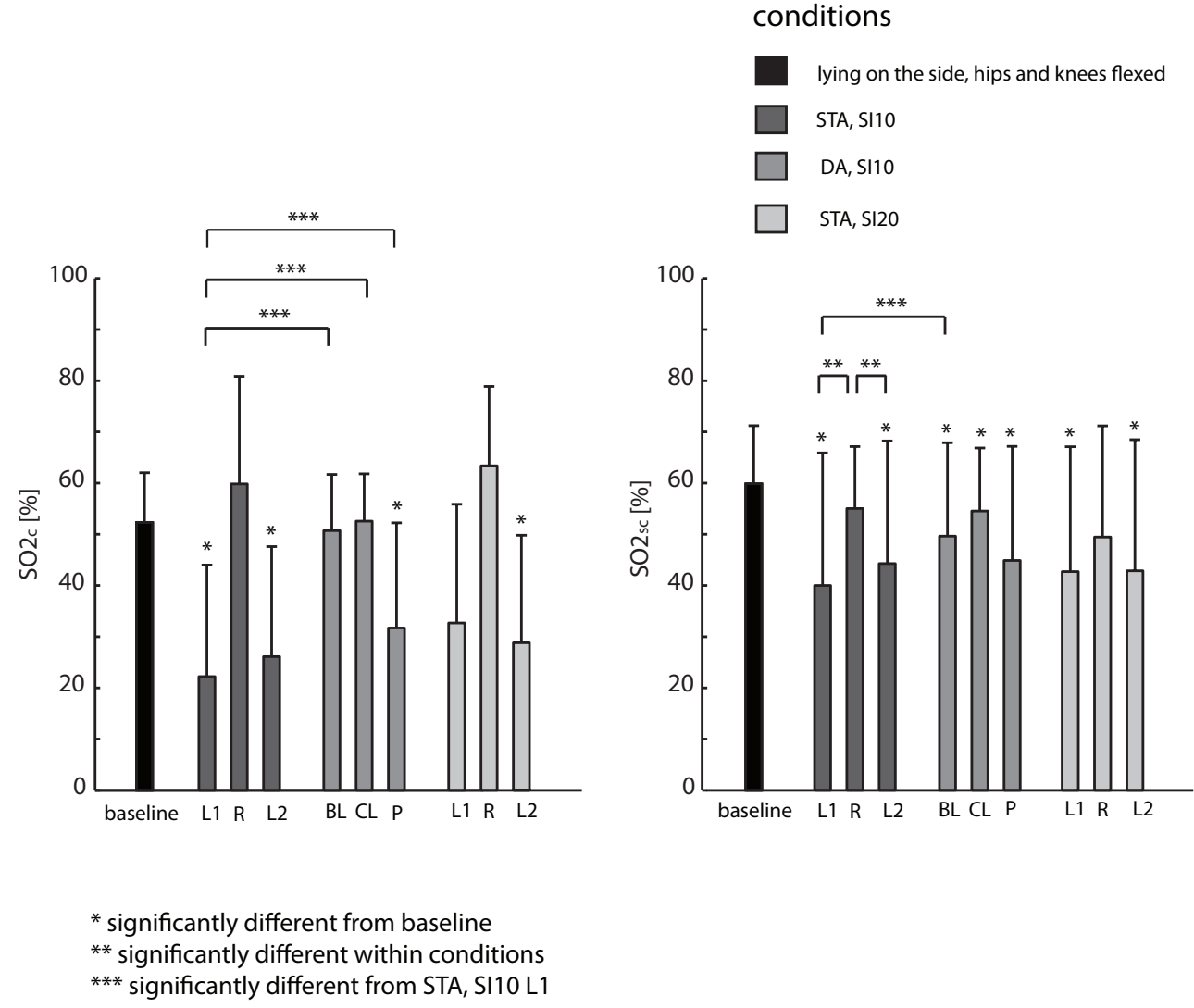

Figure 4: Average cutaneous SO2 (SO2c, left) and subcutaneous SO2 (SO2sc, right) oxygenation and their statistical significance. (SI10, Seat Inclination 10 degrees; SI20, Seat Inclination 20 degrees; ST A, Static Tuberal Actuation; DA, Dynamic Actuation; L, Loaded; R, Relieved; BL, Bi-lateral; CL, Contra-lateral; P, Pelvic).

During the base-line measurement cutaneous oxygenation is $52.3 \pm 9.7 \%$ while subcutaneous tissue oxygenation is $59.9 \pm 11.3 \%$. In the first loaded STA SI10 condition minimum cutaneous $\mathrm{SO}_{2}$ values of $22.2 \pm 21.9 \%$ and subcutaneous $\mathrm{SO}_{2}$ values of $40.0 \pm 25.9 \%$ were found. Maximal cutaneous $\mathrm{SO}_{2}$ values of $63.4 \pm 15.5$ and subcutaneous $\mathrm{SO}_{2}$ values of $55.0 \pm$ 12.1\% were found in the relieved STA SI20 and relieved STA SI10 condition respectively. Maximal cutaneous $\mathrm{SO}_{2}$ values differed statistically from the reference static sitting posture (STA SI 10, L). Unloaded cutaneous and subcutaneous oxygenation values (SI10 R and SI20 R) did not differ significantly from the baseline values. 
The increased tissue oxygenation value due to the actuation shows that there is a significant effect of actuation of the tuberal support elements on the subcutaneous tissue oxygenation $(\mathrm{p}<0.05)$ in the SI10 sitting condition. Furthermore, dynamic tubera actuation (DA BL and DA CL) caused significant positive changes in cutaneous tissue oxygenation compared to the fully supported static condition. Dynamic tubera actuation (DA BL) showed significant positive effects on the subcutaneous tissue oxygenation.

\subsection{Discussion}

In order to prevent pressure ulcers, the dynamic sitting behavior of healthy subjects can be used as a reference value for seating devices that alternate the sitting load. The present study investigated the effect of imposed dynamic sitting behavior, by means of the Dynasit chair, on cutaneous and subcutaneous tissue oxygenation in individuals with spinal cord disorders. It can be concluded that the Dynasit chair is effective in alternating the seating load in spinal cord injured subjects, resulting in significantly elevated cutaneous and subcutaneous tissue oxygenation values compared to a reference static sitting posture. In the present study, increases in $\mathrm{SO}_{2}$ values of $41.3 \%$ (cutaneous) and $15 \%$ (subcutaneous) were found as a result of actuation. While the increase in $\mathrm{SO} 2$ as a result of a single posture shift in healthy subjects is $2.2 \pm 2.4 \%$ [9], this indicates the ability and potential of the Dynasit chair to increase the tissue oxygenation and to reduce the chance of tissue degradation. While oxygenation in the loaded sitting conditions (SI10 L1, L2 and SI20 L1, L2) were significantly lower than baseline, unloaded cutaneous and subcutaneous oxygenation values (SI10 R and SI20 R) did not differ significantly from the baseline values. During unloading of the ischial tuberosities, tissue oxygenation was as high as the unloaded baseline values. The Dynasit chair is therefore capable of imposing a dynamic sitting behavior that mimics the sitting behavior of healthy subjects as described in the literature $[8,9]$.

Previous research has shown the positive effects of alternating sitting postures on the buttock load in healthy subjects and spinal cord injured patients. Significant effects of different sitting postures on interface pressure were found [16-17] and previous experiments with the Dynasit chair confirmed positive effects of postural variation on sitting load in healthy subjects [11-13]. Other studies demonstrated the ability to change cutaneous tissue oxygenation by means of a dynamic cushion [6] and by means of a wheelchair in which the back part of the seat could be lowered to relieve the ischial tuberosities [7]. The present study confirmed the ability of a seating device to create an alternating load on the seating surface of individuals with spinal 
cord disorders and, unlike the aforementioned studies, based its experimental protocol on the sitting behavior of healthy subjects [9].

Like previous studies, the present study used the non-invasive measurement of cutaneous oxygenation. In addition, it non-invasively measured the subcutaneous tissue oxygenation by means of the $\mathrm{O} 2 \mathrm{C}$. The $\mathrm{O} 2 \mathrm{C}$ is at present the only device that is capable of non-invasively measuring the oxygenation of the subcutaneous tissue up to a maximum depth of approximately 8 millimeters. Previously used techniques to quantify tissue perfusion or oxygenation do not possess penetration depths sufficient to reach the muscle tissue and therefore are restricted to measure the perfusion and oxygen saturation of the skin and subcutis only [18-20]. However, because of its high metabolic demand, muscle tissue is most sensitive for developing pressure ulcers [21]. During sitting the m. Gluteus Maximus is located at approximately 7 to 15 millimeters deep, depending on the anatomy and geometry of the other tissue structures. This means that in this study part of the signal from the subcutaneous measurement indeed originates from the $\mathrm{m}$. Gluteus Maximus, and part of the signal originated from other subcutaneous structures.

The present study demonstrated higher cutaneous and subcutaneous tissue oxygenation values as a result of dynamic sitting. Tissue oxygenation is an important factor in the development of especially deep tissue injury. It is plausible that the elevation of the tissue oxygenation to a level comparable with the unloaded baseline values indicates a reduced change of tissue degradation during long term sitting. However, more factors play a role in the development of pressure ulcers and deep tissue injury. Friction and shear are associated with the development of superficial pressure ulcers $[22,23]$. Deformation of the tissue is an important factor in the development of deep tissue injury [24, 25]. Individual factors that influence the ability of the tissue to withstand load, like level of mobility, atrophy and vascularization also play a role. Based on the assumption that higher oxygenation leads to a reduced chance of tissue degradation, and accounting for the factors mentioned earlier, it is plausible to state that individuals with spinal cord disorders should be able to sit for longer periods of time without tissue breakdown if dynamic sitting behavior is imposed compared to static sitting.

It can be concluded that the developed system for actuated dynamic sitting support is effective in alternating the seating load in individuals with a spinal cord disorder. The imposed dynamic seating pattern that alternates the load on the sitting surface (by means of static and dynamic actuation of the tuberal support elements), resulted in significantly elevated cutaneous and subcutaneous tissue oxygenation compared to the reference static sitting posture. 
Consequently, the Dynasit chair is capable of imposing dynamic sitting behavior in individuals with a spinal cord disorder and as such reducing the chance of tissue degradation compared to static sitting. This reduced chance of tissue degradation should enable individuals that use a wheelchair for their mobility to sit for prolonged periods of time without tissue breakdown. At present, the Dynasit chair is an experimental seating device intended for research purposes. However, conceptual parts of the Dynasit chair, like the concept for tuberal actuation, can be integrated into standard wheelchairs. 


\subsection{References}

1. Brienza D. Pressure ulcers, more questions than answers. Proceedings of the $23^{\text {rd }}$ International Seating Symposium, Orlando, Fl 2007.

2. Garber SL, Rintala DH. Pressure ulcers in veterans with spinal cord injury: a retrospective study. Journal of Rehabilitation Research and Development. 2003 Sep-Oct;40(5):433-41

3. Agency for Health Care Policy and Research (AHCPR). Treatment of pressure ulcers, in: Clinical Practice guidelines no.15 US Department of health and Human Services, Publication no. 95-0652, 1994.

4. Merbitz CT, King RB, Bleiberg J, Grip JC. Wheelchair push-ups: measuring pressure relief frequency. Archives of Physical and Medical Rehabilitation. 1985 Jul; 66(7):433-8.

5. Stockton L, Parker D. Pressure relief behavior and the prevention of pressure ulcers in wheelchair users in the community. Journal of Tissue Viability. 2002 Jul; 12(3):84, 88-90, 92 passim.

6. Bader DL. The recovery characteristics of soft tissues following repeated loading. Journal of Rehabilitation Research and Development, 1990, 27, 141-50

7. Makhsous M, Lin F, Hendrix RW, Hepler M, Zhang LQ. Sitting with adjustable ischial and back supports: biomechanical changes. Spine, 2003, 28, 1113-21; discussion 1121-2.

8. Linder-Ganz E, Scheinowitz M, Yizhar Z, Margulies SS, Gefen A. How do normals move during prolonged wheelchair-sitting? Technology and Health Care, 2007, 15(3), 198-202.

9. Reenalda J, van Geffen P, Nederhand M, Jannink M, IJzerman M, Rietman JS. Analysis of healthy sitting behavior: Interface Pressure distribution and subcutaneous tissue oxygenation. Submitted: Journal of Rehabilitation Research and Development 2009.

10. Van Geffen P, Molier BI, Reenalda J, Veltink PH, Koopman BF. Body segments decoupling in sitting: Control of body posture from automatic chair adjustments. Journal of Biomechanics. 2008 Dec 5; 41(16):3419-25.

11. Van Geffen P, Reenalda J, Veltink PH, Koopman BF. Effects of sagittal postural adjustments on seat reaction load. Journal of Biomechanics. 2008 Jul 19; 41(10):2237-45.

12. Reenalda J, van Geffen P, Nederhand M, Veltink P, Koopman B, Jannink M, IJzerman M, Rietman JS. Effects of Actuated Pelvic Rotation on Sitting Forces and Pressure Distribution. Proceeding of the 2008 RESNA Conference, Arlington VA.

13. Reenalda J, van Geffen P, Nederhand M, Jannink M, IJzerman M, Rietman JS. Effect of actuated tuberal support on sitting load, tissue perfusion and tissue oxygenation. Submitted Journal of Rehabilitation Research and Development, 2009.

14. Linder-Ganz E, Shabshin N, Itzchak Y,Gefen A. Assessment of mechanical conditions in sub-dermal tissues during sitting: a combined experimental-MRI and finite element approach. Journal of Biomechanics, 2007; 40: 1443-54

15. Bender R, Lange S. Adjusting for multiple testing - when and how? Journal of clinical epidemiology, 2001; 54: 343-349.

16. Hobson D. Comparative effects of posture on pressure and shear at the body-seat interface. Journal of Rehabilitation Research and Development, 1992 Fall;29(4):21-31.

17. Maurer C L, Sprigle S. Effect of seat inclination on seated pressures of individuals with spinal cord injury. Physical Therapy, 2004 Mar;84(3):255-61. 
18. Assaoui R, Lacoste M, Dansereau J. Analysis of sliding and pressure distribution during a repositioning of persons in a simulator chair. Analysis of sliding and pressure distribution during a repositioning of persons in a simulator chair. IEEE Transaction on Neural Systems and Rehabilitation Engineering. 2001 Jun; $9(2): 215-24$.

19. Mayrovitz HN, Macdonald J, Smith JR. Blood perfusion hyperemia in response to graded loading of human heels assessed by laser-Doppler imaging. Clinical Physiology. 1999 Sep;

20. Sprigle S, Linden M, Riordan B. Analysis of localized erythema using clinical indicators and spectroscopy. Ostomy Wound Manage. 2003, 49(3):42-52.

21. Salcido R, Fisher SB, Donofrio JC, Bieschke N, Knapp C, Liang R, LeGrand EK, Carney JM. An animal model and computer-controlled surface pressure delivery 19(5):351-9.

22. Ohura T, Takahashi M, Ohura N Jr. Influence of external forces (pressure and shear force) on superficial layer and subcutis of porcine skin and effects of dressing materials: are dressing materials beneficial for reducing pressure and shear force in tissues? Wound Repair Regen. 2008 Jan-Feb; 16(1):102-7.

23. Linder-Ganz E, Gefen A. The effects of pressure and shear on capillary closure in the microstructure of skeletal muscles. Annals of Biomedical Engineering. 2007 Dec; 35(12):2095-107.

24. Ceelen KK, Stekelenburg A, Mulders JL, Strijkers GJ, Baaijens FP, Nicolay K, Oomens CW. Validation of a Numerical Model of Skeletal Muscle Compression with MR Tagging: A Contribution to Pressure Ulcer Research. Journal of Biomechanical Engineering. 2008 Dec; 130(6):061015.

25. Stekelenburg A, Strijkers GJ, Parusel H, Bader DL, Nicolay K, Oomens CW. Role of ischemia and deformation in the onset of compression-induced deep tissue injury: MRI-based studies in a rat model. Journal of Applied Physiology. 2007 May; 102(5):2002-11. 
CHAPTER 7

DISCUSSION AND CONCLUSIONS 


\section{$7 \quad$ Discussion and conclusions}

\subsection{Main study findings and outline of this chapter.}

The present thesis intends to contribute to the clinical problem of pressure ulcers in spinal cord injured patients by investigating the benefits of a different approach at the prevention of pressure ulcers. In contrast to the current clinical practice of optimizing one static sitting posture, dynamic sitting based on a reference of healthy sitting behavior, has been imposed by means of the Dynasit chair. The main finding of this thesis was that dynamic sitting indeed can be realized by means of actuation with the Dynasit chair. Further, this imposed sitting behavior resulted in significant elevation of the cutaneous tissue oxygenation and a positive trend for elevation of the subcutaneous tissue oxygenation. By assuming that the oxygenation of the tissue is related directly to the tissue viability, an increase in tissue oxygenation suggests an increase in tissue viability. As a consequence, the wheelchair user can sit for prolonged periods of time without tissue breakdown. Dynamic sitting can therefore be used as an effective strategy in the prevention of pressure ulcers. The present chapter discusses the different chapters of this thesis as well as their consequences to clinical decision making. First, the different steps taken to achieve the main goal of this thesis are described. Following this description, the value of tissue perfusion and tissue oxygenation in predicting the risk of pressure ulcers development and the effects of dynamic sitting in healthy individuals and spinal cord injured patient will be discussed. The present chapter concludes with the clinical implications and generalization of the results.

\subsection{From an etiological model to a dynamic sitting chair}

An etiological model has been introduced in chapter 1 of this thesis to obtain more insight into the development of pressure ulcers. From this etiological model it was derived that more insight is needed into the quantification of the external and internal load and the subsequent relation with the development of pressure ulcers. From the etiological model, three subsequent study steps were defined in order to achieve the main goal of this thesis. These include (1) the assessment of tissue oxygenation as an adjunct to quantify the risk of developing pressure ulcers, (2) the assessment of reference sitting behavior in healthy subjects and (3) the development and validation of a sitting device to impose dynamic sitting.

1) Further knowledge on the relation between the interface pressure and the development of pressure ulcers by measuring the tissue oxygenation. 
Up to date, a clear quantitative model to predict pressure ulcer susceptibility is lacking. In order to gain more insight into this relation a systematic review on the literature has been performed. It was found that there appears to be a weak qualitative relation between the interface pressure and the development of pressure ulcers. Unfortunately, no conclusive clinical threshold for the interface pressure was found. Combined with the influence of subject specific characteristics, the low internal validity of interface pressure measurement and an unclear relation between pressure magnitude and duration, this results in the fact that no quantification of the predictive or prognostic value of interface pressure can be given. Therefore, the use of interface pressure as a clinical tool to prevent pressure ulcers is questionable, indicating a need for other clinically usable tools that can non-invasively quantify the load on the tissue. In order to quantify the load on the tissue, the Oxygen to See (O2C, LEA Medizintechnik, Giessen Germany) is introduced in chapter 3. The $\mathrm{O} 2 \mathrm{C}$ is a device that combines laser Doppler flowmetry and white light spectrophotometry to measure the cutaneous and subcutaneous tissue perfusion and oxygenation non-invasively. In addition to the present perfusion and oxygenation measurement techniques, the $\mathrm{O} 2 \mathrm{C}$ possesses a measurement depth of $8 \mathrm{~mm}$ at maximum. The $\mathrm{O} 2 \mathrm{C}$ is therefore capable of assessing the effects of the external load on the skin and subcutaneous tissue.

\section{2) To establish a reference for dynamic sitting behavior in bealthy individuals.}

From the systematic review of the literature it was concluded that there is a need for an alternative way of preventing pressure ulcers, because no clinically usable threshold for the use of interface pressure could be identified. Healthy individuals do not develop pressure ulcers due to a continuous variation in sitting posture. Therefore, an analysis of the dynamic sitting behavior of healthy subjects has been performed. The $\mathrm{O} 2 \mathrm{C}$ was used to measure the perfusion and oxygenation of the buttocks tissue of healthy subjects in order to quantify this sitting behavior. It was found that healthy subjects change their sitting posture at least every eight minutes of which each posture shift corresponded to a significant increase in subcutaneous tissue oxygenation. The frequency of the posture shifts performed by the healthy individuals was higher than the clinical guidelines developed by the Agency for Healthcare Research and Quality (AHRQ, AHCPR guidelines). According to these guidelines wheelchair users should reposition themselves every 15 minutes. Individuals who cannot reposition themselves should be repositioned by outside assistance at least every hour [1]. Previous research indicated that 
the frequency of the performed posture shifts by wheelchair users is far less than the AHRQ guidelines and the recommended sitting time from this study [2, 3]. It can be concluded from the analysis of the healthy sitting behavior in chapter 3 that wheelchair users should to reposition more frequently. In addition current clinical AHRQ guidelines are no longer valid and in need of modifications. It is advisable for wheelchair users to change their sitting posture at least every eight minutes in order to prevent pressure ulcer development.

3) To develop and validate an experimental sitting device (the Dynasit chair) to impose dynamic sitting controlled by the established reference values.

In order to impose dynamic sitting behavior the Dynasit chair has been developed. It was found in chapter 4 that it is possible with the Dynasit chair to adjust the seat angle, back angle and pelvic orientation in such a way that the cutaneous and subcutaneous tissue oxygenation increased in a group of healthy individuals. However, although significant differences were found, the actuation frequency was too high for clinical purposes as the posture was changed every minute. With lower actuation frequencies, larger effect actuation was needed, especially to relieve the ischial tuberosities. To overcome this, the system for actuated tuberal support was developed in order to create complete unloading of the tuberal regions. It was found in chapter 5 that the system for actuated tuberal support is effective in significantly elevating the subcutaneous tissue perfusion and oxygenation in healthy individuals.

The last step was to impose healthy dynamic sitting behavior by means of the Dynasit chair on individuals with a spinal cord injury (chapter 6). The Imposed dynamic sitting pattern, a combination of different sitting postures, pelvic orientations and tuberal support, resulted in elevation of the cutaneous tissue oxygenation and a positive trend for elevation of the subcutaneous tissue oxygenation. It can be speculated that these increased oxygenation values show increased tissue viability, allowing wheelchair users to sit for prolonged periods of time without tissue breakdown.

\subsection{The value of tissue perfusion and tissue oxygenation in predicting pressure ulcer risk.}

The quantification of the external load and its relation with pressure ulcer development was one of the missing links in the etiological model. The systematic review (chapter 2) showed that for clinical purposes, the value of interface pressure measurement is limited. Besides the 
technical limitations of the measurement devices (limited test-retest reliability due to creep, drift and hysteresis of the pressure sensors), the measurement of interface pressure provides only quantification of the external load. In addition it has been suggested that the capillary closure, which causes ischemia, depends on local pressure gradients across the blood vessel and not just on the interface pressure at skin level [4]. Therefore, the measurement of interface pressure alone is not suitable for the quantification of the internal load. From the etiological model it can also be concluded that the internal tissue load, quantified in the subcutaneous tissue perfusion and oxygenation, is an important factor in the development of deep pressure ulcers. The $\mathrm{O} 2 \mathrm{C}$ was used to measure the cutaneous and subcutaneous tissue perfusion and oxygenation non-invasively. Although the $\mathrm{O} 2 \mathrm{C}$ has been used in other research fields and has been proven to be reliable [5-8], it had not been used in the research field of pressure ulcers. Prior to the actual studies described in this thesis, several pilot measurements were performed in order to gain more insight into the applicability of the $\mathrm{O} 2 \mathrm{C}$ in the present research area. Pilot measurements with phantoms that were simulating human tissues and Monte-Carlo modeling showed that the maximum measurement depth of the $\mathrm{O} 2 \mathrm{C}$ is approximately $8 \mathrm{~mm}$ [9]. This measurement depth is approximately 4 times as deep as the depth reached with current measurement techniques $(\mathrm{tcPO}$, laser Doppler flowmetry, tissue reflectance spectrometry), that are not able to provide information of the at-risk tissue. The maximal measurement depth of the $\mathrm{O} 2 \mathrm{C}(8 \mathrm{~mm})$ should be sufficient to reach during sitting the muscle tissue of the m. gluteus maximus. This is the region with the highest internal load when the tissue is compressed against the bony prominences of the pelvis. The muscle tissue is therefore most sensitive to developing pressure ulcers due to its high metabolic demand [10].

Important factor is that the $\mathrm{O} 2 \mathrm{C}$ is capable of measuring the subcutaneous tissue perfusion and oxygenation non-invasively. The probes of the $\mathrm{O} 2 \mathrm{C}$ were custom made with a maximum thickness of $4 \mathrm{~mm}$ with the intention not to disturb the interface between seat and buttocks. Although no distinct influence of the $\mathrm{O} 2 \mathrm{C}$ probes could be witnessed during and after the experiments on interface pressure and blood flow, some form of reactive hyperemia (blanchable redness) was visible during visual inspection by the nursing staff after removal of the probes. Therefore it is advisable to limit sitting time during $\mathrm{O} 2 \mathrm{C}$ measurements at 60 minutes. As a result the $\mathrm{O} 2 \mathrm{C}$ is at present only suitable for measurements in the experimental setting. Further development of the probes is needed before application in the clinical setting 
can be considered. Smaller and thinner probes are necessary to prevent tissue breakdown due to long term probes placement.

For clinical use of the $\mathrm{O} 2 \mathrm{C}$, the same limitations apply as to the measurement of interface pressure. Although the measurement of the tissue oxygenation present a more direct assessment of the internal load compared to the measurement of the interface pressure, at present no threshold values exist for the viability of the tissue. Therefore, it is not known which levels of tissue oxygenation are necessary to maintain sufficient tissue viability. Standardized experiments with a pressure indenter should provide information about the reaction of the subcutaneous tissue to controlled external load. Results from these experiments can be coupled to data derived from Finite Element Models to assist future threshold development. Future studies should focus on the combination of subject specific Finite Element Models combined with interface pressure and perfusion and oxygenation measurements. In addition the $\mathrm{O} 2 \mathrm{C}$ can be used to clinically validate data about tissue deformation, derived from animal experiments and modeling. Longitudinal (randomized) controlled clinical trials are necessary to determine the exact relation between the subcutaneous tissue oxygenation and the development of pressure ulcers. These studies are necessary to develop threshold values and can aid in the future prevention of pressure ulcers.

The use of electric gluteal muscle stimulation has been mentioned in the introduction section of this thesis as a promising method to decrease interface pressures (by reversing atrophic effects and increasing muscle bulk) and increase gluteal perfusion and as such to prevent pressure ulcers [11, 12]. Due to its non-invasive measurement method and it measurement depth, the $\mathrm{O} 2 \mathrm{C}$ will be capable of measuring the effectiveness of the electric gluteal muscle stimulation on cutaneous and subcutaneous tissue perfusion and oxygenation. However, the use of electrical gluteal muscle stimulation was beyond the scope of this thesis.

\subsection{The effects of dynamic sitting in healthy individuals and spinal cord injured patients}

The present study was the first study that proposed dynamic sitting behavior of healthy subjects being a reference for the sitting behavior of individuals with a spinal cord injury. The study on spinal cord injured, as presented in chapter 6 , demonstrated the positive effects of the imposed dynamic sitting behavior in spinal cord injured individuals. The dynamic sitting behavior resulted in significant elevation of the cutaneous tissue oxygenation and a positive 
trend for elevation of the subcutaneous tissue oxygenation. Therefore, dynamic sitting, compared to static sitting can be recommended for the clinical situation.

Dynamic sitting refers to all sitting behavior intended to relieve the tissues thereby preventing pressure ulcers. The extent to which sitting behavior is dynamic in spinal cord injured individuals depends on the level mobility of the individual and is mostly a result of the height of the lesion. Generally stated, higher lesions result in less dynamic sitting behavior. If a wheelchair user lacks sufficient motor control to perform posture shifts to relieve tissue load, dynamic sitting interventions are necessary. These sitting interventions can consist of dynamic cushions, of automated postural adjustments performed by the electrical wheelchair (for instance the "tilt in space" function) and of postural alterations manually performed by caregivers. Another intervention that can be regarded as a dynamic sitting intervention is the use of electrical stimulation of the gluteus muscle. Current dynamic sitting interventions use an actuation frequency based merely on practice based evidence [13, 14]. The sitting behavior of healthy subjects was first investigated by Linder-Ganz et al. [15]. They found that healthy individuals change their posture approximately every 9 minutes in the sagital plane (6.7 times per hour) and approximately every 6 minutes in the frontal plane (10 times an hour). Compared to the study of Linder-Ganz et al. subjects in the present study (chapter 3) moved more frequently in the sagital plane (80\%) and less frequently in the frontal plane $(20 \%)$. The study of Linder-Ganz et al. only quantified variation in external pressure without taking into account the internal pressure. The present study used the relative measure of the dispersion index to quantify the interface pressure. In addition the measurement of sub-cutaneous tissue oxygenation was used as a determinant of the internal pressure. In the majority of the subjects, the posture shifts, identified by a change in dispersion index, were accompanied by an increase in subcutaneous oxygen saturation. As a result of the posture shifts, subcutaneous oxygen saturation increased on average $2.2 \%$. This small but significant increase in tissue oxygenation indicates the positive effects of posture shifts on tissue viability. This means that the present analysis of healthy sitting behavior identified posture shifts, intended to relieve the internal load, creating an increase in tissue oxygenation. It can be assumed that these posture shifts do play an important role in the natural way of preventing pressure ulcers.

To impose dynamic sitting behavior on subjects that lack sufficient trunk motor function to reposition themselves, the Dynasit chair was developed. As identified in the analysis of healthy sitting behavior, the posture shifts are a mix of posture shifts in the sagital and posture shifts in the frontal plane. Most posture shifts employed by healthy subjects were in the sagital plane 
$(80 \%)$. The Dynasit chair therefore contains a mechanical concepts for postural variation in the sagital plane (parallelogram, described in depth in chapter 4) and a concept for actuated tuberal load regulation (actuated tuberal support, described in depth in chapter 5). Although healthy sitting behavior was composed of mostly posture shifts in the sagital plane, the studies performed on healthy subjects with the Dynasit chair showed that the imposed sitting behavior with Dynasit chair should consist mostly of actuation in the frontal plane (tuberal actuation). The studies described in chapter 4 and 5 demonstrated larger effects of actuation in the frontal plane (actuated tuberal support) compared to actuation in the sagital plane (parallelogram).

Although significant effects of postural actuation in the sagital plane were found on cutaneous and subcutaneous tissue oxygenation, the effects of the tuberal actuation clearly demonstrated larger effects. This can be explained by the fact that complete off-loading of the tuberal zones could be achieved by the actuation of the tuberal support while during postural actuation in the sagital plane the tuberal regions still remain loaded. This phenomenon is a result of the construction of the Dynasit chair. In order to independently actuate the pelvis and the trunk and thighs and to minimize shear forces, decoupling of the different body segments is necessary. Decoupling of the body segments can only be achieved by using two pivot points. This is in contrast to current wheelchair that are equipped with only one pivot point. The pivot point of the backrest is located approximately at the $3^{\text {rd }}$ and $4^{\text {th }}$ lumbar vertebrae and the pivot point of the seat is located under the ischial tuberosities [16]. Consequently, the ischial tuberosities remain loaded during actuation in the sagital plane [17]. Despite this continuous external loading, significant changes could be observed in the cutaneous and subcutaneous tissue oxygenation, supporting the hypothesis that the internal load is not equal to the external load.

\subsection{Clinical implication and generalization of the results}

In chapter 2 of this thesis it was identified that no interface pressure threshold for the development of pressure ulcers could be given. Therefore the sitting behavior of healthy subject was proposed, in chapter 3, as a reference value for the sitting behavior of wheelchair users at-risk of developing pressure ulcers. By measuring the interface pressure distribution and the cutaneous and subcutaneous tissue oxygenation, it was found that healthy individuals change their sitting behavior at least every eight minutes. To prevent pressure ulcer development, the AHRQ recommends that wheelchair users shift their sitting posture at least every hour. In addition, subjects who have sufficient upper body motor function are advised to 
shift their posture every fifteen minutes. The present study shows that the AHRQ guidelines are in need of modification because a higher repositioning frequency is needed to maintain tissue viability. The advised repositioning frequency is well below the repositioning frequency as performed by the healthy individuals in this study. Anecdotally, the original two-hourly turning interval (eventually changed to hourly turning intervals) is attributed to the length of time taken for nurses in the Crimean War Hospitals to reposition all patient at both sides of the ward and start again. The AHRQ guidelines are therefore based merely on clinical observations and lack a clinical basis [18]. The present study actually investigated the repositioning frequency of healthy individuals. Based on the results of the present study, it can be advised that wheelchair users should reposition themselves or be repositioned every eight minutes in order to change the load on their tissues and to prevent tissue breakdown. It can be speculated however, that due to immobilization, atrophy and limited vascularization, large differences exist between the skin anatomy and structure of healthy individuals and spinal cord injured. In order to maintain tissue viability, it is therefore plausible that an even higher reposition frequency would be worth full for wheelchair users.

The Dynasit chair has been developed primarily for research purposes. In its present form it is not clinically applicable. Design parts of the Dynasit chair, can be integrated in current wheelchairs. The pivot points of the seat and back under the ischial tuberosities and at the height of the $3^{\text {rd }}$ and $4^{\text {th }}$ vertebrae respectively in combination with the parallelogram allow for independent adjustment of the different body segments (trunk, pelvis and thighs). As a result of this construction, shear forces are minimized. This could probably lead to a lower incidence of superficial pressure ulcers. In addition, the concept for tuberal actuation can easily be implemented into current wheelchair cushions and will allow for periodically unloading of the ischial regions.

The sitting time of the present study on dynamic sitting behavior was limited to 40 minutes. It will be interesting to study the longer-term effects of dynamic seating interventions on tissue viability. Longer term measurements are necessary in order to provide information about the usefulness of the Dynasit chair and its imposed sitting behavior in the clinical setting. To achieve this, the different mechanical concepts of the chair, the parallelogram and the concept for tuberal actuation, need to be integrated into conventional wheelchairs for everyday use. 


\subsection{References}

1. Agency for Health Care Policy and Research (AHCPR). Treatment of pressure ulcers, in: Clinical Practice guidelines no. 15 US Department of health and Human Services, Publication no. 95-0652, 1994.

2. Merbitz CT, King RB, Bleiberg J, Grip JC. Wheelchair push-ups: measuring pressure relief frequency. Archives of Physical and Medical Rehabilitation. 1985 Jul; 66(7):433-8.

3. Stockton L, Parker D. Pressure relief behavior and the prevention of pressure ulcers in wheelchair users in the community. Journal of Tissue Viability. 2002 Jul; 12(3):84, 88-90, 92 passim.

4. Bouten CV, Oomens CW, Baaijens FP, Bader DL. The etiology of pressure ulcers: Skin deep or muscle bound. Archives of physical and medical rehabilitation, 2003, Vol. 84:616-619.

5. Beckert S, Witte MB, Königsrainer A, Coerper S. The Impact of the Micro-Lightguide O2C for the Quantification of Tissue Ischemia in Diabetic Foot Ulcers, Diabetes Care, 2004; vol. 27, nr. 12: 2863-2867.

6. Ghazanfari M, Vogt L, Banzer W, Rhodius U. Reproducibility of non invasive blood flow measurements using laser Doppler spectroscopy. Physical and Medical Rehabilitation Kuror, 2002, vol. 12, 330-336.

7. Hölzle F, Loeffelbein DJ, Nolte D, Wolff KD. Free flap monitoring using simultaneous non-invasive laser Doppler flowmetry and tissue spectrophotometry. Journal of cranio-maxillofacial surgery, 2006, vol. 34, 25-33.

8. Knobloch K, Lichtenberg A, Pilchmaier M, Mertsching H, Krug A, klima U, Haverich, A. Microcirculation of the sternum following harvesting of the left internal mammary artery. Thoracic and cardiovascular surgery, 2003, vol. 51, 255-259.

9. Hilgerink m, Reenalda J, van Leeuwen AGJM, Steenbergen W, IJzerman MJ. Perfusion and decubitus; a performance study of the O2C. MSc thesis University of Twente, 2007.

10. Salcido R, Fisher SB, Donofrio JC, Bieschke N, Knapp C, Liang R, LeGrand EK, Carney JM. An animal model and computer-controlled surface pressure delivery system for the production of pressure ulcers. Journal of Rehabilitation Research and Development, 1995, 32(2), 149-161.

11. Levine SP, Kett RL, Gross MD, Wilson BA, Cederna PS, Juni JE. Blood flow in the gluteus maximus of seated individuals during electrical muscle stimulation. Archives of Physical and Medical Rehabilitation. 1990 Aug; 71(9):682-6.

12. Van Londen A, Herwegh M, Van der Zee CH, Daffertshofer A, Smit CA, Niezen A, Janssen TW. The effect of surface electric stimulation of the gluteal muscles on the interface pressure in seated people with spinal cord injury. Archives of physical and medical rehabilitation, 2008, 89(9):1724-1732.

13. Bader DL. The recovery characteristics of soft tissues following repeated loading. Journal of rehabilitation research and development, 1990, Vol. 27(2):141-150.

14. Makhsous M, Lin F, Patel JC, Hendrix RW, Zhang LQ, Rymer, WZ. Tissue perfusion and blood flow response in a wheelchair with adjustable ischial and back support. 27th Annual Meeting of the ASB; Toledo, September 25-27 2003.

15. Linder-Ganz E, Scheinowitz M, Yizhar Z, Margulies SS, Gefen A. How do normals move during prolonged wheelchair-sitting? Technology and Health Care, 2007, 15(3), 198-202.

16. Van Geffen P, Reenalda J, Veltink PH, Koopman BF. Effects of sagittal postural adjustments on seat reaction load. Journal of Biomechanics 2008 Jul 19;41(10):2237-45. 
17. Reenalda J, van Geffen P, Nederhand M, Veltink P, Koopman B, Jannink M, IJzerman M, Rietman H.

Effects of Actuated Pelvic Rotation on Sitting Forces and Pressure Distribution. Proceedings of the 2008 RESNA Conference, Arlington VA.

18. Hagisawa S, Ferguson-Pell M. Evidence supporting the use of two-hourly turning for pressure ulcer prevention. Journal of Tissue Viability, 2008, Aug; 17 (3), 76-81. 
Chapter 7 


\section{SUMMARY}

Pressure ulcers occur frequently in individuals that use a wheelchair for their mobility. In order to gain more insight in the development of pressure ulcer, an etiological model for superficial and deep pressure ulcers has been presented the chapter 1 of this thesis (fig 1). The different steps in the development of superficial and deep pressure ulcers are described and discussed in the introduction. Important finding was that it is at present not possible to quantify the risk of superficial and deep pressure ulcers because important links in the etiological model are still missing. This is mainly a result of technical limitations of the currently used measurement techniques.

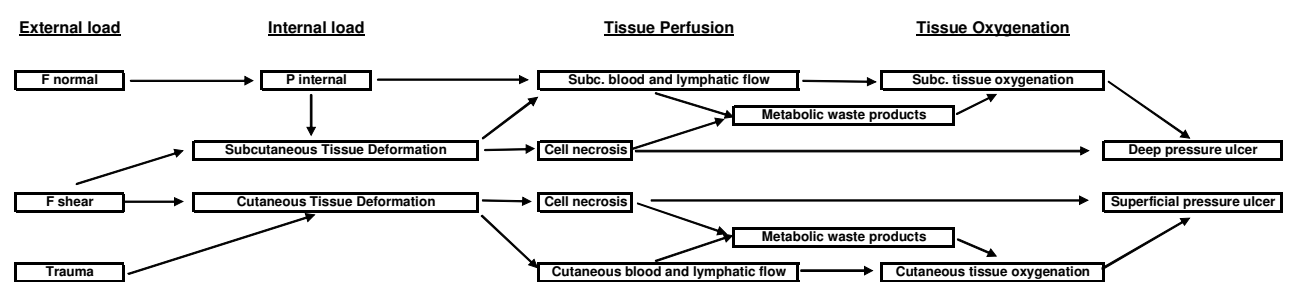

Figure 1: Etiological model for superficial and deep pressure ulcers.

From the discussion of the etiological model it became clear that important steps in the development of pressure ulcers are missing. As a result, clinically usable threshold values are lacking. In order to define the risk of pressure ulcer development and to aid pressure ulcers prevention, more research is required. Considering the external load, more insight is needed into the quantification of the external load and its relation with the development of pressure ulcers.

Because interface pressure measurements have been performed frequently in the research setting, a systematic review of the literature on interface pressure measurements and pressure ulcers could help developing a relation between the interface pressure and the development of pressure ulcers. In addition, it can be concluded from the discussion of the etiological model, that especially the internal tissue load is important in the development of pressure ulcers. However, up till now, it has not been possible to quantify the representatives of the internal tissue load (the subcutaneous tissue perfusion and oxygenation) due to technological limitations. In order to quantify the internal load and to define its relation with the external 
load, new measurement techniques are required that are able to non-invasively measure the internal state of the tissue.

At present, the clinical interventions to prevent pressure ulcers are not fully successful in defining the risk of pressure ulcer development and as such in eventually preventing pressure ulcers. As a result, the prevalence and incidence values of pressure ulcers remain unacceptably high. The present thesis proposed an alternative approach at preventing pressure ulcers. It is common sense that healthy subjects do not develop pressure ulcers due to a dynamic variation in sitting posture. This dynamic sitting behavior can be identified and used as a reference value for the optimal sitting behavior and repositioning frequency of wheelchair user at-risk of developing pressure ulcers. Because wheelchair users with a spinal cord injury often lack sufficient motor control to reposition, an experimental sitting device needs to be developed to impose this dynamic sitting behavior. The effects of the imposed dynamic sitting behavior on the tissue viability can be investigated by a measurement technique that is able to noninvasively measure the perfusion and oxygenation of the subcutaneous tissue.

\section{General conclusions of this thesis}

The main research question that has been answered in this thesis was: "Does imposing dynamic sitting behavior by means of the Dynasit chair result in elevated tissue viability in spinal cord injured individuals?" In order to answer this research question, different subsequent steps have been taken of which the objective was threefold:

1) To gain more insight into the relation between the interface pressure and the development of pressure ulcers and to introduce a new measurement technique to quantify the load on the internal tissues.

2) To investigate the dynamic sitting behavior of healthy subjects and to use this sitting behavior as a reference value for the sitting behavior of spinal cord injured subjects.

3) To develop and experimental seating device (the Dynasit chair) in which the dynamic sitting behavior can be imposed on wheelchair users that lack sufficient motor control to reposition and to investigate the effects of these interventions on the tissue viability.

Considering objective 1), it could be concluded from the performed systematic review (chapter

2) that there appears to be a weak qualitative relation between interface pressure and the 
development of pressure ulcers. Unfortunately, no conclusive clinical threshold for the interface pressure could be given. In combination with the influence of individual characteristics, the low internal validity of interface pressure measurement and an unclear relation between pressure magnitude and duration, this results in the fact that no quantification of the predictive or prognostic value of interface pressure can be given. The use of interface pressure measurements as a clinical tool to prevent pressure ulcers is therefore questionable, indicating a need for other clinically usable tools that can non-invasively quantify the load on the tissue. In order to quantify the load on the tissue, the Oxygen to See (O2C, LEA Medizintechnik, Giessen Germany) was used in chapter 3. The O2C is a device that combines laser Doppler flowmetry and white light spectrophotometry to used to measure non-invasively the cutaneous and subcutaneous tissue perfusion and oxygenation.

Because clinical interventions are not always effective and pressure ulcers incidence values remain high, there is a need for alternative way of preventing pressure ulcers. Healthy individuals do not develop pressure ulcers due to a continuous variation in sitting posture. Regarding objective 2) of this thesis, the $\mathrm{O} 2 \mathrm{C}$ was used in chapter 3 to analyze the sitting behavior of healthy individuals. It was found that healthy subjects change their sitting posture at least every eight minutes. Each posture shift corresponds to a significant change in subcutaneous tissue oxygenation of $2.2 \%$. The frequency of the posture shifts is higher than the AHRQ guidelines The Agency for Healthcare Research and Quality [AHRQ, AHCPR guidelines 1994]. These guidelines recommend wheelchair users to reposition every 15 minutes. Individuals who cannot reposition themselves should be repositioned by outside assistance at least every hour. It can be concluded from the analysis of the healthy sitting behavior in chapter 3 that wheelchair users should reposition more frequently. In addition current clinical AHRQ guidelines are no longer valid and in need of modifications. It is advisable for wheelchair users to change their sitting posture at least every eight minutes in order to prevent pressure ulcer development.

In respect to objective 3), the Dynasit chair was developed and presented in chapter 4. The Dynasit chair is an experimental simulator chair developed to investigate the effects of different sitting postures, alternating tuberal support and pelvic orientations on the (sub-)cutaneous tissue oxygenation. Chapter 4 describes a study performed with the Dynasit chair on healthy individuals. In this study, different sitting postures and pelvic orientations were imposed in the sagital plane. It was found that it is possible with the Dynasit chair to adjust the seat angle, back angle and pelvic orientation in such a way that the cutaneous and subcutaneous tissue 
oxygenation can be increased significantly. However, although significant effects were found, the frequency of actuation was too high for clinical purposes, because the sitting posture was changed every minute. Larger effect actuation was needed, especially to relieve the ischial tuberosities. To obtain larger effects Chapter 5 describes experiments on healthy individuals with the concept for actuated tuberal support, that has been integrated into the Dynasit chair. The system for actuated tuberal support has been developed to create complete unloading of the tuberal regions. It was found that the system for actuated tuberal support is effective in significantly elevating the subcutaneous tissue perfusion and oxygenation.

The main research question of this thesis was answered in chapter 6 . It has been proven that it is possible to impose dynamic sitting behavior by means of the Dynasit chair in spinal cord injured individuals. This imposed dynamic sitting behavior, based on the reference for healthy sitting behavior, resulted in significant elevation of the cutaneous tissue oxygenation and a positive trend for elevation of the subcutaneous tissue oxygenation. By assuming that the oxygenation of the tissue is directly related to the tissue viability, an increase in tissue oxygenation suggests an increase in tissue viability. This elevated tissue viability implies that due to dynamic sitting the wheelchair user can sit for prolonged periods of time without tissue breakdown. Dynamic sitting can therefore be used as an effective strategy in the prevention of pressure ulcers. 


\section{SAMENVATTING}

Decubitus (“doorliggen") is een groot probleem, getuige de hoge incidentie en prevalentie cijfers. Ondanks klinische en wetenschappelijk inspanningen is er nog steeds veel niet bekend over het ontstaan van decubitus. Om meer inzicht te krijgen in de etiologie van decubitus is er een etiologisch model opgesteld. In dit model, gepresenteerd in hoofdstuk 1 van dit proefschrift, worden de stappen doorlopen in de ontwikkeling van decubitus; van externe belasting via interne weefselbelasting naar weefselschade (zie figuur 1). De verschillende stappen in de ontwikkeling van oppervlakkige en diepe decubitus worden uitgebreid beschreven in de introductie van dit proefschrift. Een belangrijke conclusie van de bespreking van de verschillende stappen in het model was dat er op het moment niet mogelijk is om het risico op oppervlakkige en diepe decubitus te schatten aangezien belangrijke stappen in het model nog niet duidelijk zijn. Dit is voornamelijk een gevolg van de technische beperkingen van de meettechnieken die momenteel klinisch en wetenschappelijk gebruikt worden om het risico op decubitus in kaart te brengen.

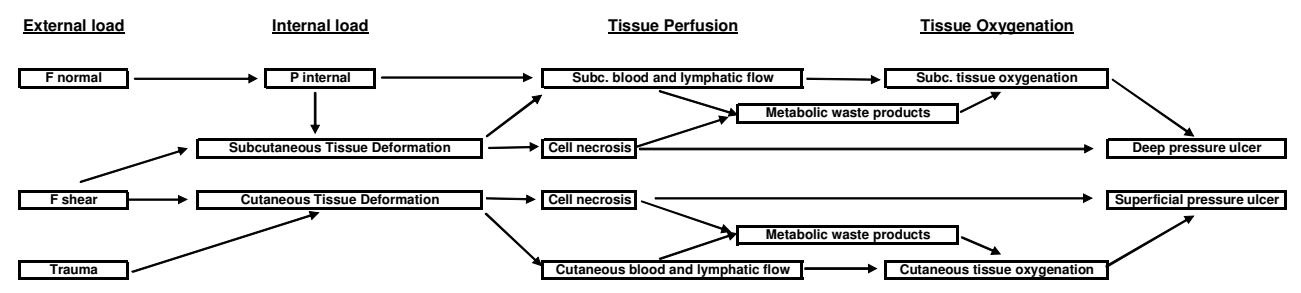

Figuur 1: Etiologisch model voor oppervlakkige en diepe decubitus.

Uit de discussie van het etiologisch model kwam naar voren dat bepaalde stappen in het model onduidelijk zijn. Een gevolg hiervan is dat er nog steeds geen klinisch bruikbare drempelwaarden zijn ontwikkeld, waardoor het in de praktijk niet mogelijk is om decubitus adequaat tegen te gaan. Er is duidelijk meer onderzoek nodig om het risico op decubitus in te schatten en om preventie van decubitus te verbeteren. Van belang is het onder andere om meer inzicht te verwerven in de kwantificering van de externe belasting en de exacte rol die deze externe belasting speelt in het ontstaan van decubitus. De maat die momenteel klinisch het meest wordt gebruikt om de externe belasting te kwantificeren is de interface druk. Ook in wetenschappelijk onderzoek is dit de meest gebruikte meettechniek. Hoewel deze maat veel 
wordt gebruikt is de exacte waarde ervan onduidelijk. Uit de bespreking van het model kwam verder naar voren dat naast de externe druk ook de interne druk in het weefsel van groot belang is in het ontstaan van decubitus. Doordat het weefsel intern tegen de botpunten wordt gedrukt neemt de interne druk extreem toe, met weefselschade als gevolg. Tot op heden is het als gevolg van technische beperkingen niet goed mogelijk gebleken om de interne belasting, of afgeleiden daarvan zoals weefsel perfusie en weefsel oxygenatie, te kwantificeren. Nieuwe meettechnieken zijn noodzakelijk om op een niet invasieve manier de interne staat van het weefsel, wat belangrijk is voor het ontstaan van decubitus, te kunnen meten.

De huidige klinische interventies zijn niet voldoende succesvol in het definiëren van het risico op decubitus en daarmee samenhangend het voorkomen van decubitus. Als een gevolg hiervan blijven de incidentie en prevalentie waarden onacceptabel hoog. Dit proefschrift stelt een andere benadering in de preventie van decubitus voor. Het is duidelijk dat mensen zonder sensorische en motorische beperkingen geen decubitus oplopen tijdens langdurig zitten door een continue variatie in zithouding en ondersteuning. Dit "gezond" zitgedrag heeft een dynamisch karakter en zou als referentie gebruikt kunnen worden voor het wenselijke en optimale zitgedrag van rolstoelgebruikers met een verhoogd risico op decubitus. Gezien het feit dat rolstoelgebruikers met een beperkte motoriek zelf niet of niet voldoende kunnen verzitten, zou het dynamische zitgedrag opgelegd moeten worden door een geautomatiseerd zitsysteem. Dit zitsysteem zou elke gewenste zithouding en ondersteuning mogelijk moeten kunnen maken. Het door middel van het zitsysteem opgelegde "dynamisch" zitgedrag zou het risico op decubitus moeten verkleinen. Het effect van dit dynamisch zitsysteem op de toestand en levensvatbaarheid ("tissue viability") van het zitweefsel dat een verhoogd risico heeft op het ontwikkelen van decubitus zou moeten worden bepaald. Dit kan gebeuren door middel van een meettechniek waarbij niet-invasief de subcutane weefsel perfusie en oxygenatie wordt gemeten.

\section{Algemene conclusies van dit proefschrift.}

De centrale onderzoeksvraag van dit proefschrift luidde: "Kan door middel van de "Dynasit" stoel dynamisch zitgedrag worden opgelegd aan personen met een dwarslaesie en resulteert dit dynamisch zitgedrag in een verhoogde levensvatbaarheid van het zitweefsel?” Om deze onderzoeksvraag te kunnen beantwoorden moest een aantal opeenvolgende stappen worden gezet waarbij het doel drieledig was: 
1) Het verkrijgen van meer inzicht in de relatie tussen interface druk en het ontstaan van decubitus en het introduceren van een nieuwe meettechniek welke de belasting op het interne weefsel kan kwantificeren.

2) Het onderzoeken van "gezond" dynamisch zitgedrag van personen zonder motorische en sensorische beperkingen en dit zitgedrag gebruiken als referentie voor het zitgedrag van personen met een dwarslaesie.

3) Het ontwikkelen van een experimentele zitopstelling (de “Dynasit”stoel) waarmee dynamisch zitgedrag opgelegd kan worden aan rolstoelgebruikers met onvoldoende motoriek om zichzelf te verzitten en het onderzoeken van de effecten van dit dynamisch zitgedrag op de levensvatbaarheid van het zitweefsel.

Met betrekking tot doelstelling 1) werd een systematische review van de literatuur uitgevoerd (hoofdstuk 2). Uit deze systematische review kwam naar voren dat er een zwakke kwalitatieve relatie lijkt te bestaan tussen de hoogte van de interface druk en het daadwerkelijk ontstaan van decubitus. Helaas kon er geen definitieve klinisch bruikbare drempelwaarde voor de interface druk worden aangegeven. In combinatie met individuspecifieke karakteristieken, de lage interne validiteit van interface-druk metingen en een niet-eenduidige relatie tussen de externe en interne belasting op het weefsel resulteert dit in het feit dat er geen kwantificering van de prognostische waarde van interface druk metingen is aan te geven. Er kunnen derhalve vraagtekens worden geplaatst bij het gebruik van interface druk als een klinisch instrument ter preventie van decubitus. Dit geeft een duidelijk behoefte aan een klinisch bruikbare meettechniek aan welke in staat zou moeten zijn om niet-invasief de belasting op en in het weefsel te bepalen tijdens het zitten. Om de belasting op het weefsel tijdens het zitten in kaart te brengen werd de Oxygen to See (O2C, LEA Medizintechnik, Giessen, Germany) gebruikt (hoofdstuk 3). De O2C is een meetinstrument welke door een combinatie van wit licht spectrophotometry en laser Doppler flowmetry in staat is om niet-invasief zowel de cutane als de subcutane weefsel perfusie en oxygenatie te meten. De perfusie en oxygenatie van het weefsel zijn belangrijke afgeleide van de interne belasting van het weefsel en daarmee samenhangend de levensvatbaarheid van het weefsel.

Doordat, ondanks de huidige klinische interventies, decubitus blijft voorkomen, is een alternatieve preventieve strategie noodzakelijk. Deze alternatieve strategie bestaat uit het opleggen van "gezond" dynamisch zitgedrag. Hiervoor is het echter eerst noodzakelijk in kaart te brengen wat "gezond" zitgedrag inhoudt. Met betrekking tot doelstelling 2) van dit 
proefschrift werd in hoofdstuk 3 de $\mathrm{O} 2 \mathrm{C}$ gebruikt om een analyse te maken van het dynamisch zitgedrag van personen zonder sensorische en motorische beperking. Uit deze analyse kwam naar personen zonder sensorische en motorische beperkingen op zijn minst eens per 8 minuten van zithouding wisselen. Elke houdingsverandering correspondeerde met een toename van $2.2 \%$ in de subcutane weefsel oxygenatie. Deze frequentie van houdingsveranderingen is hoger dan de huidige aanbeveling voor rolstoelgebruikers (AHRQ richtlijnen). De AHRQ richtlijnen schrijven voor dat rolstoel gebruikers eens per 15 minuten zouden moeten verzitten of eens per uur opnieuw gepositioneerd zouden moeten worden. Op basis van de analyse van "gezond" zitgedrag kan worden geconcludeerd dat rolstoelgebruikers meer frequent zouden moeten verzitten dan op basis van de richtlijnen wordt voorgeschreven. De huidige klinische richtlijnen zijn daardoor niet meer bruikbaar en zouden aangepast moeten worden. Het advies voor rolstoelgebruikers is dan ook om op zijn minst eens per 8 minuten van houding te wisselen om zodoende het ontstaan van decubitus te voorkomen.

Rolstoelgebruikers met een beperkte motoriek kunnen vaak zelf niet verzitten en hebben hierbij hulp nodig. In relatie tot doelstelling 3) van dit proefschrift werd dan ook de Dynasit stoel ontwikkeld en gepresenteerd in hoofdstuk 4. De Dynasit stoel is een experimentele zitopstelling welke ontwikkeld is om de effecten van verschillende zithoudingen, tuberale ondersteuningen en bekkenoriëntaties op de weefselbelasting te onderzoeken. Hoofdstuk 4 beschrijft een onderzoek naar de effecten van verschillende opgelegde zithoudingen en bekkenoriëntaties op de weefsel oxygenatie in een groep proefpersonen zonder motorische en sensorische beperkingen. Er werd gevonden dat de Dynasit stoel in staat is om door middel van het veranderen van de zitting- en rugleuning-hoek en de bekkenoriëntatie de cutane en subcutane weefsel oxygenatie significant te verhogen. Hoewel tijdens deze experimenten significante positieve effecten werden gevonden bleek voor klinische toepassing de frequentie van houdingsverandering te hoog, angezien de houding eens per minuut werd veranderd. Verder was een groter effect van de actuatie door middel van de Dynasit stoel gewenst om de belasting onder de ischiale tubera te veranderen. Om een groter effect op de weefsel perfusie en oxygenatie te bewerkstelligen werd een concept voor tuberale actuatie ontwikkeld en geïntegreerd in de Dynasit stoel. Dit systeem werd ontwikkeld om totale ontlasting van de ischiale tubera te realiseren. Hoofdstuk 5 beschrijft het onderzoek dat werd uitgevoerd om de effecten van het systeem voor tuberale actuatie op de weefsel oxygenatie te bepalen. Complete ontlasting van de tubera door middel van het systeem voor tuberale actuatie resulteerde in significante positieve effecten op de cutane en subcutane weefsel perfusie en oxygenatie. 
De centrale onderzoeksvraag van dit proefschrift werd beantwoord in hoofdstuk 6. Hoofdstuk 6 beschrijft eens studie waarbij door middel van de Dynasit stoel getracht werd om dynamisch zitgedrag op te leggen aan een groep van 9 mannelijk personen met een dwarslaesie. In dit onderzoek kon worden angetoond dat het mogelijk is om middels de Dynasit stoel dynamisch zitgedrag op te leggen volgens de referentiemaat voor "gezond" dynamisch zitgrdrag. Het opgelegde dynamisch zitgedrag resulteerde in significante toenames in zowel de cutane als de subcutane weefsel oxygenatie. Er kan worden aangenomen dat de oxygenatie van het weefsel direct gerelateerd is aan de levensvatbaarheid van het weefsel. Een toename van de oxygenatie zou dan een toename in levensvatbaarheid van het weefsel tot gevolg hebben. Deze toegenomen levensvatbaarheid van het weefsel als gevolg van het dynamische zitgedrag zou er voor kunnen zorgen dat rolstoelgebruikers gedurende langere perioden in een rolstoel zouden kunnen zitten zonder weefselschade. Dynamisch zitgedrag kan derhalve als een effectieve strategie ingezet kan worden in de preventie van decubitus. 


\section{CURRICULUM VITAE}

Jasper Reenalda was born in Enschede, the Netherlands on February 18th 1979. After receiving his high school degree at SG Twickel in 1997, he studied Human Movement Science at the Vrije Universiteit in Amsterdam. He specialized in sports sciences and graduated in 2002 on a study on the factors that determine the optimal step length in running. In addition he wrote a thesis on the psychological determinants of ultra distance runners, based on a literature review. In November 2004 Jasper started as a PhD student at Roessingh Research and Development, working on the Dynasit project. The present thesis is the result of this $\mathrm{PhD}$ research.

Besides his work on the Dynasit project, Jasper teaches Physiology of Sports and Exercise at the University of Twente. In addition, Jasper is currently working at Roessingh Research and Development on the Heelless project. In this research project a newly developed running shoe concept will be evaluated biomechanically and kinematically. Jasper will continue working at Roessingh Research and Development on research projects in the field of Rehabilitation Science and Sport Science.

Jasper is also a triathlete. He finished 11 Ironman-distance races and competed in the Ironman Triathlon World Championship in Kailua-Kona, Hawaii twice (2003 and 2007). 


\section{PUBLICATIONS}

\section{Peer-reviewed journal papers}

Van Geffen P, Reenalda J, Veltink P, Koopman H. Effects of sagittal postural adjustments on seat reaction load. Journal of Biomechanics 2008 Jul 19;41(10):2237-45.

Van Geffen P, Molier BI, Reenalda J, Veltink PH, Koopman BF. Body segments decoupling in sitting: Control of body posture from automatic chair adjustments. Journal of Biomechanics. 2008; 41(16):3419-25.

Van Geffen P, Reenalda J, Veltink P, Koopman H. Decoupled pelvis rotation in sitting: A passive motion technique that regulates buttock load associated with pressure ulcer development. Journal of Biomechanics 2009; 42 (9): 1288-1294.

Reenalda, J, Jannink M, Nederhand M, IJzerman M. The clinical use of interface pressure: a systematic review. Assistive Technology 2009; 21 (2): 76-85.

Reenalda J, van Geffen P, Nederhand M, Jannink M, IJzerman M, Rietman JS. Analysis of healthy sitting behavior: Interface Pressure distribution and subcutaneous tissue oxygenation.. Journal of Rehabilitation Research and Development , 2009; 46 (5).

Van Geffen P, Reenalda J, Veltink P, Koopman B. Decoupled pelvis adjustment to induce lumbar motion. A Technique that Controls Low Back Load in Sitting International Journal of Industrial Ergonomics, 2009.

\section{International conference participations}

Van Geffen P, Reenalda J, Veltink P, Koopman H. Effects of actuated pelvis control on shear and pressure distribution. Proceedings of the 2007 ISB conference, Taipei, Taiwan.

Reenalda J, van Geffen P, Nederhand M, Veltink P, Koopman B, Jannink M, IJzerman M, Rietman H. Effects of Actuated Pelvic Rotation on Sitting Forces and Pressure Distribution. Proceedings of the 2008 RESNA Conference, Arlington VA, United States of America. 
Van Geffen P, Reenalda J. Dynasit: an assistive seating system that controls sitting posture and regulates body load associated with sitting related mobility problems. Proceedings of the 2008 RESNA Conference, Arlington VA, United Stated of America. (Student Design Paper Award Finalist).

Van Geffen P, Molier B, Reenalda J, Veltink P, Koopman H. A system that adjusts chair configuration for desired postural change. Proceeding of the 2008 RESNA Conference, Arlington VA, United States of America.

Van Geffen P, Reenalda J, Veltink P, Koopman H. The effects of decoupled pelvis rotation on balance control in sitting. Second Dutch BME Conference 2009, Egmond aan Zee, the Netherlands.

Reenalda, J. Dynasit: Dynamic sitting to prevent pressure ulcers in spinal cord injured. $12^{\text {th }}$ Annual European Pressure Ulcer Advisory Panel meeting, September 2009, Amsterdam, the Netherlands, invited presentation. 


\section{DANKWOORD}

De afgelopen jaren heb ik naast het werken aan het Dynasit project ook veel tijd besteed aan de, mijn inziens, mooiste van alle sporten: de Triathlon. De Ironman om precies te zijn. Op 18 februari 1978, exact een jaar voor mijn geboorte, werd deze discipline op Hawaï voor het eerst volbracht door een groep mariniers die wel van een uitdaging hield. Alleen zij die deze afstanden konden volbrengen hadden het recht om de titel 'Ironman' te dragen.

Gedurende mijn promotietraject viel het mij op dat er veel parallellen zijn tussen het volbrengen van een Ironman en het schrijven van een proefschrift. Zoals de naam triathlon al zegt bestaat de sport uit drie verschillende onderdelen. Er wordt achtereenvolgens gezwommen, gefietst en gelopen. Ook in mijn promotieonderzoek heb ik deze driedeling ervaren.

De eerste fase, als startende promovendus, is goed te vergelijken met het zwemonderdeel. Je bent je nog nauwelijks bewust van wat er allemaal nog gaat komen en je dobbert voor je gevoel wat rond. Door het lezen van vele artikelen en vele gesprekken met begeleiders komen de boeien in zicht en worden het doel en de richting die je op gaat steeds concreter. Je bent klaar voor de eerste wissel. Het fietsonderdeel dat volgt is het langste onderdeel en heeft daarmee veel overeenkomsten met het daadwerkelijke onderzoek. De experimenten worden uitgevoerd, de benodigde data moeten worden verzameld en het belang van goed materiaal blijkt net als bij het fietsen zeer groot te zijn. Waar bij het fietsen een lekke band voor veel tijdverlies kan leiden zijn een haperende $\mathrm{O} 2 \mathrm{C}$ of Dynasit stoel obstakels die tijdens deze fase moeten worden overwonnen. Al met al is dit onderdeel het langst en lijkt er soms letterlijk geen einde aan te komen. Uiteindelijk begin je echt uit te kijken naar het laatste onderdeel. Het lopen oftewel het daadwerkelijke schrijven. Hoewel dit onderdeel in tijd minder lang is dan het fietsen vraagt het meer doorzettingsvermogen. Je bent vermoeid maar je moet door, nu nog opgeven zou doodzonde zijn. Je berekent je mogelijke eindtijd en merkt dat deze gaandeweg de nodige keren moet worden bijgesteld. Maar natuurlijk zet je door en uiteindelijk is daar dat geweldige finishpodium. Het einddoel is bereikt! Hoewel er veel overeenkomsten zijn is er wat mij betreft een groot verschil. Tijdens een Ironman is het verboden hulp te krijgen van anderen en ben je gedurende de hele race op jezelf aangewezen. Ik weet zeker dat ik dit onderzoek niet had kunnen volbrengen als deze regel op promotieonderzoek van toepassing zou zijn geweest. Ik ben daarom aan veel mensen mijn 
dank verschuldigd omdat zij voor mij, ergens op het promotieparcours, van onschatbare waarde zijn geweest.

Een eerste woord van dank zou ik willen richten aan mijn promotoren, Hans Rietman en Maarten IJzerman en assistent promotor Michiel Jannink. Zij kozen de wedstrijd uit, bepaalden het tijdschema en hielden nauwlettend de voortgang in de gaten. Als trainer en coach stonden zij het gehele traject langs het parcours, klaar om gevraagd of ongevraagd advies te geven. Soms traden ze op als verkeersregelaar en een enkele keer als scheidsrechter of jurylid. Voor adviezen, over welk onderdeel dan ook, kon ik altijd terugvallen op experts als Marc Nederhand, Bart Freriks, Govert Snoek en Jaap Buurke. Daarnaast stonden op de UT Bart Koopman en Peter Veltink altijd klaar.

Gelukkig kon ik een groot deel van de wetenschappelijke Ironman samen optrekken met mijn trainingsmaat Paul van Geffen, die ik hiervoor hartelijk zou willen bedanken. Het werd er onderweg een stuk makkelijker en vooral veel gezelliger door. De ravitaillering (lees koffiepauze) was een vast en belangrijk onderdeel. En als één van ons het even niet zag zitten waren we ook nog eens mental coach voor elkaar.

Net als bij een triathlon zijn er bij een promotietraject vrijwilligers nodig om de deelnemers te assisteren en één en ander in goede banen te leiden. Onderweg kreeg ik gelukkig veel hulp van de enthousiaste vrijwilligers Marjolein Hilgerink, Birgit Molier en Karel van de Hengel. Zij hebben als student in het kader van hun Master of Bachelor projecten een belangrijke bijdrage geleverd aan het slagen van het Dynasit onderzoeksproject. Andere enthousiaste vrijwilligers waren de dwarslaesieverpleegkundigen van Revalidatiecentrum het Roessingh (Alice Plegt, Joke Broeze, Desiree Barkel en Roelien Brink) die de patiëntmetingen in goede banen wisten te leiden. Ook zou ik graag alle proefpersonen willen bedanken die voor mij een groot deel van hun tijd hebben opgeofferd.

Voor het ontwikkelen, prepareren en onderhouden van het benodigde materiaal zou ik graag Harrie Staarink, Louis Huttenhuis en Wouter Hoppenbrouwer (namens PR Sella), Hans Scholten, Rini Zwikker en Bianca Screever (namens Demcon) en Bert Faber (namens Welzorg Special Products) willen bedanken. Eventuele kramp en blessures (haperende O2C, PC, etc.) werden bij RRD altijd vakkundig behandeld door Leendert Schaake, Rik Vegt, Wil de Groot en Jos Spoelstra. Op de verversingsposten onderweg stonden de collega's van RRD klaar om door middel van support of deelname als proefpersoon hun bijdrage te leveren. 
In de finishstraat wordt ik gelukkig vergezeld door mijn paranimfen Jeroen Leusink en Wout Ruijter, die ik daarvoor graag hartelijk zou willen bedanken.

Net als bij een triathlon stonden ook bij dit promotietraject mijn vaste supporters aan de zijlijn om mij te steunen als het goed ging maar ook als het even wat zwaarder ging. Pap en Mam, Marloes en Ramon, Jan en Mirjam, Jojanneke en Maarten, hartelijk bedankt!

En zoals na elke wedstrijd kan ik ook nu na de finish moe maar voldaan in de armen vallen van mijn trouwste supporter. Marieke, zonder jou was dit proefschrift er hoogstwaarschijnlijk niet gekomen. Bedankt voor alles wat we samen hebben meegemaakt en hopelijk nog zullen gaan meemaken! Ik ben zo blij en gelukkig met jou! 


\section{PROGRESS RANGE}

The following publications have also been published in the Progress range by Roessingh Research and Development, Enschede, the Netherlands. Copies can be ordered, when available, via info@rrd.nl.

1. Pot JWGA, Boer H, van Harten WH, Hermens HJ, Seydel ER. Comprehensive Need-Assessment. Ontwikkeling van een meetinstrument voor zorgbehoeften en kwaliteitsbeoordeling door patiënten. Roessingh Research and Development, the Netherlands, September 1994, ISBN 90-25452-01-2.

2. Van Leerdam NGA, Hermens HJ. Revalidatietechnologie in Euregio. Roessingh Research and Development, the Netherlands, July 1995, ISBN 90-75452-02-0.

3. Duda L, van Noort LO, Röseler S, Greitemann BOL, van Harten WH, Klazinga NS. Rehabilitation in Germany and the Netherlands, A comparison of two rehabilitation-systems. Roessingh Research and Development, the Netherlands, August 1995, ISBN 90-75452-03-9.

4. Hermens HJ, Nene AV, Zilvold G. Electrophysiological Kinesiology. Proceedings of the 11th congress of the International Society of Electrophysiologie and Kinesiology in Enschede, TheNetherlands 1996, Roessingh Research and Development, the Netherlands, October 1996, ISBN 90-75452-04-7.

5. Van Harten WH. Bouwen aan een kwaliteitssysteem in de revalidatiezorg. Een poging tot constructieve technology assessment van een kwaliteitssysteem in een gezondheids-zorginstelling. Roessingh Research and Development, the Netherlands, December 1997, ISBN 90-75452-07-1.

6. Baardman G, IJzerman MJ. Design and evaluation of a hybrid orthosis for people with paraplegia. Roessingh Research and Development, the Netherlands, November 1997, ISBN 90-75452-08-X.

7. Hutten MMR. Lumbar Dynamometry: A useful method for assessment of patients with chronic low back pain? Roessingh Research and Development, the Netherlands, November 1999, ISBN 90-75452-13-6.

8. Van der Salm A, van Harten WH, Maathuis CGB. Ketenkwaliteit Cerebrale Parese Zorg. Een beschrijving van de cerebrale parese zorg en mogelijke verbeteringen hierin. Roessingh Research and Development, the Netherlands, April 2001, ISBN 90-75452-19-5.

9. Nederhand MJ. Muscle activation patterns in post traumatic neck pain. Roessingh Research and Development, the Netherlands, March 2003, ISBN 90-75452-27-6.

10. Jannink MJA. Usability of custom-made orthopaedic shoes in patients with degenerative disorders of the foot. Roessingh Research and Development, the Netherlands, September 2004, ISBN 90-75452-28-4.

11. Blokhorst M. State-dependent factors and attention in Whiplash associated disorder. Roessingh Research and Development, the Netherlands, January 2005, ISBN 90-365-2111-4.

12. Buurke JH. Walking after stroke co-ordination patterns \& functional recovery. Roessingh Research and Development, the Netherlands, February 2005, ISBN 90-365-2140-8.

13. Van der Salm A. Spasticity reduction using electrical stimulation in the lower limb of spinal cord injury patients. Roessingh Research and Development, the Netherlands, October 2005, ISBN 90-365-2253-6.

14. Snoek GJ. Patient preferences for reconstructive interventions of the upper limb in tetraplegia. Roessingh Research and Development, the Netherlands, December 2005, ISBN 90-365-2255-2. 
15. De Kroon J. Therapeutic electrical stimulation of the upper extremity in stroke. Roessingh Research and Development, the Netherlands, December 2005, ISBN 90-365-2269-2.

16. Van Dijk H. Motor skill learning, age and augmented feedback. Roessingh Research and Development, the Netherlands, March 2006, ISBN 90-365-2302-9.

17. Mes CAJ. Improving non-optimal results in chronic pain treatment. Roessingh Research and Development, the Netherlands, January 2007, ISBN 90-365-2435-0.

18. Voerman GE. Musculoskeletal neck-shoulder pain: a new ambulant myofeedback intervention approach. Roessingh Research and Development, the Netherlands, March 2007, ISBN 90-365-2460-1

19. Kallenberg LAC. Multi-channel array EMG in chronic neck-shoulder pain. Roessingh Research and Development, the Netherlands, March 2007, ISBN 90-365-2459-8

20. Huis in 't Veld MHA. Work-related neck-shoulder pain: The role of cognitive-behavioural factors and remotely supervised treatment. Roessingh Research and Development, The Netherlands, December 2007, ISBN 978-90-365-2584-8

21. Fleuren JFM. Assessment of spasticity - from EMG to patients' perception. Roessingh Research and Development, The Netherlands, October 2009, ISBN 978-90-365-28 
Stellingen behorende bij het proefschrift

\section{Dynamic sitting to prevent pressure ulcers in spinal cord injured}

J. Reenalda, 8 oktober 2009

1. "Gezond" dynamisch zitgedrag kenmerkt zich door een gemiddelde van acht houdingsveranderingen per uur (dit proefschrift).

2. De huidige klinische richtlijn voor de frequentie van houdingsverandering van rolstoelgebruikers dient op basis van de resultaten van dit proefschrift aangepast te worden (dit proefschrift).

3. Een opeenvolging van verschillende statische houdingen levert ten alle tijden dynamisch zitgedrag op (dit proefschrift).

4. Aangezien er geen relatie tussen de hoogte van de interface druk en het ontstaan van decubitus is aangetoond, is de duur van die druk des te belangrijker (dit proefschrift).

5. De beste druk is de volgende druk.

6. De toename in de laatste jaren van het aantal diagnoses van ADHD op de basisschool zou moeten resulteren in een gemiddeld dynamischer zitgedrag van basisschoolleerlingen.

7. Als men het schrijven van dit proefschrift wil vergelijken met een Ironman triathlon, is het te hopen dat de spierpijn achteraf meevalt.

8. If triathlon was easy, they would have called it soccer (algemene wijsheid). 